Florida International University

FIU Digital Commons

FIU Electronic Theses and Dissertations

University Graduate School

6-7-2019

\title{
Cavity Nest Webs as a Template for Studying Non-trophic Interactions in Invasion Ecology
}

Joshua M. Diamond

jmadiamo@fiu.edu

Follow this and additional works at: https://digitalcommons.fiu.edu/etd

Part of the Biodiversity Commons, Ornithology Commons, Other Forestry and Forest Sciences

Commons, and the Terrestrial and Aquatic Ecology Commons

\section{Recommended Citation}

Diamond, Joshua M., "Cavity Nest Webs as a Template for Studying Non-trophic Interactions in Invasion Ecology" (2019). FIU Electronic Theses and Dissertations. 4234.

https://digitalcommons.fiu.edu/etd/4234

This work is brought to you for free and open access by the University Graduate School at FIU Digital Commons. It has been accepted for inclusion in FIU Electronic Theses and Dissertations by an authorized administrator of FIU Digital Commons. For more information, please contact dcc@fiu.edu. 


\title{
FLORIDA INTERNATIONAL UNIVERSITY
}

Miami, Florida

\section{CAVITY NEST WEBS AS A TEMPLATE FOR STUDYING NON-TROPHIC INTERACTIONS IN INVASION ECOLOGY}

A dissertation submitted in partial fulfillment of

\author{
the requirements for the degree of \\ DOCTOR OF PHILOSOPHY \\ in
}

EARTH SYSTEMS SCIENCE

by

Joshua M. Diamond 
To: Dean Michael R. Heithaus

College of Arts, Sciences and Education

This dissertation, written by Joshua M. Diamond, and entitled Cavity Nest Webs as a Template for Studying Non-Trophic Interactions in Invasion Ecology, having been approved in respect to style and intellectual content, is referred to you for judgment.

We have read this dissertation and recommend that it be approved.

Hong Liu

Joel T. Heinen

Philip K. Stoddard

Michael S. Ross, Major Professor

Date of Defense: June 7, 2019

The dissertation of Joshua M. Diamond is approved.

Dean Michael R. Heithaus

College of Arts, Sciences and Education

Andrés G. Gil

Vice President for Research and Economic Development and Dean of the University Graduate School

Florida International University, 2019 
(C) Copyright 2019 by Joshua M. Diamond All rights reserved. 


\section{DEDICATION}

For Pearl Klionsky, and Carole and Marvin Diamond: Thank you for your years of love and support. 


\section{ACKNOWLEDGMENTS}

I would like to thank my advisor, Dr. Michael Ross and my committee members, Dr. Hong Liu, Dr. Joel Heinen, and Dr. Philip Stoddard for their guidance of my

dissertation research. The conversations regarding research we had shaped the course of my field work, data analysis, and writing over the course of several years. I hope to continue these conversations over a long career of research and education. I particularly need to thank Dr. Ross, who exceeded expectations as an advisor in all aspects of this project, from searching his own neighborhood with me for cavity nests, bringing me along to search in the lower Florida Keys, and always having helping insights into the process of research and writing.

The field work presented in this project was enabled by volunteers, as well as field contacts, residents, park rangers, and land managers. For their assistance in field data collection, finding and monitoring the nests of cavity-nesting birds, often in difficult field conditions, I thank: Alana Rodriguez, Alex Arbelaez, Ana Guzman, Ana Lemos, Chris Beck, Douglas Gramajo, Ingrid Moncada, Jason F. Lopez, Lucas Biehler, Marcel Bozas, Miguel Valencia, Olivier Ade, Scott Schlossman, Stella Roa, Stephanie Torres, Tasha Trujillo, Thomas Spencer, Tivonia Potts, Valentina Acosta, Yeni Fernandez, and Zac Diamond. I thank my lab colleagues past and present: Susana Stoffela, Jesus Blanco, Alison Jirout, Josue Sandoval, Jay Sah, Suresh Subedi, Pablo Ruiz, Jack Meeder, Carlos Pulido, Katherine Castrillon, Rosario Vidales, Danielle Ogurcak, and others. I appreciate the assistance of several agencies and institutions who welcomed me onto their property. I thank Miami-Dade County, Department of Parks, Recreation and Open Spaces who 
assisted with my permit review. I thank Montgomery Botanical Center, especially Joanna Tucker Lima and Christina Dupuy. I thank Fairchild Tropical Botanic Garden, especially Jason Lopez, for his assistance at the site. I thank Jennifer Tisthammer and the Deering Estate, which funded me as a research assistant during the two years I was actively collecting most of the field data. I thank the park staff at Everglades National Park, especially the staff working at Flamingo in the peak of bug season. I thank Karen Relish and Mike Owens from Fakahatchee Strand State Park Preserve for inviting me to search their forest. I thank Ann Wiley for inviting me into her home, and bringing me to important birding sites in Fort Lauderdale. I thank the Village of Palmetto Bay, Department of Public Works, and the City of Miami Beach, Division of Urban Forestry for providing tree inventories used in this research. Thank you to Gail Excell for continual assistance navigating the forms and paperwork of two successive graduate programs. I thank Seema Sah for her assistance scheduling my teaching responsibilities around field work, conferences, and other deadlines. I thank other friends, especially my girlfriend Amy Tra, for their support. My research was supported by the FIU Tropics Program and the Susan S. Levine Trust, which funded the purchase of some of the field equipment used in this project.

Finally, I would like to thank my immediate family: my parents, Elaine Klionsky and Mayer Diamond, and my brother Zac Diamond. 


\section{ABSTRACT OF THE DISSERTATION \\ CAVITY NEST WEBS AS A TEMPLATE FOR STUDYING NON-TROPHIC INTERACTIONS IN INVASION ECOLOGY}

by

\section{Joshua M. Diamond}

Florida International University, 2019

Miami, Florida

\section{Professor Michael S. Ross, Major Professor}

Invasive exotic animals are considered destructive forces in cities for preying on and competing with native species. I examined an aspect of competition from a different perspective, focusing on the role of Miami's rich exotic bird assemblage in its cavity nest web, where a supply of woodpecker-created cavity nests limited by urbanization is the focal point of competition. We located 967 nest trees with 1,864 cavities and determined that woodpeckers successfully nested in this tropical urban region by exploiting standing dead palms (snags). Native upland forests were the most important cover type for woodpeckers but planted landscapes like parks and botanical gardens supported a similar density of nests. Fluctuations in nest resource availability were studied following Hurricane Irma in 2017. After the storm, the proportion of nests in palm snags increased relative to other substrates. Compared to other substrates, palm snags persisted at intermediate rates after the hurricane but were the dominant type excavated by woodpeckers. I monitored 750 cavities to determine species occupancy and turnover. Of special interest were Miami's many parrot species, which have been suspected of 
breeding in woodpecker nests. I determined that two exotic parrot species commonly use woodpecker nests but are far less abundant than the native birds or other exotic bird species in the cavity nest web. Geographic analysis of nests combined with citizen science data suggest the parrots are closely linked to urban areas, and do not pose a risk of invading the Florida Everglades. The parrots also do not disrupt the urban cavity nest web, despite sharing nest preferences with similarly large-bodied birds, because of an offset in breeding phenology; parrots breed months later than the native birds they would be competing with. Invasive European Starlings and Common Myna do pose a significant threat to native birds, usurping active nests from species with similar nest preferences. Starlings are a well-established invasive species, but a growing population of mynas would exert considerable pressure on the nest web based on their nest selection and phenology. 


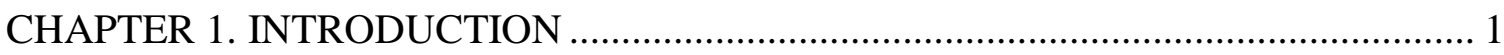

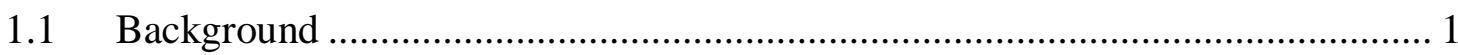

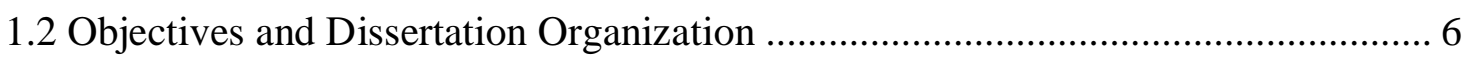

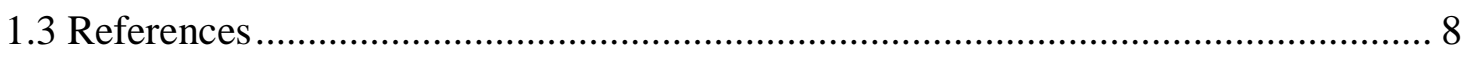

CHAPTER 2. PALM SNAGS ARE A CRITICAL NESTING RESOURCE FOR WOODPECKERS IN AN URBANIZED TROPICAL REGION .................................. 12

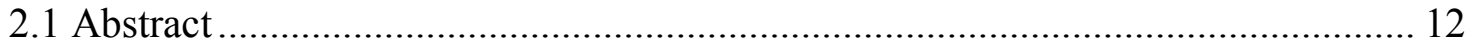

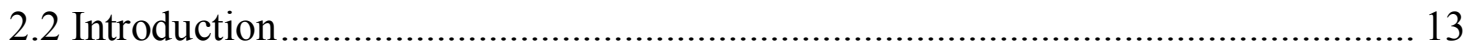

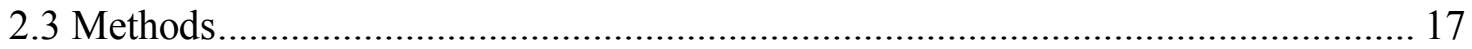

2.3.1 Field Methods for Locating Woodpecker Cavity Trees .................................. 17

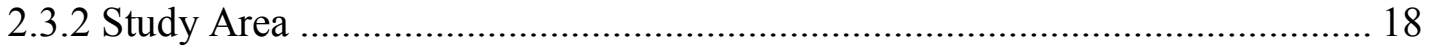

2.3.3 Field Methods for Recording and Monitoring Nest Trees ................................ 18

2.3.4. Field Methods for Inspecting Woodpecker Nests ............................................ 19

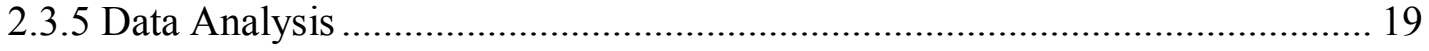

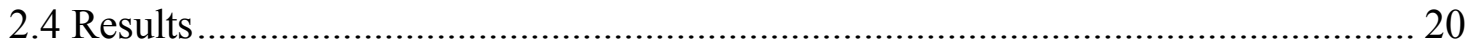

2.4.1 Woodpecker Nests by Habitat Type .......................................................... 20

2.4.2 Woodpecker Nests by Tree Category ............................................................ 21

2.4.3 Tree Categories across Habitat Types ............................................................. 22

2.4.4 Role of Four Woodpecker Excavator Species ................................................. 23

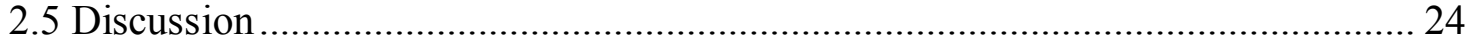

2.5.1 Importance of Palm Trees to Woodpeckers .................................................... 24

2.5.2 Substrate Availability in Urban Forest Fragments and Developed Areas ....... 25

2.5.3 Distribution and Substrate Usage by Four Woodpecker Excavators ............... 26

2.5.4 Changes from Historical Woodpecker Species Composition in the Study

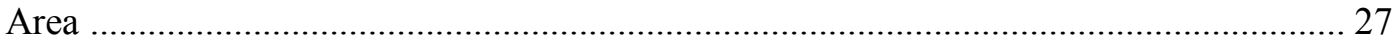

2.5.5 Palm Snags as a Critical Resource in Urban Areas ...................................... 28

2.5.6 Caribbean Woodpeckers and Palm Snags.................................................... 28

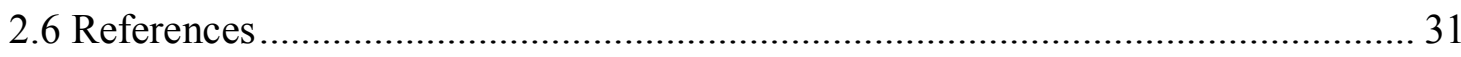

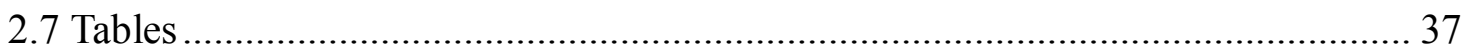

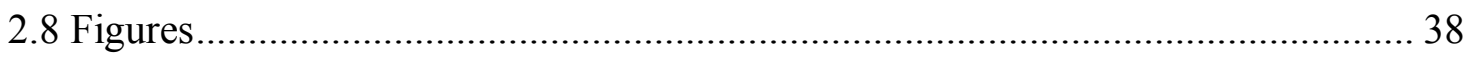

CHAPTER 3: URBAN WOODPECKER NEST SITE CHARACTERISTICS BEFORE AND AFTER A HURRICANE DISTURBANCE ……………………......................... 40 


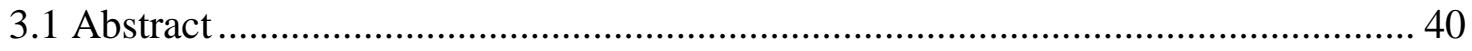

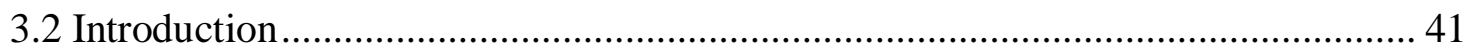

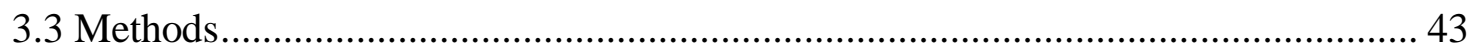

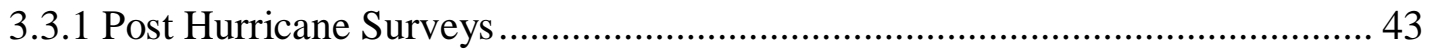

3.3.3 Field Methods for Recording Nest Trees ...................................................... 44

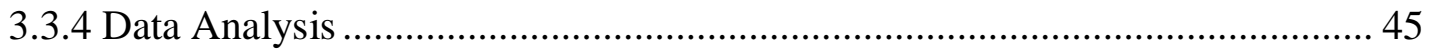

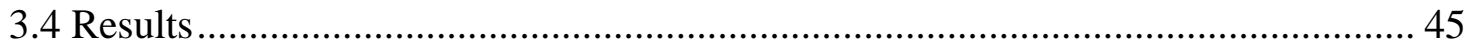

3.4.1 Tree Category and Persistence After Hurricane Disturbance .......................... 45

3.4.2 Physical Characteristics of Nest Trees Before and After Hurricane Irma ....... 46

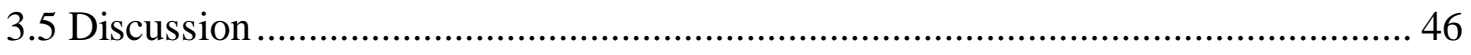

3.5.1 Characteristics of Nest Trees Persisting and Newly Excavated Snags ............. 46

3.5.2 Hardwood Trees and Survival of Living Nest Trees ........................................ 47

3.5.3 Pine Trees and Delayed Creation of New Pine Snags and Nests .................... 47

3.5.3 Increase in Palm Snag Use and Excavation of New Palm Snags .................... 48

3.5.4 Palm Snags and Conservation Opportunities Following Hurricane

Disturbance ........................................................................ 49

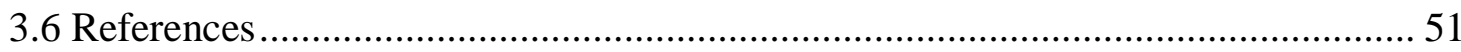

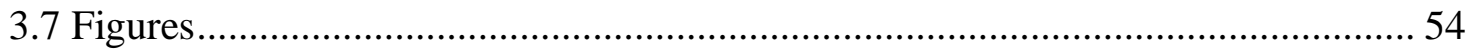

CHAPTER 4. EXOTIC PARROTS BREEDING IN TREE CAVITIES: NESTING REQUIREMENTS, GEOGRAPHIC DISTRIBUTION, AND POTENTIAL IMPACTS ON CAVITY NESTING BIRDS IN SOUTHEAST FLORIDA …………………….....58

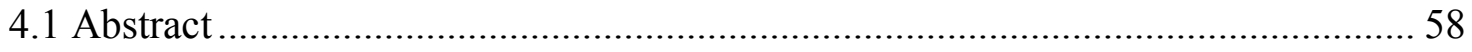

4.2 Introduction

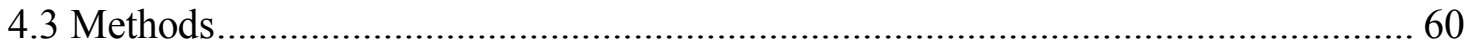

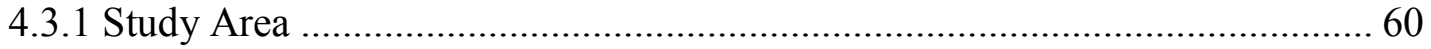

4.3.2 Field Methods for Locating and Monitoring Nest Trees .................................. 61

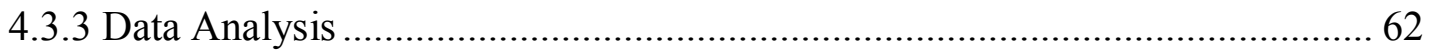

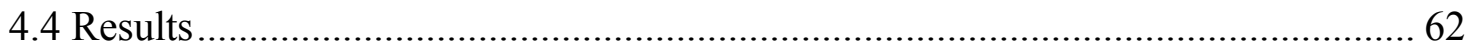

4.4.1 Active Nesting Attempts and Other Records of Parrots .................................... 62

4.4.2 Use and Enlargement of Woodpecker Cavities ................................................ 63

4.4.3 Comparison of Orange-winged Parrot and Red-masked Parakeet Nest

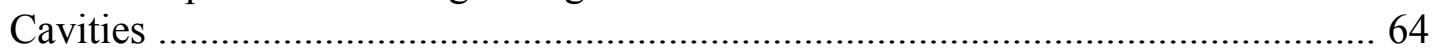

4.4.4 Interactions Between Parrots and Other Bird Species ..................................... 65

4.4.5 Geographic Range Analysis .............................................................................. 67 


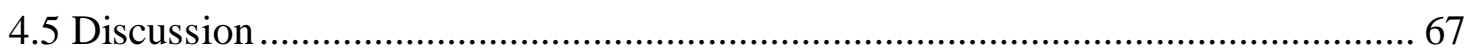

4.5.1 Species Composition of Parrots and Historical Distribution ............................ 67

4.5.2 Availability of Woodpecker Nests in the Urban Environment ......................... 68

4.5.3 Importance of Woodpecker Nests in Palm Snags to Parrots ............................ 68

4.5.4 Nest Fate, Predators, and Poachers .................................................................. 69

4.5.5 Geographic Range Analysis.................................................................... 70

4.5.6 Assessment of Threat to Cavity Nest Webs of the Florida Everglades ............ 71

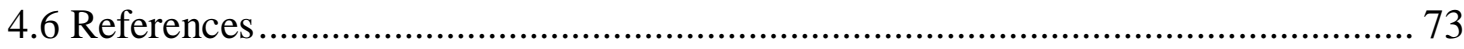

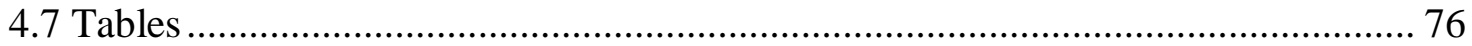

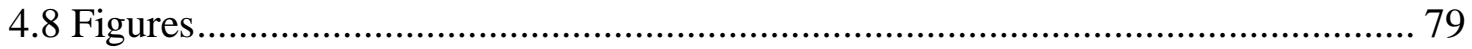

CHAPTER 5. CAVITY NEST WEB DISRUPTION DEPENDS ON HOLE PREFERENCE AND REPRODUCTIVE PHENOLOGY: THE CASE OF EXOTIC STURNIDS AND PSITTACIDS IN A TROPICAL CITY ………………………........ 82

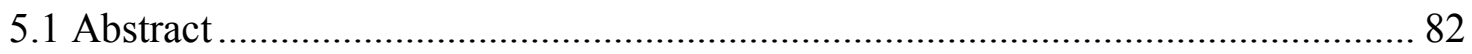

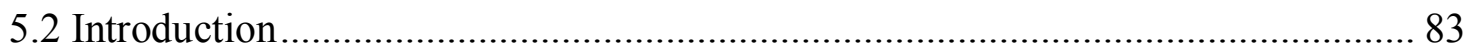

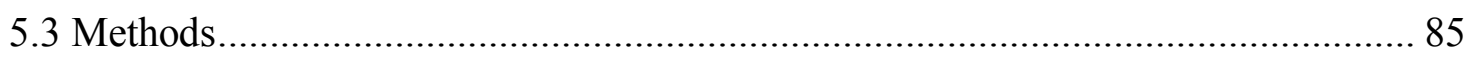

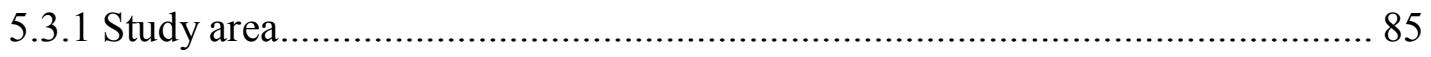

5.3.2 Field Methods for Recording and Monitoring Nest Trees .............................. 87

5.3.3 Field Methods for Recording and Inspecting Cavity Nests ............................ 88

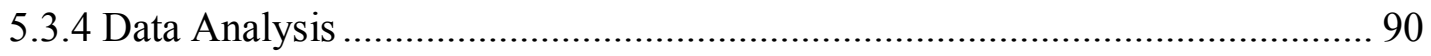

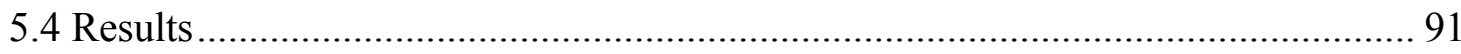

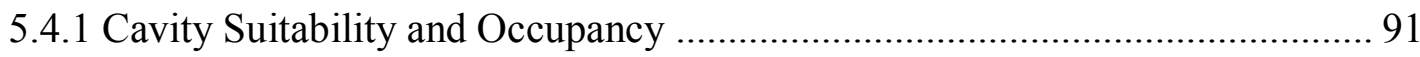

5.4.2 Cavity Nest Characteristics ........................................................................ 92

5.4.3 Overlap of phenology and nest usurpation ..................................................... 94

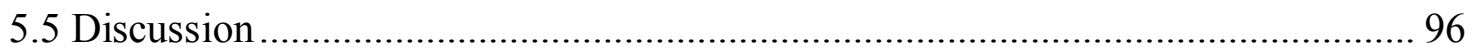

5.5.1 Cavity Occupancy and Nest Characteristics ................................................. 96

5.5.2 Phenology, nest usurpation, and management of exotic birds .......................... 98

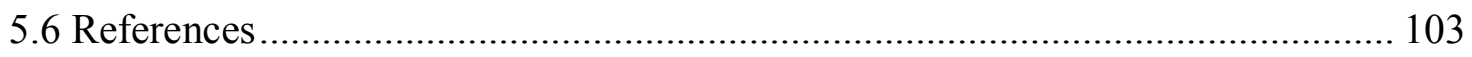

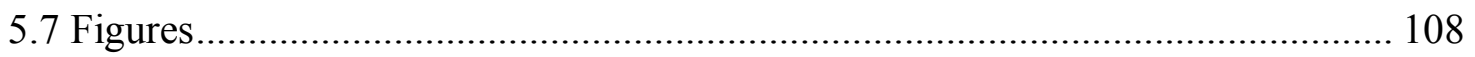

CHAPTER 6. SUMMARY AND CONCLUSIONS ...................................................... 118

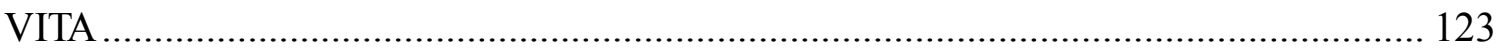




\section{LIST OF FIGURES}

FIGURE

PAGE

Figure 2.1 Search track and nests found within the core study area, Miami-Dade County, Florida. Searches were made by bicycle, foot, and automobile. Large clusters of woodpecker nest trees were found in urban parks and natural areas along the coastline. 38

Figure 2.2 Woodpeckers rarely excavated holes in live palms, 93.5\% of palm cavities were excavated in snags. Woodpecker cavities in live palms were often too shallow, and poorly-drained even in the dry season. The nest inspection camera is seen in the reflection of standing water during the dry season (a). Snags were used more for active nesting attempts; (b) a female Red-bellied Woodpecker incubates eggs in a palm snag two days after (a) and less than two km away.

Figure 3.1 Location of 251 woodpecker nest trees sampled before and after Hurricane Irma in Miami and nearby Everglades National Park. Each point represents one woodpecker nest tree. Points have been minimally dispersed for visibility.

Figure 3.2 The proportion of each nest tree category found before and after Hurricane Irma. Nests found before the hurricane varied in age, having been excavated from months to years before the disturbance. Nests found the year after the hurricane were primarily excavated during that year. All categories except palms declined proportionally in the year after the storm.

Figure 3.3 Nest trees that remained standing had no significant difference in the number of woodpecker holes compared to trees that fell. Nest snags that remained standing had no significant difference in their assessed decay class from snags that fell.

Figure 3.4 Example of a Red-bellied Woodpecker nest in a large DBH Slash Pine snag. The woodpecker has avoided the dense heartwood of the pine, creating a curved nest in the softer sapwood. Smaller DBH pines may not become usable for several years until the heartwood is sufficiently decayed for excavation. Note: The Red-bellied Woodpecker eggs are approximately $2.5 \mathrm{~cm}$ long................................. 57

Figure 4.2 Geographic ranges of cavity-nesting parrots, and observed nest trees. Numbering of nest trees follows Table 1. Nest trees have been dispersed minimally for display purposes. Geographic ranges are drawn to encompass at least $96 \%$ of observations of each species, ignoring distant outliers. All cavities used are found within the core geographic range of each species.

Figure 5.1 Study region, showing search routes and nest trees found. The core study area encompassed Miami-Dade, County, Florida, but individual nest surveys were made south to the Florida Keys, north to West Palm Beach, and west to Fakahatchee Strand State 
Preserve. Survey routes followed a random walk where driving, bicycling, and walking was safely allowed.

Figure 5.2 Cavity nest web diagram highlighting the hierarchical flow of nests from creation through subsequent use. For each tree category, n indicates the total number of cavities excavated within the substrate. For primary excavators, weak excavators, and secondary cavity users, $\mathrm{n}$ indicates the number of active nests. For primary excavators, e indicates the number of cavities attributed to each woodpecker. Line weight in the nest web indicates the relative frequency of cavity creation or transfer. Within primary excavators and secondary cavity users, arrow direction indicates nest movement between species, for example from the Red-bellied Woodpecker to Northern Flicker. The alpha codes for the birds used are as follows: EASO = Eastern Screech Owl. COMY = Common Myna. DOWO = Downy Woodpecker. EUST = European Starling. GCFL = Great-crested Flycatcher. OWPA = Orange-winged Parrot. RMPA = Red-masked Parakeet. PIWO $=$ Pileated Woodpecker. $\mathrm{RBWO}=$ Red-bellied Woodpecker. NOFL $=$ Northern Flicker.

Figure 5.3 Nest tree and hole characteristics of birds breeding in Miami woodpecker cavities, A) nest height, B) entrance hole diameter, C) internal nest diameter, and D) cavity depth. For each characteristic tested, birds are listed in increasing mean, \pm 1 standard deviation. Lettered brackets indicate subsets identified by the post-hoc Tukey HSD test. All characteristics differed significantly except for DBH $(F=1.845, p=$ 0.077), which was excluded from the subsequent hierarchical cluster analysis. The alpha codes for the birds used are as follows: EASO = Eastern Screech Owl. COMY $=$ Common Myna. EUST = European Starling. OWPA = Orange-winged Parrot. $\mathrm{RMPA}=$ Red-masked Parakeet. $\mathrm{PIWO}=$ Pileated Woodpecker. $\mathrm{RBWO}=$ Red-bellied Woodpecker. NOFL $=$ Northern Flicker

Figure 5.4 The analysis of nest cavity preferences showed several clusters of bird species. The primary division is between birds of small-medium body size and large birds. The first cluster consists of Orange-winged Parrot, Red-masked Parakeet, and Pileated Woodpecker, the three largest birds in our system, which will require larger entrance sizes or deeper cavities. The other cluster is composed of the five smaller birds. The European Starling, Common Myna, and Red-bellied Woodpecker are the smallest birds in the system and the most similar in nest preferences. This cluster also includes the Northern Flicker and Eastern Screech Owl, intermediate sized birds. The alpha codes for the birds used are as follows: EASO = Eastern Screech Owl. COMY $=$ Common Myna. EUST = European Starling. OWPA = Orange- winged Parrot. $\mathrm{RMPA}=$ Red-masked Parakeet. PIWO $=$ Pileated Woodpecker. $\mathrm{RBWO}=$ Redbellied Woodpecker. NOFL $=$ Northern Flicker. 
Figure 5.5 Breeding phenologies of eight cavity nesting bird species in Miami-Dade County, Florida, during 2017-2018 breeding season, following analysis in Orchan et al. (2012). Points represent the weekly proportion of active nesting attempts per species, and trendlines follow a third order polynomial curve. Time indicated on the $\mathrm{X}$ axis is weeks starting the 3rd week in February. Visual analysis separates birds into early, peak, and late season breeders. Pileated Woodpecker and Eastern Screech Owl breed first. The peak season includes Northern Flicker, Common Myna, European Starling, and Red- bellied Woodpecker, although this last species has the longest season, extending into the late period. The two Psittacid species breed last. The alpha codes for the birds used are as follows: EASO = Eastern Screech Owl. COMY = Common Myna. EUST $=$ European Starling. OWPA = Orange-winged Parrot. RMPA = Red-masked Parakeet. PIWO $=$ Pileated Woodpecker. $\mathrm{RBWO}=$ Red-bellied Woodpecker. NOFL $=$ Northern

Flicker........................................................................ 116

Figure 5.6 Usurpations of active nests in a cavity nest web, $n=370$ cavities used for $1+$ nesting attempt, out of $n=536$ suitable cavities monitored continuously over two breeding seasons. Arrows indicate the direction of usurpation, towards the losing species. Arrow thickness reflects the number of usurpations. Species are arranged by season, according to breeding phenology. In the absence of phenology data, bees were placed in the early season. Both usurpations of active bird nests by bees occurred in the first six weeks of monitoring; other new hives were found in cavities in the early season. Psittacids were not involved in active nest usurpations. The alpha codes for the birds used are as follows: EASO = Eastern Screech Owl. COMY = Common Myna. EUST $=$ European Starling. OWPA $=$ Orange-winged Parrot. RMPA $=$ Redmasked Parakeet. PIWO $=$ Pileated Woodpecker. $\mathrm{RBWO}=$ Red-bellied Woodpecker. NOFL $=$ Northern Flicker. 


\section{ABBREVIATIONS AND ACRONYMS}

Analysis of variance

Blue-and-yellow Macaw

Blue-crowned Parakeet

Chestnut-fronted Macaw

Common Myna

Diameter at breast height

Downy Woodpecker

Eastern Screech Owl

European Starling

Great-crested Flycatcher

Institutional Animal Care and Use Committee

Nanday Parakeet

Northern Flicker

Orange-winged Parrot

Pileated Woodpecker

Red-bellied Woodpecker

Red-masked Parakeet

Scarlet-fronted Parakeet

Standard deviation
ANOVA

BYMA

BCPA

CFMA

COMY

DBH

DOWO

EASO

EUST

GCFL

IACUC

NAPA

NOFL

OWPA

PIWO

RBWO

RMPA

SFPA

SD 


\section{CHAPTER 1. INTRODUCTION}

\subsection{Background}

Cavity nest webs are non-trophic interactions within and between species of birds that use hollows to roost and breed (Martin and Eadie 1999, Bednarz et al. 2004). There is a clear hierarchical structure between primary cavity excavators that create holes, weak excavators that can modify holes, and secondary cavity users (Martin et al. 2004, Blanc and Walters 2008, Robles and Martin 2013, 2014). Primary cavity excavators in North America are all woodpeckers. Secondary cavity-nesting birds cannot create their own cavities, and are dependent upon decay processes and cavity excavators to create or modify suitable nest sites. Weak excavators are birds which may expand the entrance to a cavity they adopt, enlarging the opening to accommodate their needs. Some weak excavators may be able to enlarge the internal volume of the cavity as well. Outside of North America, birds like trogons and parrots excavate cavities in softer substrates like termite and wasp nests (Sandoval and Barrantes 2009). In the absence of arboreal termitaria and other large, soft materials like clay cliffs, weak excavators must depend on woodpeckers or natural decay to produce suitable cavities. Cavity nest webs provide a new perspective from which to study invasion ecology (Koenig 2003), where much emphasis has been placed on trophic cascades caused by novel interactions.

Cavity nest webs begin with interactions among trees, decay organisms, and avian excavators. Natural weathering and fungi excavate some cavities, but the majority of habitable cavities are created by woodpeckers. Woodpeckers favor different tree species for excavation, and prefer different habitats (Schepps et al. 1999, James et al. 2001, 
Adkins Giese and Cuthbert 2003). In a highly heterogeneous urban landscape, woodpeckers can choose from a variety of native and exotic trees. Some woodpeckers have proven to be well-adapted to urban areas, while others are locally confined to remnant forest fragments (Morrison and Chapman 2005).

Till recently the study of non-trophic interactions has focused on species pairs rather than interacting networks (Vasas and Jordán 2006). Cavity nest webs are relatively unstudied non-trophic interaction networks that may include native and exotic species. Terrestrial birds are relatively conspicuous and therefore are ready subjects for studying such interactions. The preferences woodpeckers exhibit for trees is an important determinant of nest web structure. In a developed environment, urban adapted birds have an advantage over urban avoiders (McKinney 2006, Francis and Chadwick 2012). Urban adapted birds include a suite of exotic species, including cavity-nesting taxa like Starlings, Mynas, Parrots, Parakeets, and Sparrows. Cavities are a finite resource, and the supply of cavities fluctuates over time. Disturbances like fire and hurricanes that might remove existing cavity trees from a landscape also create new snags. Human activities are one of the dominant drivers of cavity flow in urban areas, through planting trees that will eventually die, and removing dead wood when it becomes a nuisance.

The persistence of snags and cavities across a disturbance-prone landscape is needed to determine the productivity of the nest web (Edworthy et al. 2012, Edworthy and Martin 2013). Snags that persist longer can be reused for multiple seasons (Farris et al. 2004). Older snags often accumulate multiple cavities or entrances (Russell et al. 2006). Most horticultural practices, such as pruning trees, reduce the availability of substrate to woodpeckers. In addition to pruning, hurricanes are a regular disturbance, 
killing live trees, felling snags, and removing dead branches from living hardwood trees that sometimes contain nests. Woodpecker cavities are often excavated in spike tops or dead limbs in living trees, which are typically removed during pruning, and can also be destroyed in storms. Entire snags are removed from developed areas because they are a hazard and a liability to the property owner. Dead or weakened limbs that would otherwise be attractive to woodpeckers as nest sites are often removed from living broadleaved trees. The morphology of palm trees spares most species from this horticultural practice. A few horticultural practices may actually increase the longevity of snags, such as fertilization and pruning to maintain physical balance of weight distribution.

The abundance of snags has been shown to be lower in urban and suburban areas than in wild landscapes (Blewett and Marzluff 2005). Generally, densities of native cavity-nesting birds are lower in developed areas (DeGraaf and Wentworth 1986, Tilghman 1987, Tews et al. 2004). While the availability of existing cavities is thought of as a limiting factor for cavity-adopting species, the availability of suitable substrates is the limiting factor for excavator species. While the pattern of reduced snag availability is associated with a reduction in woodpecker richness in urban environments, some woodpeckers are dependent on other habitat factors. Red-cockaded Woodpeckers (Leuconotopicus borealis) excavate cavities almost exclusively in living longleaf pines (Pinus palustris), although they do occur in loblolly (Pinus taeda) shortleaf (Pinus echinata), and slash pine (Pinus elliottii) forests at lower densities (Epting et al. 1995, Doster and James 1998). In this case, the occurrence of Red-cockaded Woodpeckers was linked to forests with an open canopy, larger trees, and more herbaceous than woody 
ground cover (James et al. 2001). Anthropogenic activities like even-aged plantation forestry can reduce the availability of nest trees as well as suitable foraging habitat (Repenning and Labisky 1985, James et al. 2001). If plantation forestry can reduce the substrate available to a mature forest specialist, then urbanization should reduce substrate to all but the most generalist species, capable of adapting to the constantly shifting landuse mosaic of a human landscape.

In addition to the disturbance caused by growing human populations, cavity nesting birds must also respond to severe natural disturbances, such as hurricanes. My research area centered on Miami-Dade County, Florida, a region that was impacted by a hurricane during our planned study. Hurricane Irma hit southeast Florida on September $10^{\text {th }} 2017$, between my two field seasons spent locating and observing woodpecker nests. The combined effects of hurricane-related wind, rain, and debris carried by floodwaters can obliterate woodpecker nest trees or limbs with cavities. If different species and categories of trees have differential responses to disturbance, then a shift is expected in woodpecker nest tree characteristics and tree species composition. Prior studies of the effects of hurricane disturbance on woodpecker nest trees have been limited to the endangered Red-cockaded Woodpecker, and the longleaf pine forests where they breed (Engstrom and Evans 1990, Torres and Leberg 1996, Bainbridge et al. 2011). The impact of Hurricane Irma created a unique opportunity to study the resource fluctuation in an urban area caused by an extreme weather event.

My review of citizen science data and personal observations suggests that South Florida may have the world's greatest richness of exotic cavity-nesting parrots, even if many of these species do not have a significant breeding presence (Sullivan et al. 2009). 
All birds in this guild arrived from the exotic pet trade. Two of the most common parrots in Miami are non-cavity nesting species, which use human structures or build their own nests. Monk Parakeets are the most widespread and common exotic parrot in Florida (Pranty and Epps 2002, Epps 2007). Monk Parakeets are unique among parrots in building large stick nests, although these domed structures may resemble a large cavity from the inside (Goodfellow 2011). Most other parrots use tree cavities, and are described as weak excavators. Lacking the chiseling ability of woodpeckers, parrots have strong bills which can tear weakened wood. The breeding status of many exotic cavitynesting birds in Florida is not known. The Florida Ornithological Society counts only six cavity-nesting exotics as established; four parrot species, plus the European Starling and Common Myna. Yet, dozens of additional exotic parrots are commonly observed, presumably newer introductions or recent feral escapes. Establishment of exotic birds depends on many factors, like propagule pressure and resource matching (Blackburn et al. 2009). Since nest sites are a critical resource for reproduction, determining which species are finding suitable sites suggests which species become established or invasive. A lack of suitable nest sites may actually prevent an invasion. Rose-ringed Parakeets are the most invasive cavity-nesting bird in Europe, usurping cavities primarily in developed areas (Strubbe and Matthysen 2007, 2009a, 2009b, Orchan et al. 2012, Hernández-Brito et al. 2014, Peck et al. 2014). Nevertheless, despite repeated introductions in urban areas across Florida, the Rose-ringed Parakeet has not established any known breeding populations.

The competition for cavities has primarily been studied in environments with only one exotic competitor (but see Orchan et al. 2012 and Charter et al. 2016). The European 
Starling (Sturnus vulgaris) and Rose-ringed Parakeets (Psittacula krameri) have been studied in North America and Europe, respectively, for their impacts on native birds. Across each continent, these are the only two widespread invasive birds known to usurp tree cavities. In both continents and other parts of the world, Mynas do so locally but do not have continent-wide populations (Linz et al. 2007, Peacock et al. 2007, Charter et al. 2016).

Non-trophic interactions among members of the cavity-nesting guild are suggested to be shaped by three major factors: the timing of breeding, nesting preferences, and the ability to excavate or widen cavities (Orchan et al. 2012). Communities rich in native and exotic species have more opportunities for novel species interactions (Hobbs et al. 2009). Overlapping nesting phenology can cause competition for limited cavities (Ingold 1994, Wiebe 2003, Martin et al. 2004). Conversely, if primary and weak excavators breed first, the fecundity of later-breeding secondary users is enhanced (Orchan et al. 2012). The relationships between bird species in a novel ecosystem provides insight into what new non-trophic interactions could occur during biological invasions. As outlined below, this dissertation addresses production of cavities, persistence of nests during a hurricane, establishment success within a family of exotic bird species, and the effects of these novel actors on nest web structure.

\subsection{Objectives and Dissertation Organization}

This dissertation project investigates the relationships between groups of tree species, native woodpecker excavators, native and exotic secondary cavity nesting birds, and abiotic hurricane and anthropogenic disturbances. 
Chapter 2 (currently under review by Urban Ecosystems) aims to determine which individual trees species and categories of tree substrate (palm trees, broadleaved shade trees, coniferous trees, and wood utility poles) would be used most by woodpeckers in this urban tropical region. I asks what tree and nest characteristics are most important for woodpeckers, as well as what types of habitat cover are preferred.

Chapter 3 (currently under review by Urban Forestry \& Urban Greening) aims to evaluate the impact of hurricane disturbance on nest persistence, and comparing characteristics of nest trees that fell and trees that persisted through the storm. I consider shifts in categories of tree substrate based on loss of trees to hurricane disturbance, and standing tree death, creating new substrate for woodpeckers

Chapter 4 (to be submitted to Avian Research) aims to identify which species of exotic parrots observed and reported in our study area are actually breeding and roosting in tree cavities. I describe the physical nest characteristics of the two most common parrot species in our study. I aim to compare the geographic range and abundance of parrots to other cavity-nesting bird species, and determine if their interactions suggest a threat to native cavity nesting birds.

Chapter 5 (to be submitted to Biological Invasions) aims to find the nest preferences and breeding phenologies of cavity nesting birds, and determine if timing of reproduction combined with nest characteristics determines which species will usurp active nesting attempts and reduce fecundity of native competitors. I investigate differences between Sturnids, the family of birds including the starling and myna established here, and the Psittacid parrots breeding in woodpecker cavities. I evaluate interactions at the guild level, including transfer of active and inactive nest cavities. 


\subsection{References}

Adkins Giese, C. L., and F. J. Cuthbert. 2003. Influence of surrounding vegetation on woodpecker nest tree selection in oak forests of the Upper Midwest, USA. Forest Ecology and Management 179:523-534.

Bainbridge, B., K. A. Baum, D. Saenz, and C. K. Adams. 2011. Red-Cockaded Woodpecker Cavity-Tree Damage by Hurricane Rita: An Evaluation of Contributing Factors. Southeastern Naturalist 10:11-24.

Bednarz, J. C., D. Ripper, and P. M. Radley. 2004. Emerging Concepts and Research Directions in the Study of Cavity-Nesting Birds : Keystone Ecological Processes. The Condor 106:1-4.

Blackburn, T. M., J. L. Lockwood, and P. Cassey. 2009. Avian Invasions: The Ecology \& Evolution of Exotic Birds. Oxford University Press, New York.

Blanc, L. A., and J. R. Walters. 2008. Cavity Excavation and Enlargement as Mechanisms for Indirect Interactions in an Avian Community. Ecology 89:506-514.

Blewett, C. M., and J. M. Marzluff. 2005. Effects of urban sprawl on snags and the abundance and productivity of cavity-nesting birds. Condor 107:678-693.

Charter, M., I. Izhaki, Y. Ben Mocha, and S. Kark. 2016. Nest-site competition between invasive and native cavity nesting birds and its implication for conservation. Journal of Environmental Management 181:129-134.

DeGraaf, R. M., and J. M. Wentworth. 1986. Avian Guild Structure and Habitat Associations in Suburban Bird Communities. Urban Ecology 9:399-412.

Diamond, J. M. 2017. First North American report of an American Kestrel (Falco sparverius) roosting in a Monk Parakeet (Myiopsitta monachus) nest. Florida Field Naturalist 45:18-20.

Doster, R. H., and D. A. James. 1998. Home Range Size and Foraging Habitat of RedCockaded Woodpeckers in the Ouachita Mountains of Arkansas. The Wilson Bulletin 110:110-117.

Edworthy, A. B., and K. Martin. 2013. Persistence of tree cavities used by cavity-nesting vertebrates declines in harvested forests. Journal of Wildlife Management 77:770776.

Edworthy, A. B., K. L. Wiebe, and K. Martin. 2012. Survival analysis of a critical resource for cavity-nesting communities: patterns of tree cavity longevity. Ecological Applications 22:1733-1742.

Engstrom, R. T., and G. W. Evans. 1990. Hurricane Damage to Red-Cockaded Woodpecker (Picoides borealis) Cavity Trees. The Auk 107:608-610.

Epps, S. A. 2007. Parrots of South Florida. Pineapple Press, Inc. 
Epting, R. J., R. S. DeLotelle, and T. Beaty. 1995. Red-cockaded woodpecker territory and habitat use in Georgia and Florida.

Farris, K. L., M. J. Huss, and S. Zack. 2004. The role of foraging woodpeckers in the decomposition of ponderosa pine snags. The Condor 106:50-59.

Francis, R. A., and M. A. Chadwick. 2012. What makes a species synurbic? Applied Geography 32:514-521.

Goodfellow, P. 2011. Avian architecture: How birds design, engineer, and build. Princeton University Press, Princeton, New Jersey.

Hernández-Brito, D., M. Carrete, A. G. Popa-Lisseanu, C. Ibáñez, and J. L. Tella. 2014. Crowding in the city: Losing and winning competitors of an invasive bird. PLoS ONE 9.

Hobbs, R. J., E. Higgs, and J. A. Harris. 2009. Novel ecosystems: implications for conservation and restoration. Trends in Ecology and Evolution 24:599-605.

Ingold, D. J. 1994. Influence of nest-site competition between European Starlings and woodpeckers. Wilson's Bulletin 106:227-241.

James, F. C., C. a Hess, B. C. Kicklighter, and R. a Thum. 2001. Ecosystem Management and the Niche Gestalt of the Red-Cockaded Woodpecker in Longleaf Pine Forests. Ecological Applications 11:854-870.

Koenig, W. D. 2003. European Starlings and Their Effect on Native Cavity-Nesting Birds. Conservation Biology 17:1134-1140.

Linz, G. M., H. J. Homan, S. M. Gaulker, L. B. Penry, and W. J. Bleier. 2007. European Starlings : a Review of an Invasive Species With Far-Reaching Impacts. Managing Vertebrate Invasive Species: Proceedings of an International Symposium:378-386.

Martin, K., K. E. H. Aitken, and K. L. Wiebe. 2004. Nest sites and nest webs for cavitynesting communities in interior British Colombia, Canada: Nest characteristics and niche partitioning. The Condor 106:5-19.

Martin, K., and J. M. Eadie. 1999. Nest webs: A community-wide approach to the management and conservation of cavity-nesting forest birds. Forest Ecology and Management 115:243-257.

McKinney, M. L. 2006. Urbanization as a major cause of biotic homogenization. Biological Conservation 127:247-260.

Morrison, J. L., and W. C. Chapman. 2005. Can Urban Parks Provide Habitat for Woodpeckers? Northeastern Naturalist 12:253-262.

Orchan, Y., F. Chiron, A. Shwartz, and S. Kark. 2012. The complex interaction network among multiple invasive bird species in a cavity-nesting community. Biological Invasions 15:429-445. 
Peacock, D. S., B. J. Van Rensburg, and M. P. Robertson. 2007. The distribution and spread of the invasive alien common myna, Acridotheres tristis L. (Aves: Sturnidae), in southern Africa. South African Journal of Science 103:465-473.

Peck, H. L., H. E. Pringle, H. H. Marshall, I. P. F. Owens, and A. M. Lord. 2014. Experimental evidence of impacts of an invasive parakeet on foraging behavior of native birds. Behavioral Ecology 25:582-590.

Pranty, B., and S. A. Epps. 2002. Distribution, Population Status, and Documentation of Exotic Parrots in Broward County, Florida. Florida Field Naturalist 30:111-150.

Repenning, R. W., and R. F. Labisky. 1985. Effects of even-age timber management on bird communities of the longleaf pine forest in northern Florida. The Journal of wildlife management 49:1088-1098.

Robles, H., and K. Martin. 2013. Resource quantity and quality determine the interspecific associations between ecosystem engineers and resource users in a cavitynest web. PloS one 8:1-12.

Robles, H., and K. Martin. 2014. Habitat-mediated variation in the importance of ecosystem engineers for secondary cavity nesters in a nest web. PLoS ONE 9.

Russell, R. E., V. A. Saab, J. G. Dudley, and J. J. Rotella. 2006. Snag longevity in relation to wildfire and postfire salvage logging. Forest Ecology and Management 232:179-187.

Sandoval, L., and G. Barrantes. 2009. Relationship between Species Richness of Excavator Birds and Cavity-Adopters in Seven Tropical Forests in Costa Rica. The Wilson Journal of Ornithology 121:75-81.

Schepps, J., S. Lohr, and T. E. Martin. 1999. Does Tree Hardness Influence Nest-Tree Selection by Primary Cavity Nesters? The Auk 116:658-665.

Strubbe, D., and E. Matthysen. 2007. Invasive ring-necked parakeets Psittacula krameri in Belgium: Habitat selection and impact on native birds. Ecography 30:578-588.

Strubbe, D., and E. Matthysen. 2009a. Experimental evidence for nest-site competition between invasive ring-necked parakeets (Psittacula krameri) and native nuthatches (Sitta europaea). Biological Conservation 142:1588-1594.

Strubbe, D., and E. Matthysen. 2009b. Establishment success of invasive ring-necked and monk parakeets in Europe. Journal of Biogeography 36:2264-2278.

Sullivan, B. L., C. L. Wood, M. J. Iliff, R. E. Bonney, D. Fink, and S. Kelling. 2009. eBird: A citizen-based bird observation network in the biological sciences. Biological Conservation 142:2282-2292.

Tews, J., U. Brose, V. Grimm, K. Tielbörger, M. C. Wichmann, and M. Schwager. 2004. Keystone Structures. Journal of Biogeography 31:79-92. 
Tilghman, N. G. 1987. Characteristics of urban woodlands affecting breeding bird diversity and abundance. Landscape and Urban Planning 14:481-495.

Torres, R. A., and P. L. Leberg. 1996. Initial Changes in Habitat and Abundance of Cavity-Nesting Birds and the Northern Parula Following Hurricane Andrew. The Condor 98:483-490.

Vasas, V., and F. Jordán. 2006. Topological keystone species in ecological interaction networks: Considering link quality and non-trophic effects. Ecological Modelling 196:365-378.

Wiebe, K. L. 2003. Delayed timing as a strategy to avoid nest-site competition: testing a model using data from starlings and flickers. Oikos 100:291-298. 


\section{CHAPTER 2. PALM SNAGS ARE A CRITICAL NESTING RESOURCE FOR WOODPECKERS IN AN URBANIZED TROPICAL REGION}

\subsection{Abstract}

Critical resources for birds nesting in cities can support populations in spite of the challenges imposed by urbanization, and the identification of such resources can shed light on how species are able to adapt to novel environments. In the case of woodpeckers, these resources also support the conservation of secondary cavity-nesters. Woodpecker nesting has been well-studied in temperate regions, including within urban areas, but in subtropical and tropical regions, less is known. Here we ask what types of trees and what habitats are used most by woodpeckers, and which species of woodpeckers create the most nest cavities. We recorded information from 967 woodpecker nest trees in the region surrounding Miami, Florida, USA, which contained a total of 1,864 nest cavities excavated by four woodpecker species. Palm trees were used more than all other tree categories, and royal palms (Roystonea regia) were the most-used species overall. Palm snags were preferentially excavated in every habitat where they were available and three of the four woodpecker species used palms snags over all other categories of trees. Red-bellied Woodpeckers (Melanerpes carolinus) were the most prolific cavity excavators, creating $78.1 \%$ of holes. Remnant patches of two native forest types contained the highest densities of woodpecker nest trees. We found a higher density of nest trees in moderately-developed suburban areas than either rural, agricultural areas or in the highly-developed urban core. We consider how these results 
can inform conservation efforts in the developing tropics, and especially within similar urbanizing environments in the nearby Caribbean.

\subsection{Introduction}

Woodpeckers are globally distributed birds, absent only from Australasia, Antarctica, Madagascar, remote islands, and treeless environments (Mikusiński 2006; Ilsøe et al. 2017). The tropics have the greatest richness of woodpecker species, as well as the greatest richness of imperiled woodpecker species (Mikusiński 2006; Lammertink 2014). Woodpeckers are considered keystone species due to their role in maintaining many cavity-nesting bird populations, as well as myriad other species that use tree cavities, by excavating holes (Martin et al. 2004; Blanc and Walters 2008; Robles and Martin 2013; Cockle and Martin 2015). Despite the great threats to conservation in the tropics, most research on imperiled woodpeckers have focused on three temperate North American species, the Red-headed (Melanerpes erythrocephalus), Red-cockaded (Picoides borealis) and Ivory-billed Woodpeckers (Campephilus principalis)

(Lammertink 2014). Woodpecker conservation is needed in tropical regions, where deforestation and urbanization follow rapid population growth (Meyer and Turner 1992; Cincotta et al. 2000). Much human population growth in Latin America and the Caribbean occurs in coastal or lowland regions, and half of the woodpecker species redlisted by IUCN occur in these regions (Lammertink 2014).

Managing expanding urban areas for woodpeckers will be a major conservation challenge. As urban regions grow to cover more land area in the tropics, better policies are needed to conserve species within the heterogeneous matrix of developed areas, urban parks, and conservation lands that comprise the urban matrix. The effects of urbanization 
on species richness and abundance of cavity-nesting birds is a topic of some debate. Strong negative effects are observed in some environments (Luck and Smallbone 2010) and positive effects in others (Chace and Walsh 2006). Generally, land birds are excellent indicators of the effects on urbanization, due to their mobility and rapid response to changes in the landscape (Hutto 1998; Marzluff et al. 1998; Alberti 2008). The ecology of urban woodpeckers has been studied in many temperate regions (Moulton and Adams 1991; Morrison and Chapman 2005; LaMontagne et al. 2015; Anderson and LaMontagne 2016; Tomasevic and Marzluff 2017, 2018; Figarski and Kajtoch 2018), where managers have identified critical resources such as the characteristics and densities of snags (standing dead trees), and green space requirements. In some environments, specific tree taxa may be important for nesting woodpeckers, such as cactus, bamboo, pines, or palms (Kerpez and Smith 1990; Kratter 1998; James et al. 2001). For example, resource managers in Arizona, USA have legally protected the saguaro cactus (Carnegiea gigantea) in part because of its importance to cavity-nesting birds (Brush et al. 1983; Pavek 1993). In some tropical and subtropical regions, woodpeckers are less important to cavity nest webs due to availability of natural cavities (Cockle et al. 2011a; b). Resource managers in the tropics need more information on the ecology of urban woodpeckers, as well as tropical woodpeckers more broadly.

South Florida (USA), centered on Miami-Dade County resembles other Caribbean cities in its size and mixture of land uses. Its location is subtropical in latitude but tropical in climate given its low elevation and proximity to the warm currents flowing through the Straits of Florida and up the eastern US coast. Native forest communities and developed areas of the county are both dominated by tropical vegetation, and the 
environments and biota are more similar to the Caribbean than to temperate North America (Lee and West 2011). In Miami, and other tropical cities, palm trees are a major presence in both urban forests and natural plant communities. A study in adjacent Broward County, Florida found a preference among residents for non-shade trees like palms in urban tree distribution programs (Dawes et al. 2018). In densely-packed urban environments, trees with small canopies are horticulturally preferred over spreading shade trees, and palms are often valued for this morphology. Native palms are a major component of relict natural areas in Miami, including upland forests and wetlands, and produce fruits consumed by birds and mammals. Both native and exotic palms are widely planted for their aesthetic properties. Several exotic palms have escaped cultivation through wide use as landscape trees, such as coconut palm (Cocos nucifera) and queen palm (Syagrus romanzoffiana) (Florida Exotic Pest Plant Council 2017). The uplands of the region were historically covered with pine rockland forest, an open, savanna-like community dominated by South Florida slash pine (Pinus elliottii var. densa) in the canopy, but containing a diverse mixture of tropical understory plants (Possley and Maschinski 2008; Maschinski et al. 2011; Trotta et al. 2018). As they occur on the highest elevations in this hurricane and flood-prone region, pine rocklands were the first areas developed for permanent human settlements. Even where they were not directly cleared, the condition of these forests declined greatly due to fire suppression. Isolated patches remain throughout the southern, less-developed portion of Miami-Dade County, where fire can be used more effectively for management (Diamond and Heinen 2016). In the absence of fire, hardwood trees grow in the understory, pine regeneration is stifled, and tropical hardwood hammock forest (hereafter hardwood hammocks) 
develops. These are closed-canopy tropical dry forests dominated by a variety of broadleaved trees. Native Florida hardwood trees are primarily of West Indian origin. Pine trees remaining from early seral stages and understory palms are components of some hardwood hammocks.

The modern landscapes of Miami-Dade County uplands are predominantly urban. The county itself has nearly three million residents, but much of its ca. $5,000 \mathrm{~km}^{2}$ is wetland occupied by national, state, or local preserves. Most prominent is Everglades National Park, a Category 2 protected area, World Heritage Site, Biosphere Reserve, and Wetland of International Importance (Heinen 1995). The broader Miami metropolitan area has over six million residents, and is the seventh most populous metropolitan area in the United States (United States Census Bureau 2010). Despite high property values and development pressures, significant portions of urban Miami-Dade have been preserved in natural or semi-natural states, including county and state parks and conserved private forests (Alonso and Heinen 2011; Giannini and Heinen 2014). The County's street tree master plan calls for increasing tree canopy cover to a countywide average of $30 \%$ by 2020, up from 10\% in 1996 (Miami-Dade County 2007). These actions thus provide habitat for woodpeckers to excavate in most terrestrial environments, and at every level of urban development. The objectives of this paper are to determine (1) what tree species and physical attributes are important for woodpecker nesting, (2) what habitat cover types (including urbanized areas at different levels of development) are used most frequently by woodpeckers for nesting, and (3) which temperate woodpecker species are the most prevalent in the southernmost portion of their range? We also consider how preferences 
for specific types of nest trees in urban regions can help conservation efforts elsewhere in the tropics, especially within the Caribbean.

\subsection{Methods}

\subsubsection{Field Methods for Locating Woodpecker Cavity Trees}

We modified the United States Forest Service protocol for locating and monitoring cavity-nesting birds for an urban environment (Dudley and Saab 2003). Belt transects searching for snags and cavities are not possible in an urban environment, so we used a random walk search following whatever paths would allow us to investigate safely. The metrics for comparing responses to habitat change were changed from comparisons of nests per unit area to nests per unit distance searched, as total area sampling is not possible in developed areas. Almost all nests were located by search image and, during the breeding season, some nests were located by following woodpeckers and/or secondary-cavity nesters, or by hearing nestlings beg. We used GPS tracking to determine search distances in each habitat type, and record all nest trees. Searches were conducted by driving, bicycling, and/or walking through various urban and natural habitats (Figure 2.1). We assumed a difference in detectability in searches, with the highest likelihood of detection walking, intermediate by bicycle, and lowest by motor vehicle. In order to avoid overly searching native upland forests by foot and bicycle, we selected additional sites outside of our core area to search exclusively by motor vehicle, such as Dagny Johnson Key Largo Hammock Botanical State Park, and a portion of Long Pine Key, Everglades National Park. We searched for nests from 
October 2016 to August 2018, encompassing two full breeding seasons. All data was collected by a single observer, with the assistance of over two dozen volunteers.

\subsubsection{Study Area}

Our study region focused on Miami-Dade County. The City of Miami Beach and the Village of Palmetto Bay, two urbanized municipalities within Miami-Dade County, had recently collected street tree inventories. The inventories were collected by arborists and contain species identification of every tree that intersects the public right-of-way. These two tree surveys contained over 55,000 trees and are representative of the tree composition of the county as a whole. We used the inventories to compare woodpecker nest tree species in developed areas to the overall urban forest composition. We surveyed less frequently outside the County, making one visit each north to West Palm Beach, the northern limit of the metropolitan region, and southwest to Key West, the southernmost point of the continental USA.

\subsubsection{Field Methods for Recording and Monitoring Nest Trees}

We recorded data for each nest tree: tree species, habitat type, tree height, decay class, and diameter at breast height (DBH) were recorded (Dudley and Saab 2003). We recorded 20 different habitat types in our surveys. These included multiple native forest types, herbaceous wetlands, and different densities of urban development. Key characteristics for each habitat are described in Appendix 1. Habitats with less than 50 $\mathrm{km}$ of distance searched were pooled for analysis as "other habitats." We divided tree species into four categories: palms, pines, hardwoods, and wooden telephone/utility poles (hereafter referred to as poles). We also recorded the decay class for each snag on a scale from zero to ten, where decay class one appears recently dead and stable, and decay class 
nine is disintegrating and appears unsteady and ready to fall. Live trees were assigned a value of zero and not included in the analyses of snags. Trees that had already fallen but had observable nest holes were assigned a value of ten and were also not included in the analysis of snags. Poles were not assigned a decay class. Snags are particularly important for woodpeckers, as these standing dead trees provide ample opportunities for cavity excavation (Drapeau et al. 2009). By contrast, a live tree may not have any dead branches suitable for excavation. For each woodpecker cavity, we recorded the height, entrance hole diameter, and the species of woodpecker that was the original excavator (e.g. Dudley and Saab (2003), using cues of cavity size and shape when direct observations were unavailable.

\subsubsection{Field Methods for Inspecting Woodpecker Nests}

We inspected the interior of woodpecker nest cavities using a wireless video camera designed for the study of cavity-nesting birds (Luneau and Noel 2010). The camera was mounted on a collapsible fiberglass pole capable of reaching nests up to approximately $15 \mathrm{~m}$ above the ground. Inspections were done in non-breeding and breeding seasons to determine which cavities were sufficiently large and suitable for nesting.

\subsubsection{Data Analysis}

We completed all statistical analyses using IBM SPSS version 20.0 and ArcMap GIS version 10.4. Using univariate analysis of variance, we compared the four categ ories of tree species for mean height, mean DBH, number of woodpecker nest holes per tree, amount of decay, and nest height ratio, the nest height as a proportion of tree height. We used chi-square tests for differences in the proportions of excavated trees that were snags 
or living trees, and in the proportions of trees available in developed regions to the trees excavated by woodpeckers. We used univariate analysis of variance to compare the four woodpecker excavators for tree height, tree $\mathrm{DBH}$, nest height proportion of tree height, and nest entrance hole diameter. We used aerial photographs in combination with field notes and GPS tracks to measure search distance in each habitat in ArcMap. Mean values reported in the results are \pm 1 standard deviation (SD).

\subsection{Results}

\subsubsection{Woodpecker Nests by Habitat Type}

We searched more than $50 \mathrm{~km}$ of 13 different habitats across developed and wildland areas (Table 1). The two native upland forest types, pine rocklands and hardwood hammocks, contained the greatest concentrations of woodpecker nest trees. Habitats dominated by pine trees are the major exception to the trend towards the use of palms. Nests in pine rocklands were exclusively in P. elliottii var. densa trees, at a density of 0.38 nest trees per $\mathrm{km}$ searched. Despite their importance to woodpeckers in these forests, pines were only $0.1 \%$, and all coniferous trees were only $0.2 \%$, of trees recorded in the two urban tree inventories. Nest trees in hardwood hammocks were found every $0.34 \mathrm{~km}$ and were evenly split between palms and hardwoods. Parks and botanical gardens also featured high concentrations of nests, 0.33 and 0.31 per $\mathrm{km}$ respectively, mostly in palm trees. The inventories for Miami Beach and Palmetto Bay contained 55,101 trees: $53.6 \%$ palms, $46.2 \%$ hardwoods, and $0.2 \%$ conifers. Within those developed areas, palms were $83.0 \%$ of nest trees, hardwoods were $12.2 \%$, telephone poles were $3.9 \%$, and conifers were $0.8 \%$ of nest trees. 


\subsubsection{Woodpecker Nests by Tree Category}

We recorded data on 967 nest trees throughout the study, although 17 were removed from some analyses due to incomplete data beyond species identification. Of the nest trees in the sample, $63.1 \%$ were palms, $18.8 \%$ were hardwoods, $11.4 \%$ were pines, and $6.7 \%$ were poles. Nest trees found in urban and suburban areas, and mowed urban parkland (excluding urban natural plant communities) accounted for $49.7 \%$ of all nests. A chi-square test of independence for whether woodpecker nest tree types differed from the urban forest community as a whole was highly significant in favor of palms ( $\chi^{2}$ $(2, \mathrm{~N}=55,565)=230.6, \mathrm{p}<0.001)$. We recorded 26 different species of palms in total, and four additional nest trees were unidentified palm snags. Nests were most common in the most abundant palms species: royal palm (Roystonea regia), coconut palm (Cocos nucifera), and cabbage palm (Sabal palmetto). However, we also recorded nests in rare, exotic palm snags in botanical gardens, such as the critically endangered Haitian endemic carossier palm (Attalea crassispatha).

Royal palm plays an important role as a substrate for woodpeckers in the region (Table 2) and they were the most commonly excavated species in urban areas, suburban areas, rural areas, developed parkland, and surprisingly, tropical hardwood hammocks. Royal palms are uncommon in hammocks, found primarily at edges and in gaps, and we estimated they usually represent $<1 \%$ of arborescent stems in these forests. This was the most common tree species used by woodpeckers and $28.0 \%$ of all nests were found in royal palm alone. In developed areas, they represented $37.1 \%$ of all excavated trees. Within the urban tree inventories, they were the third most common tree species, but represented only $6.6 \%$ of the total trees. One quarter of all nest trees found in hardwood 
hammocks were royal palms, but many hardwood hammocks contained no royal palms, or any other palm species. We found several hammocks with no royal palms that contained few to no nest trees.

The four categories of tree differed significantly in their height, DBH, decay class, and nest height ratio (all $\mathrm{p}<0.001$, Table 3). Palm trees were shorter than the other categories of trees except for pines. Pine trees had the lowest diameter, and often the excavated snags had already lost their bark and sapwood, with only a thin, decayed heartwood spear remaining. Hardwood trees had the largest diameter, with a mean DBH double that of most other trees. Palm trees were the least decayed category of tree. Cavities in hardwood trees were proportionally lower in height than in other trees. Between hardwoods, palms, and pines, the proportion of nests made in snags versus live trees differed significantly $\left(\chi^{2}(2, \mathrm{~N}=780)=106.5, \mathrm{p}<0.001\right)$. Less than two thirds of hardwood nest trees were snags (65 of 105), compared to over $90 \%$ of those in palms (528 of 565) and pines (108 of 110). Woodpecker cavities in live hardwood trees were most often found in dead limbs or limb stubs below canopy height. All four categories of trees supported an average of about two nest holes per tree, and an ANOVA indicated no differences between tree categories $(\mathrm{p}=0.866)$. Likewise, the number of nest holes per tree did not differ among the 20 most abundant species excavated $(p=0.219)$. Seven of these 20 species are exotic invasive trees (Florida Exotic Pest Plant Council 2017).

\subsubsection{Tree Categories across Habitat Types}

The coastal habitats, i.e., mangrove forests and coastal prairies, featured moderately high numbers of woodpecker nests, 0.27 and 0.23 per km, respectively. Mangrove forests were the only habitat in which a majority of woodpecker nests were 
found in broadleaved trees, many in the exotic invasive hardwood Australian Pine

(Casuarina equisetifolia) which are emergent above the mangrove canopy. Coastal prairie nests were primarily in palm trees. We found a moderate number of nest trees in suburban areas and campuses; both were 0.16 per $\mathrm{km}$. Nests in both environments were found primarily in palms. Beaches, cypress prairie, prairie, rural, and urban environments all had woodpecker nest trees in relatively low numbers $(\leq 0.12$ per $\mathrm{km})$. The environments in which nest trees were less common also had relatively few trees. Rural areas were variable, some had high concentrations of trees, but others were treeless agricultural lands. Telephone poles were important nest sites for woodpeckers in prairie and cypress prairie environments, but palms were the main nest substrate in beaches, rural areas and urban environments.

\subsubsection{Role of Four Woodpecker Excavator Species}

Four woodpecker species were responsible for the creation of nest cavities. Of the 1,864 cavities we recorded, $78.1 \%$ were excavated by Red-bellied Woodpeckers (Melanerpes carolinus), 16.0\% were by Pileated Woodpeckers (Dryocopus pileatus), $3.7 \%$ by Northern Flickers (Colaptes auratus), and $2.3 \%$ by Downy Woodpeckers (Picoides pubescens). Downy Woodpeckers were the only species to largely avoid palm trees, favoring pines and hardwoods for excavation. Only $16.7 \%$ of Downy Woodpecker nest trees were palms. They were also the rarest of the woodpecker species recorded here. The other three species used palms for over half of their cavities. Pileated woodpeckers were the primary user of telephone poles, particularly in the treeless prairie and dwarf cypress prairie. Telephone poles excavated in suburban landscapes were exclusively the work of Red-bellied Woodpeckers. We additionally recorded only 38 
natural cavities in our study area, none of which were used by nesting birds. An Eastern Screech Owl (Megascops asio) was once observed in one natural cavity, and bees constructed a hive in another.

The four woodpecker species differed significantly in their nest tree height, DBH, and entrance hole diameter (all $\mathrm{p}<0.001$, Table 4). Downy and Red-bellied Woodpeckers used shorter trees $(9.7 \pm 3.3$ and $9.1 \pm 3.9 \mathrm{~m})$ than Northern Flickers $(11.7$ $\pm 4.0 \mathrm{~m})$ and Pileated Woodpeckers $(12.7 \pm 3.9 \mathrm{~m})$. There was no difference in the nest height ratio $(\mathrm{p}=0.835)$. All woodpecker species placed nests at approximately $80 \%$ the height of the tree, although Red-bellied Woodpeckers were more variable in their height selection, and at least one created a nest only a few decimeters above the ground (Diamond 2018). Red-bellied Woodpecker nest trees did not differ in DBH from other species $(30.2 \pm 18 \mathrm{~cm})$. Downy Woodpecker nest trees were smaller in diameter $(23.4 \pm$ $11.7 \mathrm{~cm})$ than either Northern Flicker $(32.1 \pm 13.1 \mathrm{~cm})$ or Pileated Woodpecker $(36.8 \pm$ $24.9 \mathrm{~cm}$ ) nest trees. All four woodpecker species created different diameter entrance holes, with sizes roughly proportional to their body size. Downy Woodpecker holes were the smallest $(3.3 \pm 0.6 \mathrm{~cm})$, followed by Red-bellied Woodpeckers $(6.4 \pm 0.9 \mathrm{~cm})$, Northern Flickers $(7.9 \pm 1.1 \mathrm{~cm})$, and Pileated Woodpeckers $(11.6 \pm 2.9 \mathrm{~cm})$.

\subsection{Discussion}

\subsubsection{Importance of Palm Trees to Woodpeckers}

Palm trees are disproportionately important for woodpeckers in our study area; seven of the top ten excavated tree species were palms. Palms were the most excavated trees across all habitat types and were even used more by woodpeckers in developed than 
in more rural areas. Palms were also the least decayed category of tree. Softer wood is preferred by woodpeckers, indicating that palms require less decay than many other trees to reach optimal hardness (Schepps et al. 1999; Lorenz et al. 2015; Gutzat and Dormann 2018). The structure of a palm trunk, with a tough exterior and soft, pithy core, may expedite cavity formation processes and thus make them more appealing to woodpeckers (Boyle et al. 2008). In a study of wood density across 2456 neotropical tree species, palms (Arecaceae) had a mean wood density of $0.488 \mathrm{~g} / \mathrm{cm}^{3}$ compared to a $0.645 \mathrm{~g} / \mathrm{cm}^{3}$ for all species (Chave et al. 2006).

Woodpecker nests in palm snags may also persist longer in the environment because less-decayed snags are more resistant to disturbances (Russell et al. 2006). In contrast to Boyle et al. (2008), who found holes in palms exclusively in snags, we found a small number of cavities in living palm trees. These were primarily old, large royal palms which had dead portions of their main bole. Still, $93.5 \%$ of woodpecker holes in palms were in dead snags. We inserted a pole-mounted nest inspection camera into cavities in live palms, but the holes were usually too shallow, or poorly-drained to support nests. Cavities in palm snags rarely contained standing water. We inspected 750 cavities starting before the rainy season began, and three cavities contained water, all of which were in live palm trees, which we never observed in palm snags (Figure 2.2). Woodpeckers may thus select palm snags over live palms because of better drainage as well as less dense wood.

\subsubsection{Substrate Availability in Urban Forest Fragments and Developed Areas}

The two native upland forest habitats, pine rockland and hardwood hammock, contained the highest density of nests per km searched but not all native environments 
supported large numbers of woodpecker nests. For example, various prairie types had few and/or dwarf-sized trees. Some prairies had nest substrates only in wooden poles. Mowed parkland and botanical gardens contained a greater density of nests than lowland forests and grasslands. Woodlots in urban and suburban areas are thought to retain a greater density of snags than rural areas because of a lower intensity of harvest (Mörtberg and Wallentinus 2000). This pattern may not be true in developing countries, where concentrated poverty in urban environments can drive the complete exploitation of small woodlots (Makonese and Mushamba 2004). In the absence of extractive harvest, woodpecker nesting peaks at intermediate levels of urban disturbance, a pattern frequently observed among birds (Blair 1996; Alberti 2008; Evans 2010).

\subsubsection{Distribution and Substrate Usage by Four Woodpecker Excavators}

The Red-bellied Woodpecker is present in nearly every terrestrial environment in South Florida and, in a study of native and exotic birds in urban Miami-Dade County, they were located at near-constant rates across a large gradient of development (Abdelrahman 2000). Pileated Woodpecker nests were common in parks near the urban core that contained hardwood hammocks, especially near the coastline. Historically, they were thought of as birds of undisturbed, mature forest (Hoyt 1957), but similar to what we observed, Pileated Woodpecker in Seattle, Washington, were found nesting in urban parks and other green spaces where snags were retained (Tomasevic and Marzluff 2018). We found Pileated Woodpecker cavities in palms along the coastal prairies of Everglades National Park as well as in telephone poles in the treeless prairies of the East-central Everglades. Northern Flicker nests were found most often in the rural fringes of our study area, near the border with Everglades National Park, as well as inside the national 
park. Northern Flickers forage for ants on the ground, potentially leaving them vulnerable to feral cats, which are a common problem in Miami-Dade (Clarke and Pacin 2002; Elchuk and Wiebe 2002; Florida Fish and Wildlife Conservation Commission 2003). This observation is important as it suggests Flickers were excluded from the urban environment not because of insufficient nest substrate, but likely other ecological factors.

2.5.4 Changes from Historical Woodpecker Species Composition in the Study Area In addition to the four woodpecker species recorded here, four other woodpecker species historically nested in our study area. Red-headed Woodpeckers are a rarity in the region. We did not find any cavities excavated by Red-headed Woodpeckers in spite of searching four sites where occasional observations had been reported on eBird in the past 10 years (Sullivan et al. 2009). Hairy Woodpeckers (Picoides villosus) are occasionally found at the western edge of our study area but we did not find any nests excavated by the species in spite of searching two sites where occasional observations (i.e. Big Cypress National Preserve and Fakahatchee Strand State Preserve). Red-cockaded Woodpeckers are rarely found in the Western fringes of our study area. This species is endangered and particularly well-studied, and it is closely linked to old-growth pine forests (Hovis and Labisky 1985; James et al. 2001). We searched one site in Big Cypress National Preserve where Red-cockaded Woodpeckers have been observed but found no nest trees. Ivory-billed Woodpecker was a breeding but rare resident of hardwood hammocks in Miami-Dade as late as 1917 (Howell 1921); it appeared to have already been extirpated from this region by 1924 (Allen and Kellogg 1937) and is widely believed to be extinct (Jackson 2006). 


\subsubsection{Palm Snags as a Critical Resource in Urban Areas}

The results of our study indicate that palms may be an overlooked critical resource for the nesting of woodpeckers in urbanized tropical regions. Consequentially, it should also be a critical resource to other cavity-nesting birds that depend on woodpeckers to excavate nests. Woodpecker nests were critical for secondary users here, unlike portions of South America and Eurasia where natural cavities are plentiful (Cockle et al. 2011b). Most of these cavities are in palm snags, suggesting they are an important link in the cavity nest web. Leonard and Stout (2006) expressed surprise at the nesting relationship between woodpeckers and cabbage palms, when they had expected to find a nesting relationship with oaks (Quercus spp.) around Orlando, FL, based on studies conducted elsewhere. Cabbage palms, which are native to south Florida, were the fourth most common species excavated by woodpeckers in our study. Our results indicate that the retention of palm snags, especially within urban regions, may be important for the conservation of cavity-nesting birds. Local government policies could avoid cutting of snags, especially palms, on public lands where they are not a risk of falling on roads or buildings. Conservation education may convince some private landowners to do the same.

\subsubsection{Caribbean Woodpeckers and Palm Snags}

Palms appear to be critically important for at least two imperiled woodpeckers in the Caribbean: Fernandina's Flicker (Colaptes fernandinae) and the Guadeloupe Woodpecker (Melanerpes herminieri). The vulnerable Fernandina's Flicker is endemic to Cuba. One study found nests of this species exclusively in palm snags (Mitchell et al. 2000). The Guadeloupe Woodpecker is endemic to the two main islands of Guadeloupe 
and is listed as near-threatened and declining; a study of the species' ecology found coconut palm snags were their primary nest tree (Villard and Rousteau 1998). A strategy suggested for providing nest substrate to Guadeloupe Woodpeckers in urban areas was attaching 1 meter sections of coconut palm trunks to the upper section of utility poles (Villard et al. 2010). In addition to the rare woodpeckers that require conservation efforts, protecting the more common woodpecker species in urban areas will provide nest cavities to many secondary-cavity nesters. The endemic Hispaniolan Woodpecker (Melanerpes striatus) has been documented nesting from undeveloped coastlines to the urban center of Santo Domingo, preferring palms snags over all other trees (Short 1974) and the near-threatened Hispaniolan Trogon (Priotelus roseigaster) has been documented breeding in former Hispaniolan Woodpecker nests (Bond 1928). In Cuba, the West Indian Woodpecker (Melanerpes superciliaris) and Cuban Green Woodpecker (Xiphidiopicus percussus) excavate nests in palms, which are used by the near-threatened Cuban Parrot (Amazona leucocephala) (Acosta et al. 2004).

Protecting palm snags alone will not be enough to conserve woodpeckers in urban regions. Not all woodpecker species will prefer palm snags, as our data shows. Downy Woodpecker, for example, used but did not prefer palm snags, but it is a widelydistributed temperate species and our study area is the extreme southern edge of its geographic range. Palms are tropical trees, and woodpecker species richness is greatest in the tropics and declines rapidly in temperate latitudes (Bjorholm et al. 2005). The use of palms as nest substrates may thus be expected to decline greatly in temperate versus tropical bird communities for similar guilds. When specific plant-animal associations can be identified between woodpeckers and nest trees, conservation efforts should be made to 
maintain them (e.g. Kratter 1998). Our study shows that palm snags are critical resources for woodpeckers in one urbanized tropical area, and are likely to be important for the conservation of cavity-nesting birds elsewhere in the tropics, as evidenced by the few studies done so far in the Caribbean. We strongly encourage more such studies.

\subsection{References}

Abdelrahman, O. Z. 2000. The distribution and abundance of the exotic and native urban avifauna in Miami-Dade County Florida. Florida International University.

Acosta, M., L. Mugica, O. Torres, D. Denis, A. Jiménez, and A. Rodríguez. 2004. Current Status of Cuban Threatened Birds: Case Studies of Conservation Programs. Journal of Caribbean Ornithology 17:52-58.

Alberti, M. 2008. Advances in Urban Ecology: Integrating Humans and Ecological Processes in Urban Ecosystems. 1st Editio. Springer, Seattle, WA.

Allen, A. A., and P. P. Kellogg. 1937. Recent Observations on the Ivory-Billed Woodpecker. The Auk 54:164-184.

Alonso, J., and J. T. Heinen. 2011. Miami Dade County's Environmentally Endangered Lands Program: Local Efforts for a Global Cause. Natural Areas Journal 31:183189.

Anderson, E. C., and J. M. LaMontagne. 2016. Nest selection by red-headed woodpeckers across three spatial scales in an urban environment. Urban Ecosystems 19:297-314.

Bjorholm, S., J. C. Svenning, F. Skov, and H. Balslev. 2005. Environmental and spatial controls of palm (Arecaceae) species richness across the Americas. Global Ecology and Biogeography 14:423-429.

Blair, R. B. 1996. Land Use and Avian Species Diversity Along an Urban Gradient. Ecological Applications 6:506-519.

Blanc, L. A., and J. R. Walters. 2008. Cavity Excavation and Enlargement as Mechanisms for Indirect Interactions in an Avian Community. Ecology 89:506-514.

Bond, J. 1928. The Distribution and Habits of the Birds of the Republic of Haiti. Pages 483-521 Proceedings of the Academy of Natural Sciences of Philadelphia.

Boyle, W. A., C. N. Ganong, D. B. Clark, and M. A. Hast. 2008. Density, Distribution, and Attributes of Tree Cavities in an Old-Growth Tropical Rain Forest. Biotropica 40:241-245. 
Brush, T., B. W. Anderson, and R. D. Ohmart. 1983. Habitat Selection Related to Resource Availability Among Cavity-Nesting Birds. Pages 88-98 in J. W. Davis, G. A. Goodwin, and R. A. Ockenfeis, editors. Proceedings of the symposium on snag habitat management. Fort Collins, Colorado.

Chace, J. F., and J. J. Walsh. 2006. Urban effects on native avifauna: A review. Landscape and Urban Planning 74:46-69.

Chave, J., H. C. Muller-Landau, T. R. Baker, T. A. Easdale, T. E. R. Hans Steege, and C. O. Webb. 2006. Regional and phylogenetic variation of wood density across 2456 neotropical tree species. Ecological Applications 16:2356-2367.

Cincotta, R. P., J. Wisnewski, and R. Engelman. 2000. Human population in the biodiversity hotspots. Nature 404:990-992.

Clarke, A. L., and T. Pacin. 2002. Domestic cat "colonies" in natural areas: A growing exotic species threat. Natural Areas Journal 22:154-159.

Cockle, K. L., and K. Martin. 2015. Temporal dynamics of a commensal network of cavity-nesting vertebrates: Increased diversity during an insect outbreak. Ecology 96:1093-1104.

Cockle, K. L., K. Martin, and T. Wesołowski. 2011a. Woodpeckers, decay, and the future of cavity-nesting vertebrate communities worldwide. Frontiers in Ecology and the Environment 9:377-382.

Cockle, K., K. Martin, and K. Wiebe. 2011b. Selection of Nest Trees by Cavity-nesting Birds in the Neotropical Atlantic Forest. Biotropica 43:228-236.

Dawes, L. C., A. E. Adams, F. J. Escobedo, and J. R. Soto. 2018. Socioeconomic and ecological perceptions and barriers to urban tree distribution and reforestation programs. Urban Ecosystems 21:657-671.

Diamond, J. M. 2018. Record of an Exceptionally Low Nest of a Red-bellied Woodpecker in Florida. Southeastern Naturalist 17:N68-N71. 
Diamond, J. M., and J. T. Heinen. 2016. Conserving rare plants in locally-protected urban forest fragments: A case study from Miami-Dade County, Florida. Urban Forestry \& Urban Greening 20:1-11.

Drapeau, P., A. Nappi, L. Imbeau, M. Saint-germain, and M. Saint-germain. 2009. Standing deadwood for keystone bird species in the eastern boreal forest: Managing for snag dynamics. The Forestry Chronicle 85:227-234.

Dudley, J., and V. Saab. 2003. A Field Protocol to Monitor Cavity-Nesting Birds. Page Res. Pap. RMRS-RP-44. US Department of Agriculture, Forest Service, Rocky Mountain Research Station. Fort Collins, Colorado.

Elchuk, C. L., and K. L. Wiebe. 2002. Food and Predation Risk as Factors Related to Foraging Locations of Northern Flickers. The Wilson Bulletin 114:349-357.

Evans, K. L. 2010. Individual species and urbanisation. Pages 53-87 in K. J. Gaston, editor. Urban Ecology. 1st editio. Cambridge University Press, Cambridge.

Figarski, T., and Ł. Kajtoch. 2018. Differences in Habitat Requirements between Two Sister Dendrocopos Woodpeckers in Urban Environments: Implication for the Conservation of Syrian Woodpecker. Acta Ornithologica 53:23-36.

Florida Exotic Pest Plant Council. 2017. List of Invasive Plant Species.

Florida Fish and Wildlife Conservation Commission. 2003. Issue Assessment: Impacts of Feral and Free-Ranging Domestic Cats on Wildlife in Florida. Tallahassee, FL.

Giannini, H. C., and J. T. Heinen. 2014. Miami-Dade County's Environmentally Endangered Lands Covenant Program: Creating Protected Areas on Private Lands via Financial Incentives. Natural Areas Journal 34:338-345.

Gutzat, F., and C. F. Dormann. 2018. Decaying trees improve nesting opportunities for cavity- nesting birds in temperate and boreal forests: A meta-analysis and implications for retention forestry. Ecology and Evolution:1-11.

Heinen, J. T. 1995. Nature Preserves. Pages 551-561 in W. A. Nierenberg, editor. Encyclopedia of Environmental Biology, Volume 2. Academic Press, San Diego. 
Hovis, J. A., and R. F. Labisky. 1985. Vegetative associations of red-cockaded woodpecker colonies in Florida. Wildlife Society Bulletin 13:307-314.

Howell, A. H. 1921. A List of the Birds of Royal Palm Hammock, Florida. The Auk 38:250-263.

Hoyt, S. F. 1957. The Ecology of the Pileated Woodpecker. Ecology 38:246-256.

Hutto, R. L. 1998. Using landbirds as an indicator species group. Pages 75-92 in J. M. Marzluff and R. Sallabanks, editors. Avian Conservation: research and management. 1st editio. Island Press, Washington, DC.

Ilsøe, S. K., W. D. Kissling, J. Fjeldså, B. Sandel, and J. C. Svenning. 2017. Global variation in woodpecker species richness shaped by tree availability. Journal of Biogeography 44:1824-1835.

Jackson, J. A. 2006. Ivory-Billed Woodpecker (Campephilus Principalis): Hope, and the Interfaces of Science, Conservation, and Politics. Auk (American Ornithologists Union) 123:1-15.

James, F. C., C. a Hess, B. C. Kicklighter, and R. a Thum. 2001. Ecosystem Management and the Niche Gestalt of the Red-Cockaded Woodpecker in Longleaf Pine Forests. Ecological Applications 11:854-870.

Kerpez, T. A., and N. S. Smith. 1990. Nest-Site Selection and Nest-Cavity Characteristics of Gila Woodpeckers and Northern Flickers. The Condor 92:193-198.

Kratter, A. W. 1998. The Nests of Two Bamboo Specialists: Celeus spectabilis and Cercomacra manu (Nidos de dos Especialistas de Bambú: Celeus spectabilis y Cercomacra manu). Journal of Field Ornithology 69:37-44.

Lammertink, M. 2014. Trends in Threat Status and Priorities in Conservation of the Woodpeckers of the World. Acta Ornithologica 49:207-219.

LaMontagne, J. M., R. J. Kilgour, E. C. Anderson, and S. Magle. 2015. Tree cavity availability across forest, park, and residential habitats in a highly urban area. Urban Ecosystems 18:151-167. 
Lee, D., and S. West. 2011. Wayside Trees of Tropical Florida: A guide to the native and exotic trees and palms of Miami and tropical south Florida. 1st editio. Tellus Books, Mebane, NC.

Leonard, D. L. J., and I. J. Stout. 2006. Woodpecker Use of Forested Wetlands in Central Peninsular Florida. Southeastern Naturalist 5:621-636.

Lorenz, T. J., K. T. Vierling, T. R. Johnson, and P. C. Fischer. 2015. The role of wood hardness in limiting nest site selection in avian cavity excavators. Ecological Applications 25:1016-1033.

Luck, G. W., and L. T. Smallbone. 2010. Species diversity and urbanisation: patterns, drivers and implications. Pages 88-91 in K. J. Gaston, editor. Urban Ecology. 1st Editio. Cambridge University Press, Cambridge.

Luneau, M. D., and B. L. Noel. 2010. A wireless video camera for viewing tree cavities. Journal of Field Ornithology 81:176-185.

Makonese, M., and S. Mushamba. 2004. The policy, legislative and institutional framework for urban forestry in Zimbabwe. Urban Agricultural Magazine 13:34-35.

Martin, K., K. E. H. Aitken, and K. L. Wiebe. 2004. Nest sites and nest webs for cavitynesting communities in interior British Colombia, Canada: Nest characteristics and niche partitioning. The Condor 106:5-19.

Marzluff, J. M., F. R. Gehlbach, and D. A. Manuwal. 1998. Urban environments: influences on avifauna and challenges for the avian conservationist. Pages 283-299

in J. M. Marzluff and R. Sallabanks, editors. Avian Conservation: research and management. 1st editio. Island Press, Washington, DC.

Maschinski, J., M. S. Ross, H. Liu, J. O’Brien, E. J. von Wettberg, and K. E. Haskins. 2011. Sinking ships: conservation options for endemic taxa threatened by sea level rise. Climatic Change 107:147-167.

Meyer, W. B., and B. L. I. Turner. 1992. Human Population Growth and Global LandUse/Cover Change. Annual Review of Ecology and Systematics 23:39-61.

Miami-Dade County. 2007. A Greenprint for our Future: Miami-Dade County Street Tree Master Plan.

Mikusiński, G. 2006. Woodpeckers: distribution, conservation, and research in a global perspective. Annales Zoologici Fennici 43:86-95.

Mitchell, A. D., A. Kirkconnell, and L. J. Wells. 2000. Notes on the status and nesting ecology of Fernandina's Flicker Colaptes fernandinae. Bulletin of the British Ornithologists' Club 120:103-112.

Morrison, J. L., and W. C. Chapman. 2005. Can Urban Parks Provide Habitat for Woodpeckers? Northeastern Naturalist 12:253-262. 
Mörtberg, U., and H.-G. Wallentinus. 2000. Red-listed forest bird species in an urban environment - assessment of green space corridors. Landscape and Urban Planning $50: 215-226$.

Moulton, C. A., and L. W. Adams. 1991. Effects of Urbanization on Foraging Strategy of Woodpeckers. Pages 67-73 Wildlife Conservation in Metropolitan Environments. NIUW Sympo. National Institute for Urban Wildlife, Columbia, MD.

Pavek, D. S. 1993. Carnegiea gigantea. Page Fire Effects Information System [Online]. U.S. Department of Agriculture, Forest Service, Rocky Mountain Research Station, Fire Sciences Laboratory (producer).

Possley, J. E., and J. M. Maschinski. 2008. Patterns of Plant Composition in Fragments of Globally Imperiled Pine Rockland Forest: Effects of Soil Type, Recent Fire Frequency, and Fragment Size. Natural Areas Journal 28:379-394.

Robles, H., and K. Martin. 2013. Resource quantity and quality determine the interspecific associations between ecosystem engineers and resource users in a cavitynest web. PloS one 8:1-12.

Russell, R. E., V. A. Saab, J. G. Dudley, and J. J. Rotella. 2006. Snag longevity in relation to wildfire and postfire salvage logging. Forest Ecology and Management 232:179-187.

Schepps, J., S. Lohr, and T. E. Martin. 1999. Does Tree Hardness Influence Nest-Tree Selection by Primary Cavity Nesters? The Auk 116:658-665.

Short, L. L. 1974. Habits of Three Endemic West Indian Woodpeckers (Aves , Picidae). American Museum noitates:1-44.

Sullivan, B. L., C. L. Wood, M. J. Iliff, R. E. Bonney, D. Fink, and S. Kelling. 2009. eBird: A citizen-based bird observation network in the biological sciences. Biological Conservation 142:2282-2292.

Tomasevic, J. A., and J. M. Marzluff. 2017. Cavity nesting birds along an urban-wildland gradient: is human facilitation structuring the bird community? Urban Ecosystems 20:435-448.

Tomasevic, J. A., and J. M. Marzluff. 2018. Use of suburban landscapes by the Pileated Woodpecker (Dryocopus pileatus). The Condor: Ornithological Applications 120:113.

Trotta, L. B., B. Baiser, J. Possley, D. Li, J. Lange, S. Martin, and E. B. Sessa. 2018. Community phylogeny of the globally critically imperiled pine rockland ecosystem. American Journal of Botany 105:1-13.

United States Census Bureau. 2010. American FactFinder.

Villard, P., P. Feldmann, A. Ferchal, and C. Pavis. 2010. Population size and habitat associations of the endemic Guadeloupe Woodpecker. Journal of Field Ornithology $81: 278-286$. 
Villard, P., and A. Rousteau. 1998. Habitats, density, population size, and the future of the Guadeloupe Woodpecker (Melanerpes herminieri). Ornitologia Neotropical 9:121-128. 


\subsection{Tables}

Table 2.1 Top 13 habitats sorted by declining density of nests per km searched. We defined each habitat by their key

characteristics, described in Appendix 1. Other habitats consist of environments with less than 50 kilometers of search distance.

These consist of freshwater slough, cypress strand, melaleuca prairie, melaleuca forest, pine scrub, pine-cypress forest, and salt marsh.

Tree categories

\begin{tabular}{|c|c|c|c|c|c|c|}
\hline \multirow[b]{2}{*}{ Habitat type } & \multicolumn{4}{|c|}{ 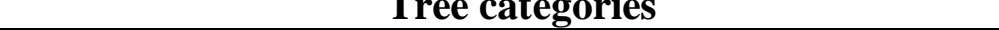 } & \multirow[b]{2}{*}{$\begin{array}{l}\text { Search distance } \\
(\mathrm{km})\end{array}$} & \multirow[b]{2}{*}{$\begin{array}{l}\text { Nests per } \\
\text { km }\end{array}$} \\
\hline & Hardwood & Palm & Pine & Utility Pole & & \\
\hline Pine rockland & & & 81 & & 212.3 & 0.38 \\
\hline Hardwood hammock & 34 & 34 & 3 & 2 & 213.3 & 0.34 \\
\hline Park & 25 & 72 & 2 & 5 & 313.7 & 0.33 \\
\hline Botanical garden & 8 & 40 & & & 157.2 & 0.31 \\
\hline Mangrove & 34 & 7 & & & 150.0 & 0.27 \\
\hline Coastal prairie & 3 & 29 & & & 138.1 & 0.23 \\
\hline Campus & & 8 & 2 & & 62.9 & 0.16 \\
\hline Suburban & 34 & 278 & & 14 & 2083.9 & 0.16 \\
\hline Beach & 2 & 5 & & & 57.2 & 0.12 \\
\hline Cypress prairie & & & & 8 & 68.2 & 0.12 \\
\hline Prairie & 3 & 2 & 5 & 33 & 369.8 & 0.12 \\
\hline Rural & 5 & 73 & & 1 & 732.1 & 0.11 \\
\hline Urban & & 43 & & & 412.8 & 0.10 \\
\hline Other habitats & 24 & 14 & 17 & & 182.1 & 0.30 \\
\hline
\end{tabular}




\subsection{Figures}

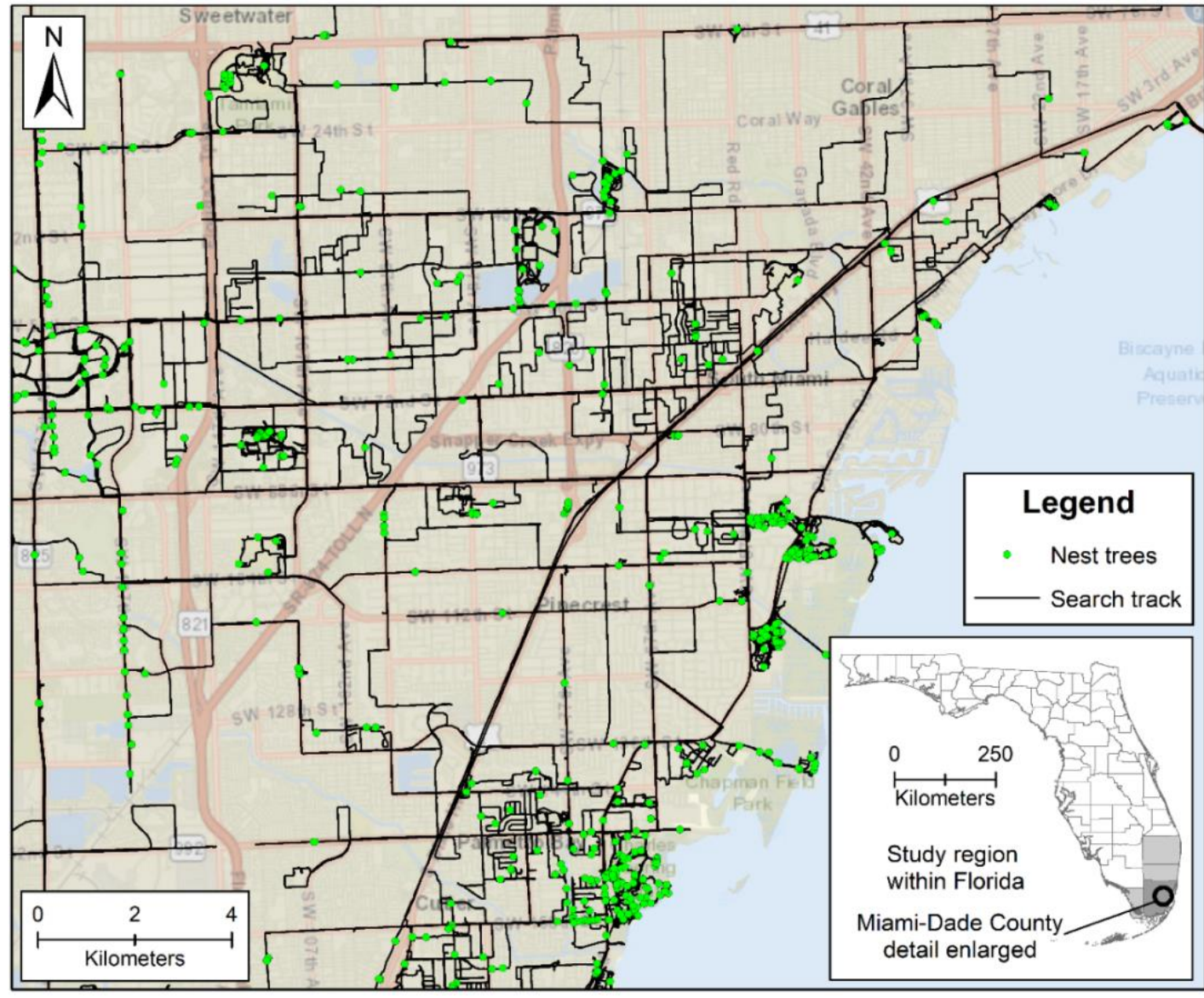

Figure 2.1 Search track and nests found within the core study area, Miami-Dade County, Florida. Searches were made by bicycle, foot, and automobile. Large clusters of woodpecker nest trees were found in urban parks and natural areas along the coastline. 


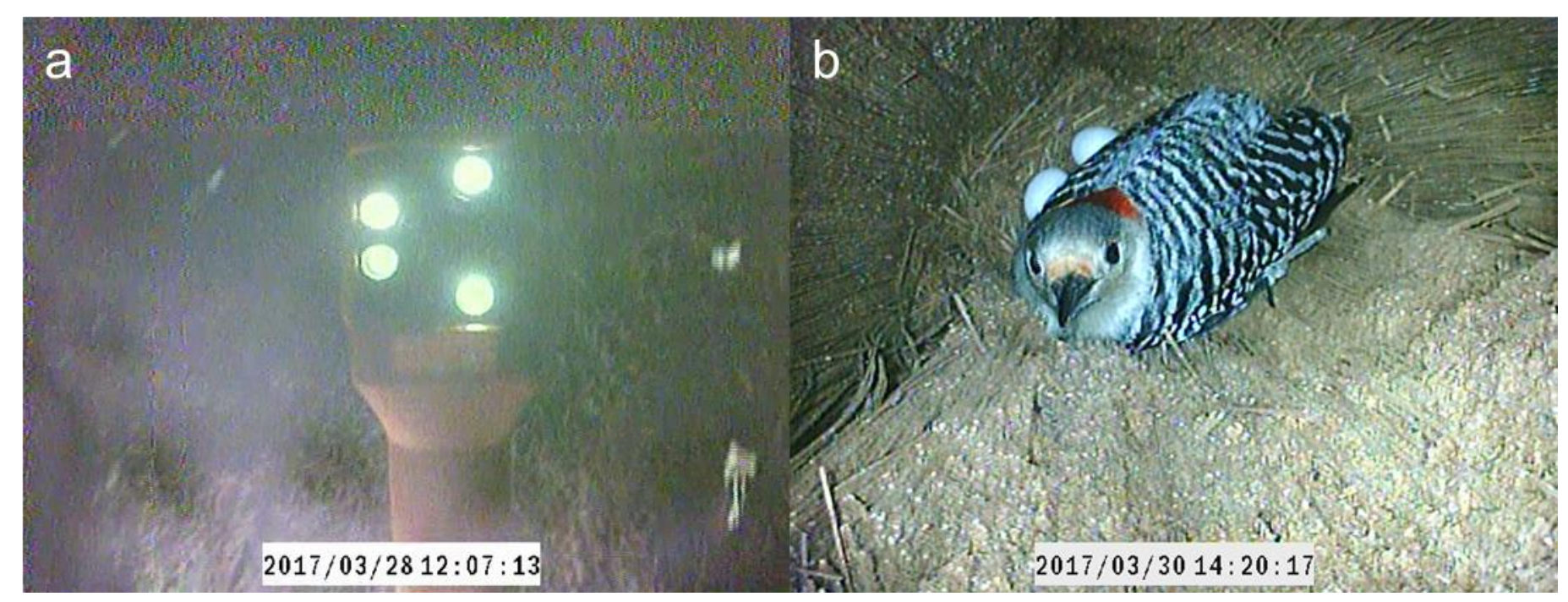

Figure 2.2 Woodpeckers rarely excavated holes in live palms, $93.5 \%$ of palm cavities were excavated in snags. Woodpecker cavities in live palms were often too shallow, and poorly-drained even in the dryseason. The nest inspection camera is seen in the reflection of standing water during the dry season (a). Snags were used more for active nesting attempts; (b) a female Red-bellied Woodpecker incubates eggs in a palm snag two days after (a) and less than two km away. 


\section{CHAPTER 3: URBAN WOODPECKER NEST SITE CHARACTERISTICS BEFORE}

\section{AND AFTER A HURRICANE DISTURBANCE}

\subsection{Abstract}

The cavities that woodpeckers excavate and use for nesting are also important for many other cavity-nesting birds. The availability of appropriate trees for cavity excavation in an urban environment is an important factor governing the abundance of woodpecker nest cavities. To understand the impacts of hurricane disturbance on characteristics of trees used by nesting woodpeckers, we surveyed woodpecker nests in Southeast Florida before and after Hurricane Irma in 2017. We used these data to understand which nest sites were most likely to persist after the hurricane, and compare nest site characteristics before and after the storm. Woodpecker nests in dead pine trees (snags) fared poorly compared to nests in palm snags, live hardwoods and hardwood snags, and telephone poles. In the year after Hurricane Irma, the proportion of new nests in palm snags increased, while the proportion of nests excavated in pines and hardwoods decreased. Palms generally have softer wood, and their physical structure could make them more attractive to woodpeckers in the first year after a storm. Trees excavated in the year after Hurricane Irma were $23 \%$ shorter than trees with nests found before the hurricane, but there was no difference in the diameter of excavated trees. The decay class of trees and the number of woodpecker holes did not significantly impact the persistence rates of woodpecker nest trees. The results of this study are relevant to the management of dead trees in urban areas, especially in the Caribbean and tropical regions which are urbanizing and vulnerable to natural disturbances like hurricanes. Cutting urban palm 
snags immediately following a storm removes a critical resource for woodpeckers during the first year of recovery.

\subsection{Introduction}

Woodpeckers are considered keystone species in forested environments because the nest cavities they create are used as breeding sites by many other species (Blanc and Walters 2008a, 2008b, Cornelius et al. 2008, Jusino et al. 2016). In the coastal region of Southeast Florida, three woodpecker species are the primary cavity excavators. The Redbellied Woodpecker (Melanerpes carolinus) is by far the most common, due to its presence in almost all terrestrial landscapes, including highly-developed areas and small urban forest patches. Both Pileated Woodpeckers (Hylatomus pileatus) and Northern Flickers (Colaptes auratus) are patchy in distribution and share an affinity for wildland settings.

Hurricane Irma impacted southeast Florida on 10 September 2017. This is the most densely-developed part of Florida, with over six million residents in Miami, Fort Lauderdale, and West Palm Beach (United States Census Bureau 2010). The combined effects of wind, rain, and flooding caused many woodpecker nest trees to fall. It also killed many trees, some of which remained standing as snags, creating favorable substrate for woodpecker excavation. This hurricane provided an opportunity to understand how major disturbances impact nesting sites of woodpeckers in a highly urbanized region.

Prior studies of the effects of hurricane disturbance on woodpecker nest trees have been limited to the endangered Red-cockaded Woodpecker (Leuconotopicus borealis), which breeds in Longleaf Pine (Pinus palustris) forests of the southeastern United States 
(Engstrom and Evans 1990, Torres and Leberg 1996, Bainbridge et al. 2011). This woodpecker is unusual because it creates cavities exclusively in live trees, while most other woodpeckers use snags, i.e., dead trees that remain standing. Other studies have surveyed the abundance of birds using point counts or similar survey data before and after hurricanes but did not collect data on woodpecker cavities (Cely 1991, Waide 1991, Wunderle et al. 1992, Wiley and Wunderle 1993, Greenberg and Lanham 2001).

Hurricane disturbance impacts on woodpecker nests have been less-well studied than the effects of fire and logging. Because they are intentional occurrences, logging and prescribed fire allow for planned comparisons of nesting activity before and after the event, as well as comparisons with nearby control plots (Brawn et al. 2001, Russell et al. 2006, 2007, Seavy et al. 2012, Wiebe 2014). Our study differed in its opportunistic nature; we were already conducting a study on woodpecker nest trees in South Florida prior to the hurricane's arrival in this region.

Our objectives were to evaluate the impact of a hurricane disturbance on nest persistence, and to compare characteristics of nest sites before and after the hurricane. Following Hurricane Irma, we expected that the storm-induced changes in the species composition and physical attributes of snag trees would alter the composition of trees excavated by woodpeckers in the following nesting season. We also hypothesized that palm snags containing woodpecker nests would be more likely to fall than other categories of nest trees, and that the physical characteristics of new palm snags would make them more attractive to woodpeckers in the first nesting season following the hurricane. Understanding the change in composition should aid in planning for cavitynesting birds when disturbances occur. We hypothesized that assessments of greater 
decay status would be associated with more nest trees falling. We hypothesized that snags would be more vulnerable to high-velocity winds if they contain a greater number of woodpecker holes, as these serve as points for wind to pass through the center of the tree. We predicted that taller snags were more susceptible to falling, as a longer bole would catch more and stronger wind gusts than a small stub, and remaining and new snags would be shorter and wider. Information learned from the physical attributes of snag survival can help managers in urban areas decide which snags pose risks to structures and which are most important for birds. We considered our results in relation to the conservation of cavity-nesting birds in urban regions of Florida and the Caribbean.

\subsection{Methods}

\subsubsection{Post Hurricane Surveys}

Woodpecker nests were located continuously starting 11 months prior to Hurricane Irma. Nests were located throughout southeast coastal Florida. Survey routes included public streets in Miami-Dade County, urban parks and natural areas, and wilderness areas of Everglades National Park. Hurricane Irma impacted our study area on 10 September 2017, peak wind speeds during the storm were recorded around our study area that day. Maximum speed of gusts were $71 \mathrm{kts}$ in South Miami, $63 \mathrm{kts}$ at Kendall Executive Airport, 62 kts at Virginia Key, and 77 kts at Florida City, adjacent to Everglades National Park. We began checking the status of woodpecker nests the day following the storm. We attempted to check as many nest trees as we could. In the first days after the hurricane, gasoline was locally unavailable, so surveys were conducted exclusively by bicycle. As various field sites became accessible, we checked on 251 nest 
trees through 13 December 2017 (Figure 3.1). After this time, it became too difficult to determine what trees had been felled by Hurricane Irma and what had been removed by land managers. Following this initial survey, we resumed recording the excavation of new woodpecker nests for seven months, through the end of the breeding season in August.

\subsubsection{Field Methods for Locating Woodpecker Cavity Trees}

Woodpecker nest trees were located using a protocol described by the United States Forest Service for studying cavity-nesting birds (Dudley and Saab 2003). Most nest trees were located by search image, while a few were located by following the flight of woodpeckers or other cavity-nesting birds. We recorded the nesting site by species, which were divided into four categories for analysis: palm trees, pine trees, hardwood trees (arborescent dicotyledons), and wood telephone/utility poles (hereafter telephone poles). We note that the telephone poles in which nests were created were once living pine trees that after harvest were shaped and chemically treated to inhibit decay.

\subsubsection{Field Methods for Recording Nest Trees}

We initially recorded several attributes of the nest tree. We recorded the height of the tree and the diameter at breast height (DBH). We recorded the number of woodpecker nest cavities in a tree. The overall decay class of the snag tree was assessed on a scale from 1 to 9 . A decay class 1 snag had minimal decay and appeared recently dead, while a class nine snag was riddled with termites, fungal conks, and was physically unsteady. Live trees were given a value of zero and not included in analyses of snags. Trees with nests that had already fallen were assigned a value of ten and also not included 
in analysis of snags. No decay class was assigned to telephone poles, which were not included in analysis of snags.

\subsubsection{Data Analysis}

Data were analyzed using IBM SPSS version 20.0, Microsoft Excel 2016, and ArcMap version 10.4. We used a chi-square test for independence to evaluate whether some categories of trees were more likely to persist after the hurricane, and if the category of trees used changed significantly before and after the storm. We used t-tests to compare attributes like the number of nest holes and decay class were different between snags that persisted and those which fell during the hurricane.

\subsection{Results}

\subsubsection{Tree Category and Persistence After Hurricane Disturbance}

The proportion of pine, hardwood, palm, and telephone pole nests that fell during Hurricane Irma differed significantly, $\chi^{2}(3, \mathrm{~N}=251)=32.14, \mathrm{P}<0.01$. Nests in pine trees fared poorly, with less than one third still standing after the hurricane. These pine trees were exclusively found in pine rockland forests, where they were the only tree species excavated by woodpeckers. Most telephone pole nests $(92.9 \%)$ survived the storm. Palm and hardwood nest trees remained standing at intermediate rates, $53.4 \%$ and $65.5 \%$ respectively. The category of tree excavated in the year after the storm changed significantly from nests found the previous year. Nests in palms increased from $55.6 \%$ of nests to $80.7 \%$, and all other categories decreased $\chi^{2}(3, \mathrm{~N}=904)=64.13, \mathrm{P}<0.01$, Figure 3.2. The proportion of new pine and hardwood trees decreased by nearly half. Telephone poles decreased from $8.3 \%$ to $0.3 \%$, as only one new telephone pole was 
found excavated the year after Hurricane Irma. The results suggest it may take longer for the dense heartwood of pines and hardwoods to decay and become suitable for excavation than palm trees. Palms have hard exteriors but softer interiors, and woodpeckers were able to excavate more freshly killed palm snags in the first year.

\subsubsection{Physical Characteristics of Nest Trees Before and After Hurricane Irma}

There was no significant difference in the number of woodpecker holes in snags that were still standing $(2.6 \pm 1.8)$ versus those which had fallen $(2.8 \pm 2.3, \mathrm{P}=0.52$, Figure 3.3). Similarly, there was no significant difference in the decay class (1-9) of snags that were still standing $(3.4 \pm 2.0)$ and those which had fallen $(3.9 \pm 2.0, \mathrm{P}=0.10$, Figure 3.3). Nests excavated in living trees were significantly more likely to survive the hurricane than nests in snags, $\chi^{2}(1, \mathrm{~N}=209)=19.51, \mathrm{P}<0.01$. Less than half of the snags remained, while only $14.3 \%$ of live trees with nests were felled by the storm.

The physical characteristics of new nest trees changed after Hurricane Irma. Trees with new nests excavated during the breeding season after Hurricane Irma were $23.0 \%$ shorter than trees found the year before the hurricane, this difference was significant $(\mathrm{P}<0.01)$. The DBH of trees excavated increased $4.3 \%$, but this difference was not significant $(\mathrm{P}=0.36)$.

\subsection{Discussion}

\subsubsection{Characteristics of Nest Trees Persisting and Newly Excavated Snags}

Several results of the hurricane disturbance on woodpecker nests matched our predictions. We had expected palm snags to be the most likely to fall in the hurricane, as well as be the most common snags excavated in the months immediately following the 
storm. Palm snags with nests survived at an intermediate proportion compared to other tree types, while pine snags fared worse. As palms were also the most common snags excavated in the first year, they became significantly more important to woodpeckers. Our hypotheses regarding the physical attributes of snags were mostly incorrect. There was no difference in the assessed decay class of snags that survived and snags that fell. Similarly, there was no difference in the number of woodpecker holes in snags that fell and those that survived. There was no difference in the $\mathrm{DBH}$ of trees found in the years before or after, but we did correctly predict that new snags excavated would be shorter, as many were snapped by hurricane winds. Other factors, such as the depth and compaction of soil, contribute to wind firmness in hurricanes (Duryea 1997).

\subsubsection{Hardwood Trees and Survival of Living Nest Trees}

Although assessed decay was not a major factor among snags, live trees with woodpecker cavities were much more likely to persist. These are almost exclusively excavated in hardwood trees. The culture and aesthetics of Miami leads to excessive pruning of hardwoods. Homeowners often believe these practices enhance safety and stability, but excessive pruning actually makes the tree more vulnerable to wind disturbance (Duryea 1997, Miami-Dade County 2007). Woodpecker nests in dead limbs of live hardwoods may be more threatened by landscaping practices than hurricanes.

\subsubsection{Pine Trees and Delayed Creation of New Pine Snags and Nests}

Nests in pine tree snags appeared to be the most vulnerable to disturbance from Hurricane Irma, and relatively few nests were excavated in pines the first breeding season after the storm. These post-hurricane responses resemble those reported for woodpeckers following fire in pine forests. In the first three years after the disturbance of a high- 
intensity forest fire in a Northwestern pine forest, woodpeckers were likely to use snags that were already dead before the fire and more heavily decayed, suggesting that pine trees required several years to decay following a disturbance event before they became useful to woodpeckers (Saab and Dudley 1998). The heavy loss of pine tree nests in our study, nearly two thirds of the stock, suggests that these may have been particularly old snags. In South Florida pine forests, the short-term effects of fire on snags showed an immediate decline in the number of heavily decayed snags, while fresh, lightly decayed snags became more abundant (Lloyd et al. 2012). The almost complete absence of new nests in telephone poles likely relates to their slow decay, inhibited by preservatives. Hurricane Irma had almost no impact on the standing stock of telephone pole nests, but did nothing to accelerate the use of new telephone poles.

\subsubsection{Increase in Palm Snag Use and Excavation of New Palm Snags}

The increase in palm trees excavated after Hurricane Irma may relate to the ease of excavation. Palm wood is softer than pine or tropical hardwoods, and was the substrate used for over $80 \%$ of all new woodpecker nests in the post-hurricane period. In a study of nearly 2,500 neotropical tree species, palms had a mean wood density of 0.488 $\mathrm{g} / \mathrm{cm}^{3}$ compared to a mean density of $0.645 \mathrm{~g} / \mathrm{cm}^{3}$ for all neotropical tree species (Chave et al. 2006). We had expected nests in existing palm snags to fare poorly in the hurricane, but over half survived, an intermediate rate among tree categories. Palms were already a slim majority of trees excavated before Hurricane Irma, and we noted in the field that many of the new palm nest snags were trees killed during the storm. A study in Miami after Hurricane Andrew indicated that Coconut Palms (Cocos nucifera), Queen Palms (Syagrus romanzoffiana), and Royal Palms (Roystonea regia) were all 
frequently killed and often still standing, with the upper trunk broken off (Duryea et al. 1996). These were three of the most common tree species excavated by woodpeckers both before and after Hurricane Irma.

The structural characteristics of palm trees make them more immediately available for woodpecker cavities than pine trees. Pine and hardwood trees both have dense heartwood at their core, surrounded by softer sapwood; woodpeckers will often not excavate heartwood until it is weakened by insects or fungal decay (Conner et al. 1976, Schepps et al. 1999, Cockle et al. 2012, Jusino et al. 2015). Where old, large hardwoods have rotten centers, these hollows can be excavated only if the surrounding wood is not sufficiently thick or hard. Nests in very large DBH pines and hardwoods often have a curve shaped woodpecker nest in the sapwood, which completely avoids the dense, undecayed heartwood core (Figure 3.4). Palm trees do not share this structure, and the hardest wood is the outer edge of the trunk (Killmann 1983, Rich 1987). The tough exterior and soft core of palms appears to speed cavity formation (Boyle et al. 2008). Palm snags can become hollow while maintaining structural integrity. The lack of heartwood in palms could mean that they are suitable for excavation at a smaller DBH than pines or hardwoods.

\subsubsection{Palm Snags and Conservation Opportunities Following Hurricane Disturbance}

Palm snags in the urban areas and parks of Miami were particularly important to woodpeckers in the first year after the storm. As in Hurricane Andrew, most urban hardwood trees which died were uprooted, while palms were more likely to remain standing dead as a snag (Duryea et al. 1996). Palm trees were more likely to survive than other tree categories in Hurricanes Hugo, Jeanne, and Charley (Francis and Gillespie 
1993, Duryea et al. 2007). Many palm snags were cut during the urban clean-up immediately following Hurricane Irma. However, many more snags remained within parks and small urban green spaces, where they were not considered a threat to roads or buildings. Some palm snags may have remained uncut for aesthetic reasons; palm snags may not be as visually displeasing as hardwood snags. Many palms such as Veitchia, Ptychosperma, Acoelorrhaphe, and Wodyetia species are planted in clusters. Individual snags in the cluster may go unnoticed by landscapers, as the snag stems blend in with the living foliage. Planning for the conservation of cavity-nesting birds in urban regions should avoid the cutting of palm snags on public property where they pose no risk to structures. In Cuba, this could be important for the conservation of the vulnerable Fernandina's Flickers (Colaptes fernandinae) and near-threatened Cuban Parrots (Amazona leucocephala) which nest in palm snags on the periphery of developed areas (Mitchell et al. 2000, Acosta et al. 2004). The near-threatened Guadeloupe Woodpecker (Melanerpes herminieri) also depends on palm snags in an urbanized region (Villard and Rousteau 1998, Villard et al. 2010). In the first year after a hurricane disturbance, palm snags may become disproportionately important for woodpeckers nesting in the urban tropics, as old nesting snags can persist through hurricane disturbance, and new palm snags are heavily used for nest excavation. 


\subsection{References}

Acosta, M., L. Mugica, O. Torres, D. Denis, A. Jiménez, and A. Rodríguez. 2004. Current Status of Cuban Threatened Birds: Case Studies of Conservation Programs. Journal of Caribbean Ornithology 17:52-58.

Bainbridge, B., K. A. Baum, D. Saenz, and C. K. Adams. 2011. Red-Cockaded Woodpecker Cavity-Tree Damage by Hurricane Rita: An Evaluation of Contributing Factors. Southeastern Naturalist 10:11-24.

Blanc, L. A., and J. R. Walters. 2008a. Cavity-Nest Webs in a Longleaf Pine Ecosystem. The Condor 110:80-92.

Blanc, L. A., and J. R. Walters. 2008b. Cavity Excavation and Enlargement as Mechanisms for Indirect Interactions in an Avian Community. Ecology 89:506-514.

Boyle, W. A., C. N. Ganong, D. B. Clark, and M. A. Hast. 2008. Density, Distribution, and Attributes of Tree Cavities in an Old-Growth Tropical Rain Forest. Biotropica 40:241-245.

Brawn, J. D., S. K. Robinson, and F. R. I. Thompson. 2001. The Role of Disturbance in the Ecology and Conservation of Birds. Annual Review of Ecology and Systematics 32:251-276.

Cely, J. E. 1991. Wildlife Effects of Hurricane Hugo. Journal of Coastal Research:319326.

Chave, J., H. C. Muller-Landau, T. R. Baker, T. A. Easdale, T. E. R. Hans Steege, and C. O. Webb. 2006. Regional and phylogenetic variation of wood density across 2456 neotropical tree species. Ecological Applications 16:2356-2367.

Cockle, K. L., K. Martin, and G. Robledo. 2012. Linking fungi, trees, and hole-using birds in a Neotropical tree-cavity network: Pathways of cavity production and implications for conservation. Forest Ecology and Management 264:210-219.

Conner, R. N., O. K. Miller, and C. S. Adkisson. 1976. Woodpecker Dependence on Trees Infected by Fungal Heart Rots. Wilson Ornithological Society 88:575-581.

Cornelius, C., K. Cockle, N. Politi, I. Berkunsky, L. Sandoval, V. Ojeda, L. Rivera, M. J. Hunter, and K. Martin. 2008. Cavity-nesting birds in neotropical forests: cavities as a potentially limiting resource. Ornitologia Neotropical 19:253-268.

Dudley, J., and V. Saab. 2003. A Field Protocol to Monitor Cavity-Nesting Birds. Page Res. Pap. RMRS-RP-44. US Department of Agriculture, Forest Service, Rocky Mountain Research Station. Fort Collins, Colorado.

Duryea, M. L. 1997. Wind and Trees: Surveys of Tree Damage in the Florida Panhandle after Hurricanes Erin and Opal. Gaines ville, Florida. 
Duryea, M. L., G. M. Blakeslee, W. G. Hubbard, and R. A. Vasquez. 1996. Wind and trees: A survey of homeowners after Hurricane Andrew. Journal of Arboriculture 22:44-50.

Duryea, M. L., E. Kampf, R. C. Littell, and C. D. Rodríguez-pedraza. 2007. Hurricanes and the Urban Forest: II. Effects on Tropical and Subtropical Tree Species. Arboriculture \& Urban Forestry 33:98-112.

Engstrom, R. T., and G. W. Evans. 1990. Hurricane Damage to Red-Cockaded Woodpecker (Picoides borealis) Cavity Trees. The Auk 107:608-610.

Francis, J. K., and A. J. R. Gillespie. 1993. Relating gust speed to tree damage in Hurricane Hugo, 1989. Journal of Arboriculture 19:369-373.

Greenberg, C. H., and J. D. Lanham. 2001. Breeding bird assemblages of hurricanecreated gaps and adjacent closed canopy forest in the southern Appalachians. Forest Ecology and Management 154:251-260.

Jusino, M. A., D. L. Lindner, M. T. Banik, K. R. Rose, and J. R. Walters. 2016. Experimental evidence of a symbiosis between red-cockaded woodpeckers and fungi. Proceedings of the Royal Society B: Biological Sciences 283.

Jusino, M. A., D. L. Lindner, M. T. Banik, and J. R. Walters. 2015. Heart rot hotel: fungal communities in red-cockaded woodpecker excavations. Fungal Ecology $14: 33-43$.

Killmann, W. 1983. Some physical properties of the coconut palm stem. Wood Science and Technology 17:167-185.

Lloyd, J. D., G. L. Slater, and J. R. Snyder. 2012. The Role of Fire-Return Interval and Season of Burn in Snag Dynamics in a South Florida Slash Pine Forest. Fire Ecology 8:18-31.

Miami-Dade County. 2007. A Greenprint for our Future: Miami-Dade County Street Tree Master Plan.

Mitchell, A. D., A. Kirkconnell, and L. J. Wells. 2000. Notes on the status and nesting ecology of Fernandina's Flicker Colaptes fernandinae. Bulletin of the British Ornithologists' Club 120:103-112.

Rich, P. M. 1987. Mechanical Structure of the Stem of Arborescent Palms. Botanical Gazette 148:42-50.

Russell, R. E., V. A. Saab, J. G. Dudley, and J. J. Rotella. 2006. Snag longevity in relation to wildfire and postfire salvage logging. Forest Ecology and Management 232:179-187.

Russell, R. E., V. a Saab, and J. G. Dudley. 2007. Habitat-Suitability Models for CavityNesting Birds in a Postfire Landscape. Journal of Wildlife Management 71:26002611. 
Saab, V. A., and J. G. Dudley. 1998. Responses of cavity-nesting birds to standreplacement fire and salvage logging in ponderosa pine/Douglas-fir forests of southwestern Idaho. USDA Forest Service Rocky Mountain Research Station Research Paper Rmrs:17.

Schepps, J., S. Lohr, and T. E. Martin. 1999. Does Tree Hardness Influence Nest-Tree Selection by Primary Cavity Nesters? The Auk 116:658-665.

Seavy, N. E., R. D. Burnett, and P. J. Taille. 2012. Black-backed Woodpecker nest-tree preference in burned forests of the Sierra Nevada, California. Wildlife Society Bulletin 36:1-7.

Torres, R. A., and P. L. Leberg. 1996. Initial Changes in Habitat and Abundance of Cavity-Nesting Birds and the Northern Parula Following Hurricane Andrew. The Condor 98:483-490.

United States Census Bureau. 2010. American FactFinder.

Villard, P., P. Feldmann, A. Ferchal, and C. Pavis. 2010. Population size and habitat associations of the endemic Guadeloupe Woodpecker. Journal of Field Ornithology 81:278-286.

Villard, P., and A. Rousteau. 1998. Habitats, density, population size, and the future of the Guadeloupe Woodpecker (Melanerpes herminieri). Ornitologia Neotropical 9:121-128.

Waide, R. B. 1991. The Effect of Hurricane Hugo on Bird Populations in the Luquillo Experimental Forest, Puerto Rico. Biotropica 23:475-480.

Wiebe, K. 2014. Responses of cavity nesting birds to fire: testing a general model with data from the northern flicker. Ecology 95:2537-2547.

Wiley, J. W., and J. M. Wunderle. 1993. The effects of hurricanes on birds, with special reference to Caribbean islands. Bird Conservation International 3:319-349.

Wunderle, J. M., D. J. Lodge, and R. B. Waide. 1992. Short-Term Effects of Hurricane Gilbert on Terrestrial Bird Populations on Jamaica. The Auk 109:148-166. 


\subsection{Figures}

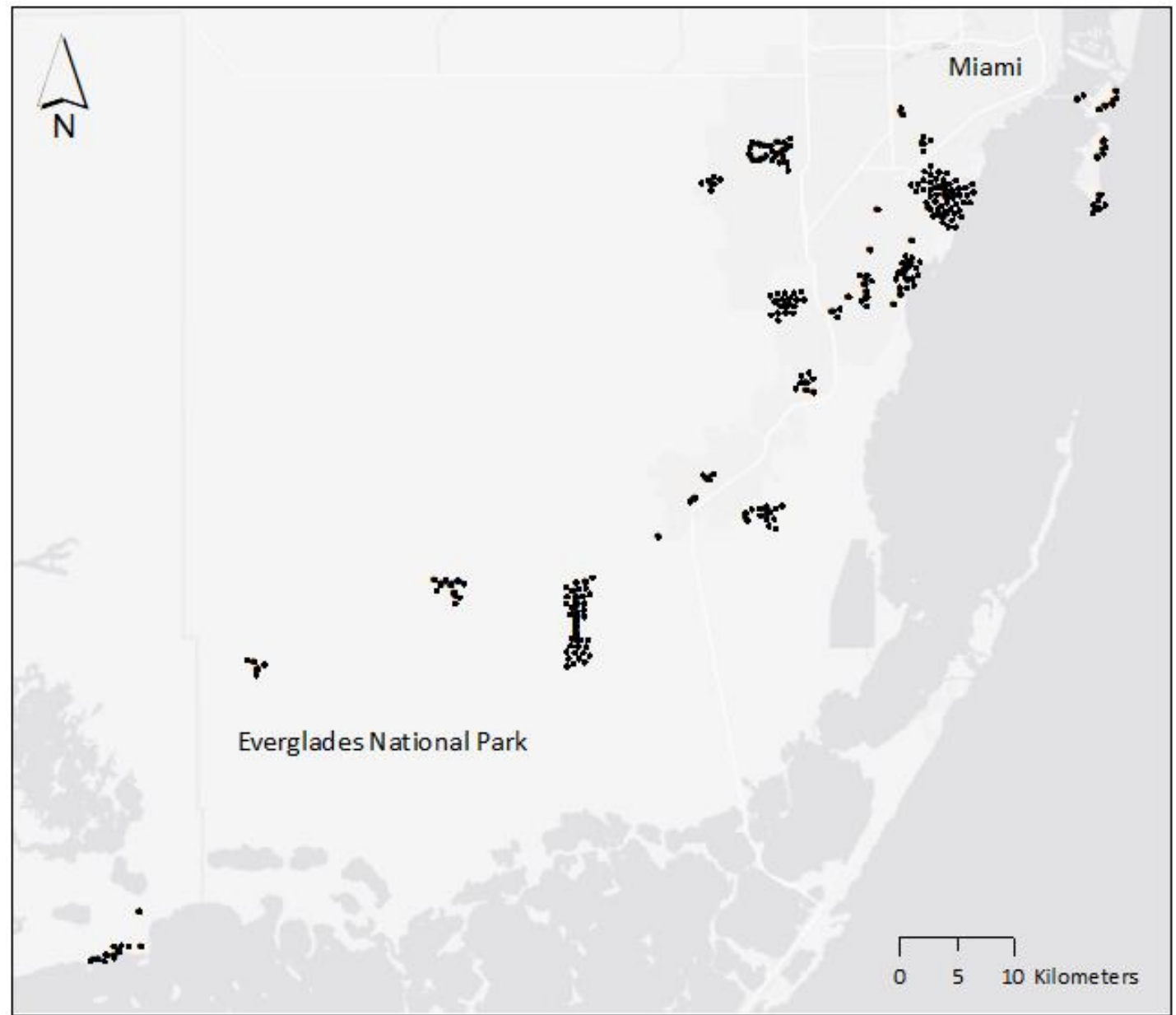

Figure 3.1 Location of 251 woodpecker nest trees sampled before and after Hurricane Irma in Miami and nearby Everglades National Park. Each point represents one woodpecker nest tree. Points have been minimally dispersed for visibility. 


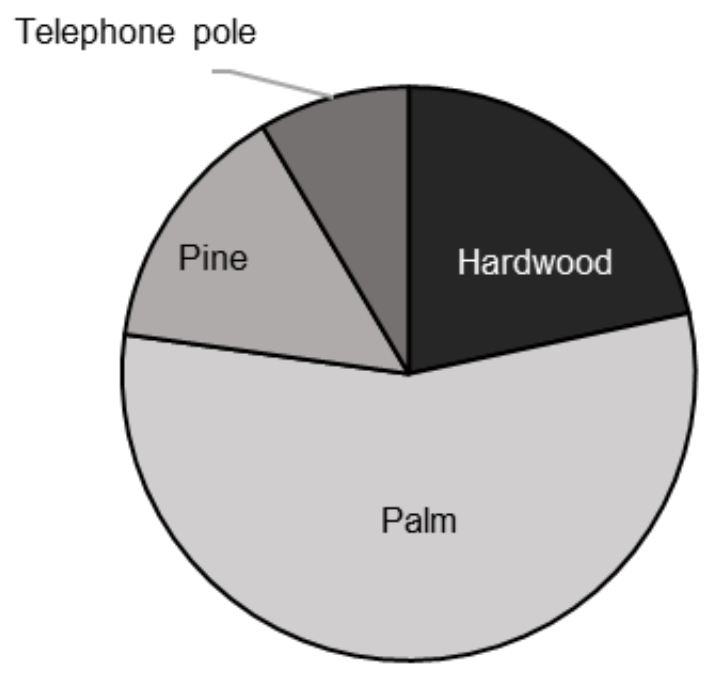

Excavated before hurricane

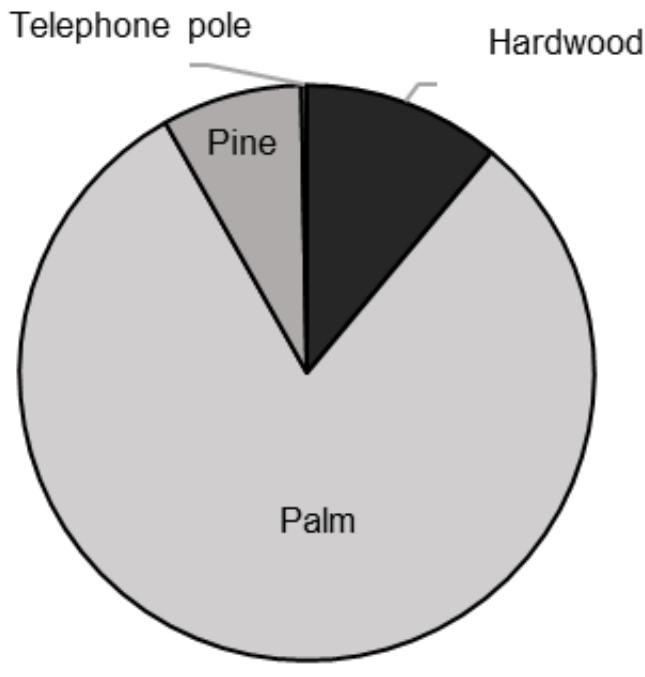

Excavated after hurricane

Figure 3.2 The proportion of each nest tree category found before and after Hurricane Irma. Nests found before the hurricane varied in age, having been excavated from months to years before the disturbance. Nests found the year after the hurricane were primarily excavated during that year. All categories except palms declined proportionally in the year after the storm. 


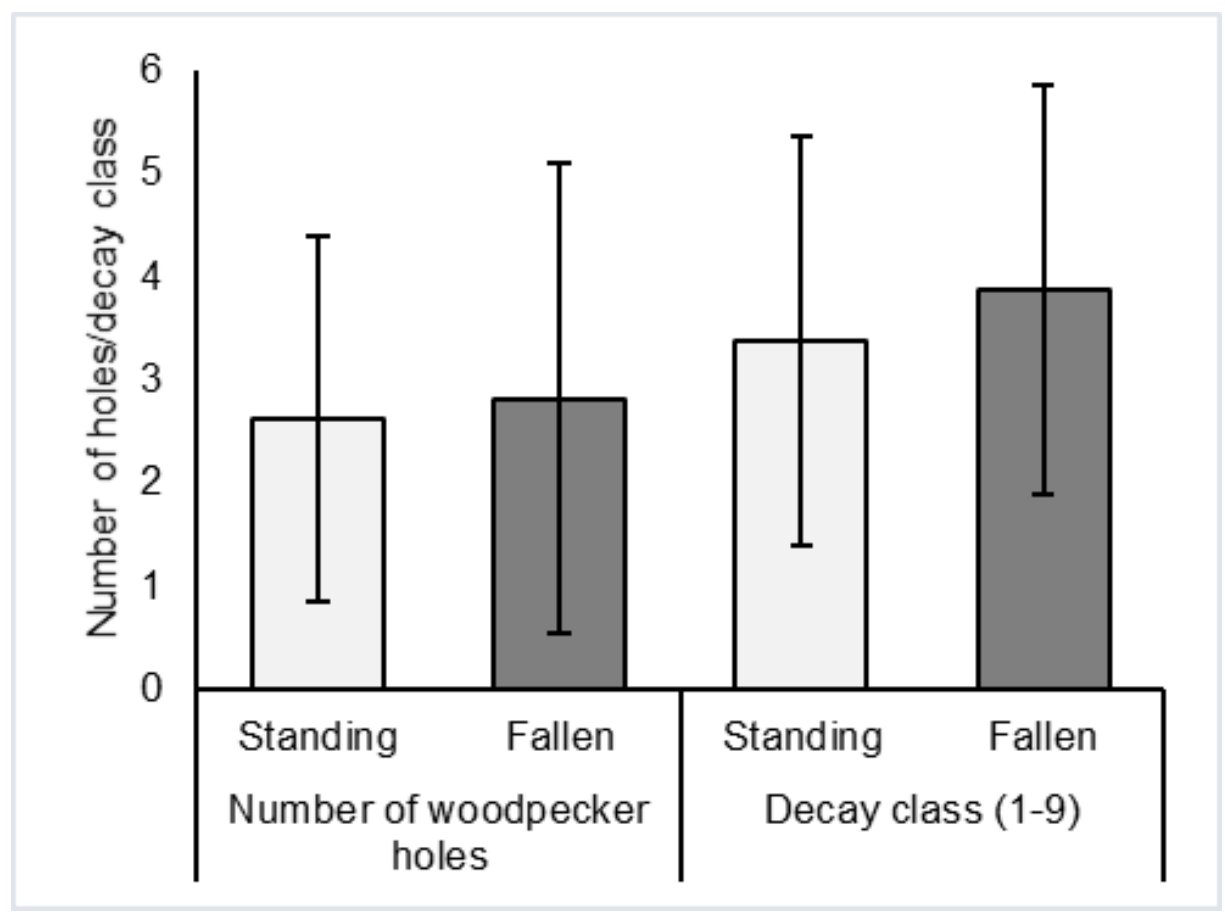

Figure 3.3 Nest trees that remained standing had no significant difference in the number of woodpecker holes compared to trees that fell. Nest snags that remained standing had no significant difference in their assessed decay class from snags that fell. 


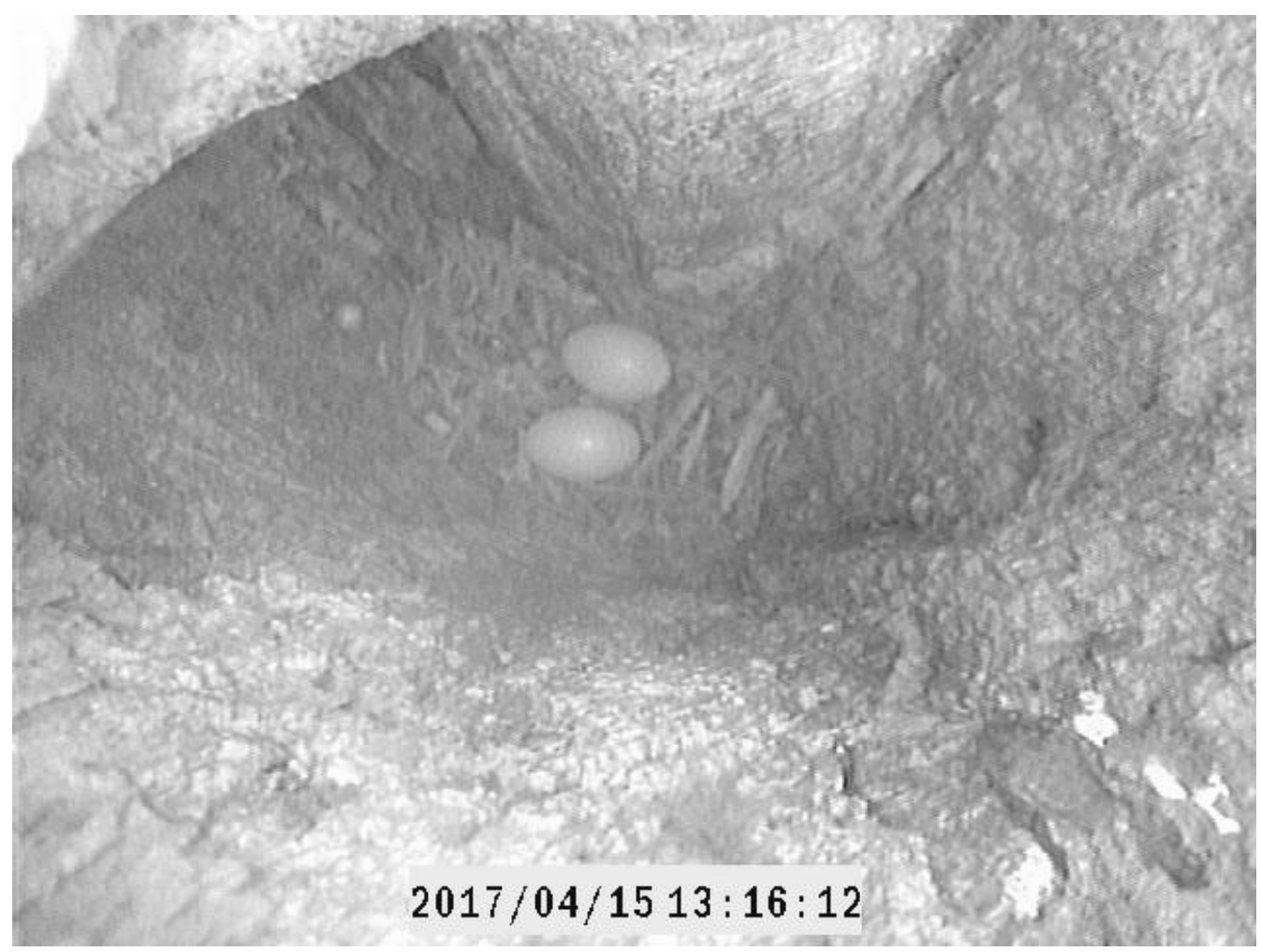

Figure 3.4 Example of a Red-bellied Woodpecker nest in a large DBH Slash Pine snag.The woodpecker has avoided the dense heartwood of the pine, creating a curved nestin the softer sapwood. Smaller DBH pines may not become usable for several years until the heartwood is sufficiently decayed for excavation. Note: The Red-bellied Woodpecker eggs are approximately $2.5 \mathrm{~cm}$ long. 


\section{CHAPTER 4. EXOTIC PARROTS BREEDING IN TREE CAVITIES: NESTING REQUIREMENTS, GEOGRAPHIC DISTRIBUTION, AND POTENTIAL IMPACTS ON CAVITY NESTING BIRDS IN SOUTHEAST FLORIDA}

\subsection{Abstract}

Exotic parrots have established breeding populations in southeast Florida, including several species that nest in tree cavities. We aimed to determine the species identity, nest site requirements, relative nest abundance, geographic distribution, and interactions of parrots with native cavity-nesting bird species. Several parrot species nest in tree cavities, Red-masked Parakeets (Psittacara erythrogenys) and Orange-winged Parrots (Amazona amazonica) being the most common ( $\mathrm{N}=7$ and 6 nests, respectively). These two parrots had similar nesting requirements, but Orange-winged Parrots use nests with larger entrance holes, which they often enlarge. Geographic analysis of nests combined with citizen science data indicates that parrots are limited to developed areas. The most common parrots were less abundant cavity nesters than the native birds which persist in Miami's urban areas, and far less abundant than the invasive European Starling (Sturnus vulgaris). Exotic parrots breeding elsewhere in the world have harmed native cavity-nesting birds through interference competition, but competitive interference in southeast Florida is minimized by the urban affinities of parrots in this region. The relative abundance and geographic distribution suggest that these parrots are unlikely to invade adjacent wilderness areas. 


\subsection{Introduction}

Southeast Florida is a global hotspot for invasive exotic fauna of all sorts, including birds. Some of these non-native species have invaded protected wilderness in Everglades National Park, threatening the native biota. Other species have taken advantage of the sprawling urban area and its exotic tropical vegetation. Miami-Dade County, Florida is the most densely developed section of the region, which continues north to Broward and Palm Beach Counties. The Miami area has a well-documented exotic avifauna, including waterbirds, passerines, and parrots (Owre 1973; James 1997; Avery and Moulton 2007; Blackburn and Cassey 2007). Parrots (Aves: Psittaciformes) are primarily tree-cavity nesting species. As a member of the cavity-nesting guild, they compete for suitable nest cavities with a variety of native and exotic birds, including the woodpeckers which make the best nest sites (Martin and Eadie 1999; Cornelius et al. 2008; Blackburn et al. 2009; Orchan et al. 2012; Menchetti and Mori 2014). Most research on the role of exotic parrots in cavity nest webs has been conducted on Roseringed Parakeets (Psittacula krameri) in Europe, which compete with native birds and mammals for nest cavities (Runde et al. 2007; Strubbe and Matthysen 2007, 2009; Czajka et al. 2011; Newson et al. 2011; Mori et al. 2013; Hernández-Brito et al. 2014, 2018; Peck et al. 2014). This research has generally concluded that the Rose-ringed Parakeet have reduced populations of native species though interference competition. This parrot is not a breeding resident in southeast Florida, but several other parrot species are participants in cavity nest webs in Miami, using woodpecker holes for reproduction.

Previous research has identified Miami-Dade County, Florida as a critical research area for the establishment of exotic parrot species, in part because of their high 
species richness in the area (Pranty and Epps 2002). More parrot species are observed in Miami than have established breeding populations, several of which have not joined the tree cavity-nesting guild. Some parrot species do not breed readily in southeast Florida but persist because of a high introduction effort. Other parrots use nest sites other than the tree nests we studied. The goals of our study were (1) to identify species of exotic parrots that breed in tree nest cavities, (2) to compare the nesting requirements of the most common parrot species, (3) to compare the abundance of parrot nests found in trees vs. nests of other cavity nesting birds, and (4) to determine if, based on their relative abundance, geographic distribution, and interactions with other cavity nesting birds, tree nesting parrots pose a threat to the native cavity nesting guild in natural areas outside of the urban matrix.

\subsection{Methods}

\subsubsection{Study Area}

Our study area encompassed all of Miami-Dade County, Florida, as well as surrounding urban and natural areas in Fort Lauderdale, Everglades National Park, and the upper Florida Keys. We searched urban, suburban, and rural developed areas, as well as pine rockland forests, tropical hardwood hammocks, recreational parklands, botanical gardens, coastal mangrove forests, freshwater and estuarine wetlands, and other habitat types found within the study region. Data collection began at the end of the 2016 breeding bird season, and continued through two full breeding seasons until October 2018. We searched roughly alternating days in urban areas and natural settings, searching for nests up to eight hours per day. Within urban areas, we did not expend 
more search area in areas with parrots reported through citizen science platforms. We did search for specific nest or roost trees reported or photographed by citizen scientists.

\subsubsection{Field Methods for Locating and Monitoring Nest Trees}

We located and monitored cavity nests following the field protocol established by the United States Forest Service (Dudley and Saab 2003). In order to inspect as many sites as possible, few locations were visited more than once every two weeks, although active parrot nests were visited approximately once per week. Previous studies of parrots in South Florida have assessed the breeding population of various species based on citizen-science observational records or based on breeding observations from the ground. This project differed by inspecting all tree cavities found in the region, not just cavities where we expected to find breeding parrots. Ground-based visual surveys of cavities have been demonstrated to detect a low proportion of active secondary-cavity nesting bird nests (Ouellet-Lapointe et al. 2012). It may also describe parrot pairs exploring or roosting in tree cavities as suspected breeders, without evidence of eggs or nestlings. We inspected all tree cavities to accurately record the status of active parrot nests and to provide a comparison to the nests of other cavity-nesting birds. We recorded several attributes for each nest tree, including tree species, diameter at breast height (DBH), tree height, and decay class. Decay class was estimated for snags on a scale from one to nine where decay class one appeared recently dead and stable, and a decay class nine appears unsteady and ready to fall. Decay class was not estimated for other surveyed cavity nesting sites, i.e., live trees and utility poles. We inspected the interior of tree nest cavities using a wireless video camera designed for the study of cavity-nesting birds (Figure 4.1) (Luneau and Noel 2010). We used two wireless cavity inspection cameras to 
record still images and videos inside nests (Treetop Peeper version 3.2 and 3.3). The cameras were mounted on a collapsible fiberglass pole capable of reaching up to $15 \mathrm{~m}$ (Crain telescoping measuring rod, model 90182). The pole was used to measure the height of nest trees and entrance holes. Cavity inspection images were used to estimate the internal diameter and internal depth of nests.

\subsubsection{Data Analysis}

We completed all statistical analyses using IBM SPSS version 20.0 and geographic analysis in ArcMap GIS version 10.4. We used t-tests to compare mean attributes of Red-masked Parakeet and Orange-winged Parrot nests. We recorded the location of all nest trees with a portable GPS unit (Garmin GPSmap 62s). We mapped nearly 4,000 citizen science observations reported to eBird from 2016-2018 for geographic range analysis, corresponding to the duration of our field study. We constructed range maps for exotic parrots in our study area by drawing minimum convex polygons around reported observations. Our polygons include at least $96 \%$ of observations of each parrot in the study area, removing errant observations outside of the core range of each species.

\subsection{Results}

\subsubsection{Active Nesting Attempts and Other Records of Parrots}

We recorded the use of tree cavities by seven species of parrots in our study area. Of these, we observed active breeding attempts by four species, the Orange-winged Parrot, Red-masked Parakeet, Nanday Parakeet (Aratinga nenday), and Blue-and-yellow Macaw (Ara ararauna). We observed tree cavity use, but could not confirm active 
breeding attempts by the Blue-crowned Parakeet (Thectocercus acuticaudatus), Scarletfronted Parakeet (Psittacara wagleri), and the Chestnut-fronted Macaw (Ara severus).

We recorded 23 cavity nest sites used by parrots during our study period (Table 4.1). All nest sites were excavated by woodpeckers, although parrots had enlarged one third of cavity entrances. Some nest trees had broken tops which were open from above, but all contained woodpecker holes, which were observed as the primary entrances and exits of the nest. Of thirteen active parrot cavity nests found (Table 2), only five were initially observed from the ground. The remaining eight nests were surprises upon inserting the nest camera, suggesting the importance of cavity nest video inspections for assessing breeding populations of parrots. Nearly all cavity nest sites $(91.2 \%)$ were in palm trees, $87.5 \%$ in the royal palm (Roystonea regia). The remaining nest sites were made in wood utility poles, formerly pine trees, shaped and treated to inhibit decay. Across our study region, palm trees were particularly important to cavity-nesting birds, and $63.1 \%$ of 967 trees excavated by woodpeckers were palms. In developed areas, where parrots are most common, $83.0 \%$ of excavated trees were palms. The royal palm is the most common tree excavated by woodpeckers in the region, representing $28.0 \%$ of all woodpecker nest trees. Only $2.4 \%$ of nest trees were used by parrots.

\subsubsection{Use and Enlargement of Woodpecker Cavities}

Two-thirds of the nest trees used by parrots were excavated by Red-bellied Woodpeckers (Melanerpes carolinus), and one third were excavated by Pileated Woodpeckers (Dryocopus pileatus). The Red-bellied Woodpecker is the main excavator of cavities of this region, creating $78.1 \%$ of all cavities $(n=1864)$. The Pileated Woodpecker only excavated $16.0 \%$ of nests in this region, many of which were outside of 
the urban matrix where parrots are most often observed. Active breeding attempts of Pileated Woodpeckers were more common in Everglades National Park and the surrounding rural areas. The parrot species observed in the region are almost never reported within Everglades National Park or other major conservation areas and are restricted almost exclusively to the developed matrix. Pileated Woodpecker cavities excavated in urban parks and botanical gardens were the most likely to be used by parrots. The Northern Flicker (Colaptes auratus) excavated few cavities within the breeding ranges of parrots, and cavities excavated by Downy Woodpeckers (Picoides pubescens) were uncommon and too small for parrots. Parrots used cavities excavated by Red-bellied Woodpeckers primarily in more densely developed areas where Pileated Woodpecker cavities are less common. Parrots enlarged Red-bellied Woodpecker entrance holes $53.3 \%$ of the time, but only enlarged a Pileated Woodpecker hole in one of eight cases.

\subsubsection{Comparison of Orange-winged Parrot and Red-masked Parakeet Nest Cavities}

Nests of Orange-winged Parrots and Red-masked Parakeets, the most numerous parrot species breeding in tree cavities, were similar in most attributes. The height of trees used for nesting by Orange-winged Parrots $(10.4 \pm 4.4 \mathrm{~m})$ was not significantly different from Red-masked Parakeets $\left(11.1 \pm 4.0 \mathrm{~m}, t_{11}=-0.3, P=0.764\right)$. The DBH of trees used for nesting was not significantly different $\left(34.7 \pm 5.2 \mathrm{~cm}\right.$ vs $36.9 \pm 4.6 \mathrm{~cm}, t_{11}$ $=-0.8, P=0.434)$. The decay class of the tree used for nesting (score assessed 1-9) was not significantly different $\left(2.2 \pm 0.8\right.$ vs $\left.3.7 \pm 1.5, t_{10}=-1.6, P=0.133\right)$. The height of the nest entrance hole above the ground surface was not significantly different $(8.8 \pm 3.2 \mathrm{~m}$ vs $\left.9.3 \pm 4.5 \mathrm{~m}, t_{11}=-0.3, P=0.752\right)$. Diameters of nest entrance holes used by the 
Orange-winged Parrot were larger than entrance holes used by the Red-masked Parakeet $\left(13.4 \pm 3.6 \mathrm{~cm}\right.$ vs $\left.8.7 \pm 2.0 \mathrm{~cm}, t_{11}=3.0, P<0.05\right)$. The Orange-winged Parrot nested in cavities excavated by the larger Pileated Woodpecker or enlarged cavities excavated by Red-bellied Woodpeckers. The Red-masked Parakeet was able to nest in some Redbellied Woodpecker cavities without enlarging the entrance hole. The internal depth of nest cavities were not significantly different $\left(181.0 \pm 72.9 \mathrm{~cm}\right.$ vs $131.7 \pm 93.8 \mathrm{~cm}, t_{9}=$ 1.0, $P=0.363)$. The internal diameters of nest cavities were not significantly different $\left(35.8 \mathrm{~cm} \pm 3.6 \mathrm{~cm}\right.$ vs $\left.33.8 \pm 6.9 \mathrm{~cm}, t_{9}=0.6, P=0.583\right)$.

\subsubsection{Interactions Between Parrots and Other Bird Species}

Our methods were not designed to calculate a population estimate for parrot species in Miami, but in the same set of trees we recorded the number of other cavitynesting birds breeding attempts for comparison. We observed one active nest each of Blue-and-yellow Macaw and Nanday Parakeet, six Orange-winged Parrot nests, and seven Red-masked Parakeet nests. We found thirteen active nests each for Pileated Woodpecker and Northern Flicker, and 183 active Red-bellied Woodpecker nests. We recorded 44 Eastern Screech Owl nests, making this the only common secondary-cavity nesting bird in the study region. We also observed two Great-crested Flycatcher nests, the only other native secondary-cavity nester. We found 337 European Starling nests, and eleven Common Myna nests.

The interactions between parrots and other cavity-nesting birds near nest cavities suggests minimal interaction with native birds. Interspecific interactions were recorded at seven of 23 parrot nest trees. The most hostile interactions were between Bluecrowned Parakeets and European Starlings (Sturnus vulgaris). A pair of Blue-crowned 
Parakeets removed starling nest material from a cavity in downtown Miami, and aggressive vocal interactions and supplanting flights were recorded at another cavity nearby. Other parrots had minimal interaction with starlings. At various times, a Pileated Woodpecker roosted in a very large royal palm snag, sharing the roost with a Scarlet-fronted Parakeet and Nanday Parakeet. The central hollow of this tree was estimated to be $7 \mathrm{~m}$ deep. Other parrots shared snags with other species sequentially. An Orange-winged Parrot nested in an old Pileated Woodpecker nest in 2017, and in late March 2018 was observed inside the snag once prior to its breeding season. By the following visit in April, an Eastern Screech Owl had laid eggs in the nest, which was followed by a Red-bellied Woodpecker breeding in June. Another snag was sequentially used first by the Pileated Woodpecker and Red-bellied Woodpecker simultaneously, excavating multiple holes before the 2018 breeding season. No woodpeckers attempted to nest in this tree, instead an Eastern Screech Owl first used a Pileated Woodpecker hole as a roost, followed by a European Starling nesting attempt in a Red-bellied Woodpecker hole. A pair of Red-masked Parakeet was seen using another Pileated Woodpecker hole in the tree later in the season, but no eggs were observed.

The most sustained interaction between parrots and native birds started in midJune of 2018, in a suburban neighborhood near Miami. A Red-bellied Woodpecker excavated two nests, in two royal palm snags, $3 \mathrm{~m}$ apart. By the end of June, the Redbellied Woodpecker and a Red-masked Parakeet were each nesting in the adjacent snags simultaneously. Although the Red-masked Parakeet took one woodpecker nest, the woodpecker was able to breed successfully. The two species appeared to share alarm calls upon observers approaching the nest snags. Adult parrots and woodpeckers would 
perch on an adjacent tree together while nest inspections were conducted. Both nests successfully fledged offspring.

\subsubsection{Geographic Range Analysis}

We created polygons to encompass citizen science observations of each parrot species in the region (Figure 4.2). The locations of nest and roost trees that we found closely matched the geographic ranges of these species we assessed from citizen-science data. For example, we found one tree used as a roost by the Scarlet-fronted Parakeet in Virginia Gardens, Florida. Nearly all sightings of this species have been made in Virginia Gardens and adjacent municipalities. We found three trees used by Bluecrowned Parakeets in Downtown Miami and Miami Beach. Most of the sightings of this species have occurred in Miami Beach, and other adjacent urban islands like Key Biscayne, as well as a broader area of Broward County, Florida. One Blue-and-yellow Macaw nest was observed in Palmetto Bay, within the narrow range of this species, which corresponds to the range of the population described from 2003-2009 (Pranty et al. 2010). We did not find any nest or roost trees outside the range of any species reported on eBird. Parrots were geographically limited to developed regions, with few/no observations of most species in major conservation areas. Parrot nest trees were found primarily in urban and suburban areas without complete cover of native vegetation. When parrots were found in natural or semi-natural settings, these were conservation areas embedded within an urban matrix, in close proximity to development. 


\subsection{Discussion}

\subsubsection{Species Composition of Parrots and Historical Distribution}

The species composition of exotic parrots breeding in Miami has changed over time. In the early 1990s, the Red-masked Parakeet, Nanday Parakeet, and Orangewinged Parrot were noted in Florida, but considered unlikely to persist as breeding populations (James 1997). Currently, the Red-masked Parakeet and Orange-winged Parrot are the most successful cavity-nesting parrots in Miami, while the Nanday Parakeet has the broadest breeding range of cavity-nesters. Budgerigars were once the most common parrot in Florida, but disappeared following boom-and-bust population cycles (Pranty 2001).

\subsubsection{Availability of Woodpecker Nests in the Urban Environment}

Tree cavities, both naturally occurring and excavated by woodpeckers, can be rare and limiting in developed areas (Tilghman 1987; Blewett and Marzluff 2005; LaMontagne et al. 2015). Holes formed by natural decay are rare in Miami due to arboriculture and hurricanes. Woodpecker cavities in Miami are common, but low cavity supply leads to interference competition. Exotic Rose-ringed Parakeets (Psittacula krameri) have been cited for outcompeting native cavity-nesting birds in European cities (Strubbe and Matthysen 2009; Newson et al. 2011; Hernández-Brito et al. 2014). Similarly, exotic parrots in Hawaii have displaced native birds from nest cavities (Runde et al. 2007). We did not find evidence in our study of cavity limitation constraining reproduction of parrots, or parrots competing with native birds for nest sites.

\subsubsection{Importance of Woodpecker Nests in Palm Snags to Parrots}

Parrot nesting in tree cavities in Miami appears strongly linked to palm snags. All palm snags we recorded contained woodpecker holes, but many parrots are considered weak excavators, and can create entrance holes in soft substrates like termitaria or heavily 
decayed palm wood (Goodfellow 2011). Arboreal termitaria are not present in Miami, making palm snags the most suitable substrate to excavate or enlarge a cavity entrance. Where Pileated Woodpeckers occur in Miami, they create nest cavities that are sufficient for larger exotic parrots without any secondary enlargement. Pileated Woodpeckers have been demonstrated to use suburban areas, where a significant portion of forest cover and snags are available in public green spaces and yards (Tomasevic and Marzluff 2018). While their disproportionately high use by parrots suggests that cavities created by Pileated Woodpeckers are preferred, Red-bellied Woodpecker cavities are also useable when excavated in the soft wood of palm trees, where they can be enlarged by parrots.

Palm snags have been reported as important nest sites for the same suite of parrot species worldwide. Pranty et al. (2010) note that Blue-and-yellow Macaws in Miami nested primarily in royal palm snags but also fan palm (Borassus spp) snags. In Peru, Blue-and-yellow Macaws nested primarily in palm snags with long stems, morphologically similar to royal palms (Brightsmith 2005; Renton and Brightsmith 2009). In Florida, 57.1\% of 49 identified Nanday Parakeet nest sites were in palm snags (Pranty and Lovell 2011). In Southern California, which shares many of the same exotic parrot species, most parrot nest trees are palms (Garrett 1997). Other parrot species are reported to breed in palm snags in their native ranges (Berkunsky et al. 2014; Dahlin et al. 2018).

\subsubsection{Nest Fate, Predators, and Poachers}

In most cases, when parrot eggs disappeared, we were not able to ascertain a cause. In one case, the cavity entrance had scratch marks and enlargement suggesting predation by a raccoon (Table 2). We observed several cavities where Eastern Rat 
Snakes (Pantherophis alleghaniensis) and Corn Snakes (Pantherophis guttatus) had predated passerine nests, which left no visible sign of the predation event afterwards. In each case when at least one egg hatched, at least one nestling fledged. All total nest failures occurred during the incubation phase. A nest was considered successful if at least one nestling fledged. We did not record any instances of suspected poaching of exotic parrots, but it has been suggested that poaching has contributed to the decline of Blue-and-yellow Macaws in Miami, which are particularly valuable in the pet trade. This species has the highest retail price of parrots present in Miami, with a mean price of nearly \$900 USD in 1988 (Wright et al. 2001), and advertised prices of ranging from \$1000-4000 USD in 2018.

\subsubsection{Geographic Range Analysis}

The Nanday Parakeet is known to be a more common breeding resident further north on the southeast coast of Florida, and in the Tampa Bay region (Pranty and Lovell 2011). We incidentally noticed a pair of Nanday Parakeets using a Pileated Woodpecker cavity in a utility pole in Bradenton during our study period and included the observation in our study. We were successfully able to inspect one Nanday Parakeet nest in a royal palm at Hugh Taylor Birch State Park in Fort Lauderdale. Ten years prior to this inspection, Pranty and Lovell (2011) reported a nesting attempt of Nanday Parakeets at the same park, in a palm tree. The main breeding population of this species appears to have shifted from Broward to Palm Beach County. At the time of that report, only one of 12 Nanday Parakeet nesting attempts in southeast Florida occurred in Palm Beach County. During the two years of our study, $73.5 \%$ of Nanday Parakeet observations in southeast Florida were in Palm Beach County. The Nanday Parakeet is the most 
widespread cavity-nesting parrot in Florida, observed in over one quarter of Florida's counties.

The geographic ranges of all parrots in Miami suggest an urban/suburban habitat association. No parrot species appears to have established a breeding presence within the major natural areas adjacent to urban southeast Florida. We inspected nest cavities at several locations within Everglades National Park, Big Cypress National Preserve, Fakahatchee Strand Preserve State Park, and Crocodile Lakes National Wildlife Refuge, but did not find parrots nesting at any of these locations. Urban areas may have more food resources for parrots, including fruiting shade trees like exotic Ficus spp., and many fruit trees cultivated for human consumption, like mangos, starfruit, loquat, and tamarind. Exotic parrots in Florida have been documented feeding on fruits, flowers, and seeds of these and many other native and exotic trees common to the urban environment, including gumbo limbo, sea grape, black olive, Australian pine, and various palms (Epps 2007). Additionally, backyard enthusiasts have attracted parrots to feeding stations. Although a diverse mix of trees are present in hardwood hammock forests, Miami's urban forest may have advantages over the Florida's native tropical dry forests. Hardwood hammocks are naturally patchy in distribution, while Miami’s urban savanna forms a nearly continuous, if sparse, canopy (Gobster 1994). The urban forest contains many of the native tree species, as well as hundreds of additional exotic species. The large variety of trees in a tropical city provide resources asynchronously, ensuring an adequate food supply. 
4.5.6 Assessment of Threat to Cavity Nest Webs of the Florida Everglades

Parrots in Miami do not appear to pose a threat of invading intact natural areas. Parrots have been present in the periphery of these natural systems for decades with no sign of a nascent invasion. Breeding attempts are widespread but less common than most native or exotic birds. They are particularly less numerous than European Starlings, the dominant exotic usurper of nest cavities. They are also less common than the woodpeckers, which excavate sufficient cavities in an urban region to prevent nest site limitation. Other imperiled hole-nesting native birds found in temperate peninsular Florida such as Red-cockaded Woodpecker (Leuconotopicus borealis), Brown-headed Nuthatch (Sitta pusilla), and Eastern Bluebird (Sialia sialis), are absent in Miami limiting the potential impacts of parrots on native birds (Blanc and Walters 2008). The biotic resistance from nest competition in urban Miami is low, allowing small populations of parrots to persist without interacting with most native species.

\subsection{References}

Avery, M. L., and M. P. Moulton. 2007. Florida's non-native avifauna. Pages 365-377 Managing Vertebrate Invasive Species, USDA National Wildlife Research Center Symposia.

Berkunsky, I., G. Daniele, F. P. Kacoliris, J. A. Díaz-Luque, C. P. Silva Frias, R. M. Aramburu, and J. D. Gilardi. 2014. Reproductive parameters in the critically endangered blue-throated Macaw: Limits to the recovery of a parrot under intensive management. PLoS ONE 9:1-7.

Blackburn, T. M., and P. Cassey. 2007. Patterns of non-randomness in the exotic avifauna of Florida. Diversity and Distributions 13:519-526.

Blackburn, T. M., J. L. Lockwood, and P. Cassey. 2009. Avian Invasions: The Ecology \& Evolution of Exotic Birds. Oxford University Press, New York.

Blanc, L. A., and J. R. Walters. 2008. Cavity-Nest Webs in a Longleaf Pine Ecosystem. The Condor 110:80-92. 
Blewett, C. M., and J. M. Marzluff. 2005. Effects of urban sprawl on snags and the abundance and productivity of cavity-nesting birds. Condor 107:678-693.

Brightsmith, D. J. 2005. Parrot Nesting in Southeastern Peru: Seasonal Patterns and Keystone Trees. The Wilson Bulletin 117:296-305.

Cornelius, C., K. Cockle, N. Politi, I. Berkunsky, L. Sandoval, V. Ojeda, L. Rivera, M. J. Hunter, and K. Martin. 2008. Cavity-nesting birds in neotropical forests: cavities as a potentially limiting resource. Ornitologia Neotropical 19:253-268.

Czajka, C., M. P. Braun, and M. Wink. 2011. Resource Use by Non-Native Ring-Necked Parakeets (Psittacula krameri) and Native Starlings (Sturnus vulgaris) in Central Europe. The Open Ornithology Journal 4:17-22.

Dahlin, C. R., C. Blake, J. Rising, and T. F. Wright. 2018. Long-term monitoring of Yellow-naped Amazons (Amazona auropalliata) in Costa Rica: breeding biology, duetting, and the negative impact of poaching. Journal of Field Ornithology 89:110 .

Dudley, J., and V. Saab. 2003. A Field Protocol to Monitor Cavity-Nesting Birds. Page Res. Pap. RMRS-RP-44. US Department of Agriculture, Forest Service, Rocky Mountain Research Station. Fort Collins, Colorado.

Epps, S. A. 2007. Parrots of South Florida. Pineapple Press, Inc.

Garrett, K. L. 1997. Population status and distribution of naturalized parrots in southern California. Western Birds 28:181-195.

Gobster, P. 1994. The Urban Savanna: Reuniting Ecological Preference and Function. Restoration and management 12:64-71. 
Goodfellow, P. 2011. Avian architecture: How birds design, engineer, and build. Princeton University Press, Princeton, New Jersey.

Hernández-Brito, D., M. Carrete, C. Ibáñez, J. Juste, and J. L. Tella. 2018. Nest-site competition and killing by invasive parakeets cause the decline of a threatened bat population. Royal Society Open Science 5.

Hernández-Brito, D., M. Carrete, A. G. Popa-Lisseanu, C. Ibáñez, and J. L. Tella. 2014. Crowding in the city: Losing and winning competitors of an invasive bird. PLoS ONE 9.

James, F. C. 1997. Nonindigenous Birds. Pages 139-156 in D. Simberloff, D. C. Schmitz, and T. C. Brown, editors. Strangers in Paradise: Impact and Management of Nonindigenous Species in Florida. Island Press, Washington, DC.

LaMontagne, J. M., R. J. Kilgour, E. C. Anderson, and S. Magle. 2015. Tree cavity availability across forest, park, and residential habitats in a highly urban area. Urban Ecosystems 18:151-167.

Luneau, M. D., and B. L. Noel. 2010. A wireless video camera for viewing tree cavities. Journal of Field Ornithology 81:176-185.

Martin, K., and J. M. Eadie. 1999. Nest webs: A community-wide approach to the management and conservation of cavity-nesting forest birds. Forest Ecology and Management 115:243-257.

Menchetti, M., and E. Mori. 2014. Worldwide impact of alien parrots (Aves Psittaciformes) on native biodiversity and environment: a review. Ethology Ecology \& Evolution 26:172-194.

Mori, E., L. Ancillotto, M. Menchetti, C. Romeo, and N. Ferrari. 2013. Italian red squirrels and introduced parakeets: Victims or perpetrators? Hystrix 24:195-196.

Newson, S. E., A. Johnston, D. Parrott, and D. I. Leech. 2011. Evaluating the populationlevel impact of an invasive species, Ring-necked Parakeet Psittacula krameri, on native avifauna. Ibis 153:509-516.

Orchan, Y., F. Chiron, A. Shwartz, and S. Kark. 2012. The complex interaction network among multiple invasive bird species in a cavity-nesting community. Biological Invasions 15:429-445.

Ouellet-Lapointe, U., P. Drapeau, P. Cadieux, and L. Imbeau. 2012. Woodpecker Excavations Suitability for and Occupancy by Cavity Users in the Boreal Mixedwood Forest of Eastern Canada. Ecoscience 19:391-397.

Owre, O. T. 1973. A Consideration of the Exotic Avifauna of Southeastern Florida. The Wilson Bulletin 85:491-500.

Peck, H. L., H. E. Pringle, H. H. Marshall, I. P. F. Owens, and A. M. Lord. 2014. Experimental evidence of impacts of an invasive parakeet on foraging behavior of native birds. Behavioral Ecology 25:582-590. 
Pranty, B. 2001. The budgerigar in Florida: the rise and fall of an exotic psittacid. North American Birds 55:389-397.

Pranty, B., and S. A. Epps. 2002. Distribution, Population Status, and Documentation of Exotic Parrots in Broward County, Florida. Florida Field Naturalist 30:111-150.

Pranty, B., D. Feinstein, and K. Lee. 2010. Natural history of blue-and-yellow macaws (Ara ararauna) in Miami-Dade County, Florida. Florida Field Naturalist 38:55-62.

Pranty, B., and H. W. Lovell. 2011. Presumed or confirmed nesting attempts by Blackhooded parakeets (Nanadayus nenday) in Florida. Florida Field Naturalist 39:75110.

Renton, K., and D. J. Brightsmith. 2009. Cavity use and reproductive success of nesting macaws in lowland forest of southeast Peru. Journal of Field Ornithology 80:1-8.

Runde, D. E., W. C. Pitt, and J. T. Foster. 2007. Population ecology and some potential impacts of emerging populations of exotic parrots. Managing Vertebrate Invasive Species. Paper 42.:338-360.

Strubbe, D., and E. Matthysen. 2007. Invasive ring-necked parakeets Psittacula krameri in Belgium: Habitat selection and impact on native birds. Ecography 30:578-588.

Strubbe, D., and E. Matthysen. 2009. Experimental evidence for nest-site competition between invasive ring-necked parakeets (Psittacula krameri) and native nuthatches (Sitta europaea). Biological Conservation 142:1588-1594.

Tilghman, N. G. 1987. Characteristics of urban woodlands affecting breeding bird diversity and abundance. Landscape and Urban Planning 14:481-495.

Tomasevic, J. A., and J. M. Marzluff. 2018. Use of suburban landscapes by the Pileated Woodpecker (Dryocopus pileatus). The Condor: Ornithological Applications 120:113.

Wright, T. F., C. A. Toft, E. Enkerlin-Hoeflich, J. Gonzalez-Elizondo, M. Albornoz, A. Rodríguez-Ferraro, F. Rojas-Suárez, V. Sanz, A. Trujillo, S. R. Beissinger, A. Vicente Berovides, A. Xiomara Gálvez, A. T. Brice, K. Joyner, J. Eberhard, J. Gilardi, S. E. Koenig, S. Stoleson, P. Martuscelli, J. Michael Meyers, K. Renton, A. M. Rodríguez, A. C. Sosa-Asanza, F. J. Vilella, and J. W. Wiley. 2001. Nest poaching in Neotropical parrots. Conservation Biology 15:710-720. 


\subsection{Tables}

Table 4.1 Characteristics of trees and cavities used by parrots. Characteristics of 23 trees and cavities with observations of parrot activity during our study period. Trees are numbered in the order they were first recorded. RBWO = Red-bellied Woodpecker, PIWO = Pileated Woodpecker, BYMA = Blue-and-yellow Macaw, OWPA = Orange-winged Parrot, RMPA = Red-masked Parakeet, BCPA $=$ Blue-crowned Parakeet, CFMA = Chestnut-fronted Macaw, SFPA = Scarlet-fronted Parakeet, NAPA = Nanday Parakeet. 


\begin{tabular}{|c|c|c|c|c|c|c|c|c|c|c|c|c|c|}
\hline $\begin{array}{l}\text { Nest } \\
\text { Tree }\end{array}$ & Location & Habitat & $\begin{array}{l}\text { Tree } \\
\text { Species }\end{array}$ & $\begin{array}{l}\text { Original } \\
\text { Excavator }\end{array}$ & $\begin{array}{l}\text { Tree } \\
\text { height } \\
\text { (m) }\end{array}$ & $\begin{array}{l}\text { DBH } \\
(\mathbf{c m})\end{array}$ & $\begin{array}{l}\text { Decay } \\
\text { Class }\end{array}$ & $\begin{array}{l}\text { Nest } \\
\text { height } \\
\text { (m) }\end{array}$ & $\begin{array}{l}\text { Nest } \\
\text { diameter } \\
(\mathrm{cm})\end{array}$ & $\begin{array}{l}\text { Nest hole } \\
\text { enlarged? }\end{array}$ & $\begin{array}{l}\text { Internal } \\
\text { depth } \\
(\mathrm{cm})\end{array}$ & $\begin{array}{l}\text { Internal } \\
\text { Diameter } \\
(\mathrm{cm})\end{array}$ & $\begin{array}{l}\text { Parrot } \\
\text { species } \\
\text { observed }\end{array}$ \\
\hline 1 & Palmetto Bay & $\begin{array}{l}\text { Freshwater } \\
\text { Slough }\end{array}$ & Royal Palm & PIWO & 13.5 & 40 & 2 & 12.5 & 14 & No & \multicolumn{2}{|c|}{ Unknown } & BYMA \\
\hline 2 & Coral Gables & $\begin{array}{l}\text { Botanical } \\
\text { Garden }\end{array}$ & Royal Palm & PIWO & 13 & 31 & 1 & 8 & 15 & No & 220 & 32 & OWPA \\
\hline 3 & Coral Gables & $\begin{array}{l}\text { Botanical } \\
\text { Garden }\end{array}$ & Royal Palm & PIWO & 7 & 30 & 6 & 5 & 11 & No & 105 & 26 & RMPA \\
\hline 4 & Miami & Urban & Royal Palm & RBWO & 9.5 & 46 & 3 & 9 & 10 & Yes & 275 & 35 & BCPA \\
\hline 5 & Miami & Urban & Royal Palm & RBWO & 24 & 55 & 1 & 11 & 8 & No & 25 & 38 & BCPA \\
\hline 6 & South Miami & Suburban & Royal Palm & RBWO & 9 & 38 & 2 & 8 & 12 & Yes & 185 & 40 & OWPA \\
\hline 7 & South Miami & Suburban & Royal Palm & RBWO & 19 & 39 & 1 & 18 & 10 & Yes & 165 & 37 & CFMA \\
\hline 8 & Miami Beach & Park & Sabal Palm & RBWO & 10 & 23 & 1 & 7.7 & 7 & No & 45 & 19 & BCPA \\
\hline 9 & Virginia Gardens & Suburban & Royal Palm & PIWO & 15 & 39 & 3 & 13 & 10 & No & 700 & 35 & $\begin{array}{l}\text { SFPA, } \\
\text { NAPA }\end{array}$ \\
\hline 10 & $\begin{array}{l}\text { North Miami } \\
\text { Beach }\end{array}$ & Urban & Royal Palm & RBWO & 18 & 39 & 3 & 15 & 12 & Yes & 85 & 38 & OWPA \\
\hline 11 & $\begin{array}{l}\text { North Miami } \\
\text { Beach }\end{array}$ & Urban & Royal Palm & RBWO & 16 & 33 & 4 & 15.5 & 6 & No & \multicolumn{2}{|c|}{ Unknown } & BCPA \\
\hline 12 & Coral Gables & Urban & Royal Palm & RBWO & 10 & 36 & 2 & 8 & 7 & No & 115 & 38 & RMPA \\
\hline 13 & Bradenton & Suburban & Utility Pole & PIWO & 16 & 27 & N/A & 13 & 10.5 & No & \multicolumn{2}{|c|}{ Unknown } & NAPA \\
\hline 14 & Coral Gables & Park & Utility Pole & PIWO & 7 & 27 & N/A & 7 & 20 & Yes & \multicolumn{2}{|c|}{ Unknown } & OWPA \\
\hline 15 & Coral Gables & $\begin{array}{l}\text { Botanical } \\
\text { Garden }\end{array}$ & Royal Palm & PIWO & 15 & 34 & 3 & 12 & 12 & No & 95 & 28 & RMPA \\
\hline 16 & South Miami & Park & Royal Palm & RBWO & 15 & 40 & 2 & 10 & 10 & Yes & 125 & 33 & CFMA \\
\hline 17 & $\begin{array}{l}\text { North Miami } \\
\text { Beach }\end{array}$ & Urban & Royal Palm & RBWO & 17.5 & 41 & 3 & 17 & 8 & Yes & \multicolumn{2}{|c|}{ Unknown } & RMPA \\
\hline 18 & Pinecrest & Suburban & Royal Palm & RBWO & 8.9 & 40 & 2 & 8.8 & 11 & Yes & 140 & 32 & OWPA \\
\hline 19 & Ft. Lauderdale & Hammock & Royal Palm & PIWO & 12.7 & 39 & 2 & 12.2 & 9 & No & 130 & 33 & NAPA \\
\hline 20 & Olympia Heights & Suburban & Royal Palm & RBWO & 10.8 & 42 & 5 & 9.1 & 7 & No & 320 & 34 & RMPA \\
\hline 21 & South Miami & Suburban & Royal Palm & RBWO & 10.9 & 41 & 2 & 10.8 & 8 & No & 90 & 45 & RMPA \\
\hline 22 & Coral Terrace & Suburban & Royal Palm & RBWO & 6.3 & 34 & 3 & 3.4 & 8 & No & 65 & 32 & RMPA \\
\hline 23 & North Miami & Urban & Royal Palm & RBWO & 6.2 & 33 & 3 & 5.8 & 10.5 & Yes & 275 & 37 & OWPA \\
\hline
\end{tabular}


Table 4.2 Active nesting attempts of parrots in tree cavities. Numbering of nest trees follows Table 1. BYMA = Blue-and-yellow

Macaw, OWPA = Orange-winged Parrot, RMPA = Red-masked Parakeet

\begin{tabular}{|c|c|c|c|c|c|c|}
\hline Nest Tree & Parrot species & $\begin{array}{l}\text { Egg laying } \\
\text { date }\end{array}$ & $\begin{array}{l}\text { Number of } \\
\text { eggs }\end{array}$ & Hatch date & Fledge date & Result \\
\hline 1 & BYMA & 28-Jun-16 & Unknown & 28-Jul-16 & $31-$ Oct-16 & 2 fledged \\
\hline 2 & OWPA & 20-Apr-17 & 2 & & & 2 eggs failed, egg fragments observed \\
\hline 2 & OWPA & 06-May-17 & 2 & 29-May-17 & 14-Aug-17 & 2 fledged \\
\hline 3 & RMPA & & & & & No eggs found but repeated visits by pair during Spring 2017 \\
\hline 6 & OWPA & 06-Apr-17 & 4 & 01-May-17 & 05-Jul-17 & 2 fledged \\
\hline 10 & OWPA & 01-Мay-17 & 3 & & & $\begin{array}{l}3 \text { eggs failed, eggs missing, probable raccoon predation based on } \\
\text { scratches and enlargement }\end{array}$ \\
\hline 12 & RMPA & 06-Jun-17 & 1 & & & 1 egg failed, egg missing \\
\hline 18 & OWPA & 20-May-18 & 2 & & & 2 eggs failed, eggs missing \\
\hline 19 & NAPA & 24-May-18 & 3 & 17-Jun-18 & 10-Aug-18 & 1 fledged \\
\hline 20 & RMPA & 17-Jun-18 & 3 & 10-Jul-18 & 17-Aug-18 & 3 fledged \\
\hline 21 & RMPA & 08-Jun-18 & Unknown & 01-Jul-18 & 14-Aug-18 & 2 fledged \\
\hline 22 & RMPA & 16-Jun-18 & 2 & 09-Jul-18 & 20-Aug-18 & $\begin{array}{l}\text { Unclear - internal cavity shape may have allowed near-fledglings } \\
\text { to hide, probable success }\end{array}$ \\
\hline 23 & OWPA & 02-May-18 & Unknown & 27-May-18 & 05-Aug-18 & 3 fledged \\
\hline
\end{tabular}




\subsection{Figures}

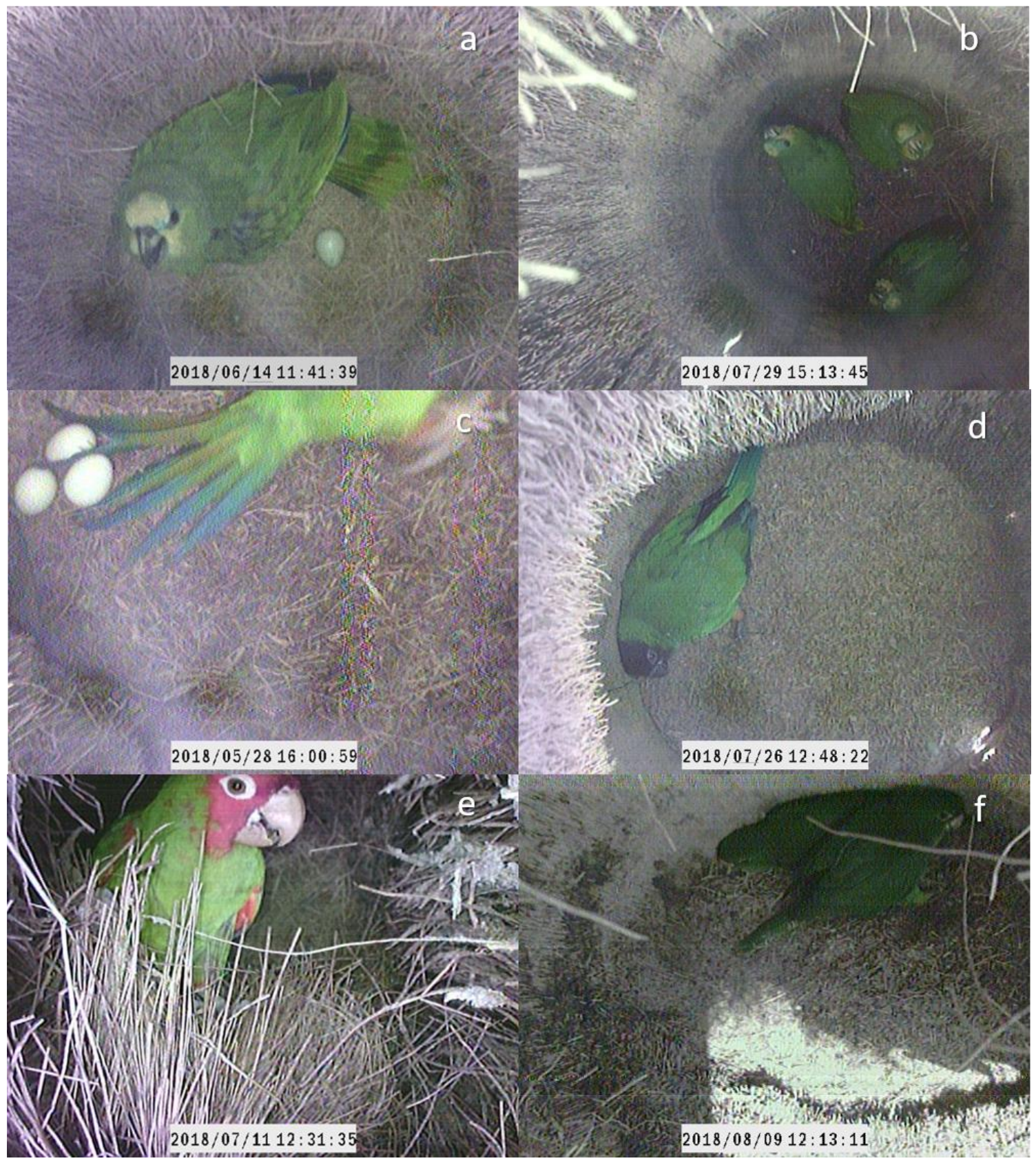

Figure 4.1 Parrots nesting in tree cavities. Orange-winged Parrot incubating eggs (a) and near fledglings (b). Nanday Parakeet eggs visible behind tail feathers (c) and near fledgling (d). Red-masked Parakeet guarding eggs (e) and nearfledglings(f). 


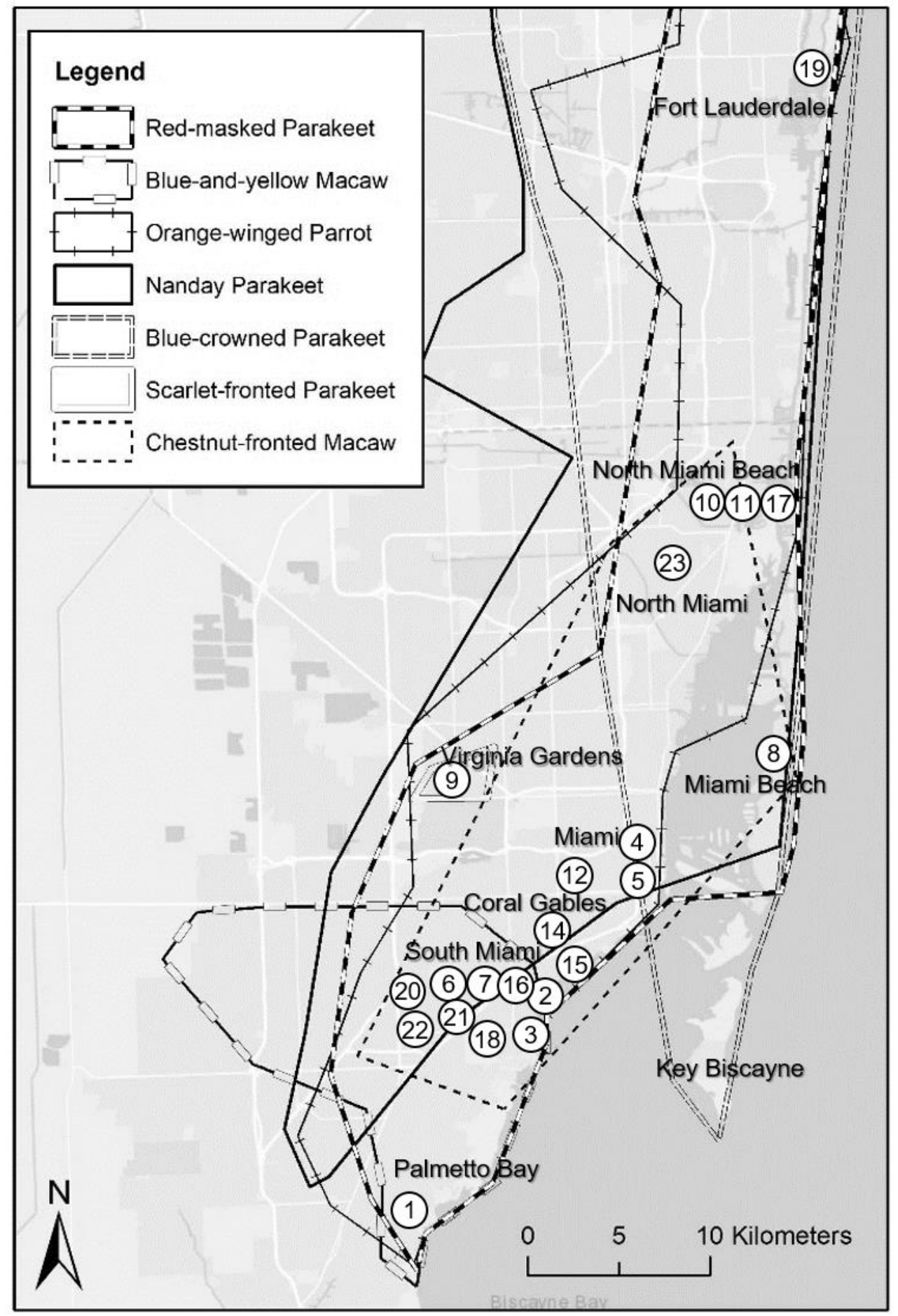


Figure 4.2 Geographic ranges of cavity-nesting parrots, and observed nest trees. Numbering of nest trees follows Table 1 . Nest trees have been dispersed minimally for display purposes. Geographic ranges are drawn to encompass at least $96 \%$ of observations of each species, ignoring distant outliers. All cavities used arefound within the core geographic range of each species. 


\section{CHAPTER 5. CAVITY NEST WEB DISRUPTION DEPENDS ON HOLE \\ PREFERENCE AND REPRODUCTIVE PHENOLOGY: THE CASE OF EXOTIC STURNIDS AND PSITTACIDS IN A TROPICAL CITY}

\subsection{Abstract}

Multiple exotic hole nesting bird species can be present in a tropical city, but they may not impact the native cavity nest web equally. We investigated the nest preferences and breeding phenologies of the hole nesting guild in the tropical urban region surrounding Miami, Florida, USA, where native woodpeckers and secondary cavity nesters compete with exotic starlings, mynas, and parrots for a limited supply of holes. We asked if the timing of reproduction determines which exotic species will usurp cavities from native birds with similar nest preferences. Competition between starlings and Miami's woodpecker species is well documented, but we predicted that a recentlyarrived Sturnid competitor and introduced Psittacids would also be active in nest usurpation. We found that a small population of Common Mynas usurped nests, but parrots bred later than expected, avoiding competition with birds sharing similar hole preferences. Our results demonstrate how analysis of cavity preferences and reproductive timing can be used to evaluate threats to a cavity nest web posed by multiple alien competitors. The results of our investigation suggest the need for control efforts of Common Myna, a small, geographically restricted population still in the establishment phase of invasion in our study region, because of its fairly-earned global reputation as a destructive influence on native cavity nest webs. 


\subsection{Introduction}

Cavity nesting birds are connected by their shared use of tree hollows for reproduction. Cavity nest webs are the network linking trees, decay fungi, and animals including birds (Martin and Eadie 1999, Martin et al. 2004, Cockle et al. 2012). Within the guild of birds nesting in tree cavities, there is a hierarchy in the network among primary excavators (who create nests), weak excavators (who can modify nests), and secondary users (who depend on hole nests but are not capable of creating or substantially modifying them) (Wiebe et al. 2007, Blanc and Walters 2008a, Orchan et al. 2012). In North American forests, a high proportion of suitable nests used by nonexcavator species are created by woodpeckers (Cockle et al. 2011). This pattern has been shown to be the consistent in both temperate northern Florida (Blanc and Walters 2008b) and the urban and tropical portion of southeast Florida (Diamond et al., in press). In these environments, suitable cavities formed by natural decay are particularly rare, and nearly all suitable cavities are excavated by woodpeckers. Woodpeckers are the primary cavity excavator in most terrestrial environments, but in Florida, they effectively create all tree cavities suitable for avian reproduction. This effect is forestalled in urban environments by landscaping practices that reduce the substrate suitable for cavity excavation, forcing competition for a smaller number of remaining woodpecker nests (Morrison and Chapman 2005, Davis et al. 2013, LaMontagne et al. 2015).

We studied the usurpation of cavity nest in the tropical urban region of Miami, Florida, USA. This focal region has three woodpecker species that excavate cavities large enough for secondary cavity-nesting birds: Red-bellied Woodpeckers (Melanerpes carolinus), Pileated Woodpeckers (Dryocopus pileatus), and Northern Flickers (Colaptes 
auratus). Downy Woodpeckers (Picoides pubescens), an occasional breeder in the area, create cavities too small for other birds. Only one native secondary cavity user, the Eastern Screech Owl (Megascops asio) is a common breeder in the urban environment. The Great-crested Flycatcher (Myiarchus crinitus) is an uncommon breeder, particularly within the core urban area.

Miami and the greater South Florida region is a hotspot for invasive exotic species, including birds (Owre 1973, Forys and Allen 1999, Pranty and Epps 2002, Blackburn and Cassey 2007, Blackburn et al. 2009). The native woodpeckers and owls must compete for nests with two exotic Sturnid (Passeriformes: Sturnidae) species, and at least two common exotic Psittacids (Psittaciformes: Psittacidae). Across North America, woodpecker cavities are the holes most used by secondary cavity nesters, and the pattern is true regardless of climate across the continent (Cockle et al. 2011). The conditions of natural and woodpecker-excavated nests in Florida are the reverse of that in Australia, where no woodpecker species are present and all nest cavities suitable for birds and marsupials are formed by natural decay (Gibbons and Lindenmayer 2000). Australia has the same Sturnids present as exotic invasive species, but there they do not compete with any primary excavators for nest cavities (Pell and Tidemann 1997, Harper et al. 2005, Lowe et al. 2011). The Common Myna is a recent invader in Miami, arriving in the 1980s and continuing to grow in population and range (Pranty 2007). The Psittacids breeding in Miami are primarily in the subfamily Arinae of Central and South American origin (Epps 2007). In their native range, they compete with both primary excavators and other weak excavators and secondary users for nest cavities (Brightsmith 2005a, 2005b, 
Cornelius et al. 2008). However, particularly in South America, the secondary users are less dependent on woodpeckers due to abundant natural cavities (Cockle et al. 2011).

The Miami area offers an opportunity to observe Sturnids, Psittacids, woodpeckers, and an owl competing over a limited number of woodpecker-excavated cavities. We investigated the nest preferences and breeding phenologies of the cavitynesting birds in Miami. We asked if the timing of reproduction determines which exotic species will usurp cavities from native birds with similar nest preferences. We predicted that exotics nesting at the peak of the breeding season would show the strongest competitive interactions, disrupting species with which they share nesting requirements and habitat. This led to further, literature-based predictions about how individual exotic species would interact with their competitors. For instance, we expected that closelyrelated European Starlings and Common Mynas would be very similar in nest requirements and phenology, leading to nest usurpations between them and any birds that shared their nest preferences (Pell and Tidemann 1997, Orchan et al. 2012). We also expected that one or more exotic parrots would be early or peak-season breeders, based on their long incubation and fledgling periods, and their phenology elsewhere in the northern hemisphere (Strubbe and Matthysen 2009, Czajka et al. 2011, Luna et al. 2017).

\subsection{Methods}

\subsubsection{Study area}

This study was conducted in and around Miami-Dade County, Florida, USA. Our core study area consisted of a major city, and numerous suburban communities, continuing into Everglades National Park along the primary public access road (Figure 
5.1). This region is tropical, despite being considerably north of the Tropic of Cancer, as the winter temperature is moderated by the Gulf Stream, allowing frost-intolerant plants to thrive. The climate is classified as tropical savanna (Duever et al. 1994). The core of our study area was almost entirely within Miami-Dade County, Florida. This focal area extended from Fort Lauderdale in Broward County, south to Miami Beach, then southwest through downtown Miami, Coconut Grove, Coral Gables, South Miami, Kendall/West Kendall, Richmond Heights, Cutler Bay, the Redlands, Homestead, and Florida City. It continued in approximately the same direction southwest along Main Park Road in Everglades National Park, all the way to the road's terminus at Flamingo, in Monroe County, Florida.

Several single visits were also made to humid subtropical sites in Palm Beach County, Florida. There, at the northern extent of the study area, the climate transitions from tropical savanna to humid subtropical. Additionally, several single visits were made to sites west of Miami: Big Cypress National Preserve, Shark Valley in Everglades National Park, and Fakahatchee Strand State Preserve. South of our core study area, we also conducted single-visit surveys along the mainline Florida Keys: Key Largo, Islamorada, Big Pine Key, and Key West, Florida. These islands are the southernmost portion of the mainland United States, and the southern range limit for many temperate American bird species.

Our study region was characterized by a broad variety of terrestrial environments, a range of human development from agricultural communities to a densely-built urban center, relict natural areas within the urban matrix, and some remote 
wilderness in the national park. All of our study region reflects some level of human interference, as even in protected parkland we surveyed along publicly accessible routes.

\subsubsection{Field Methods for Recording and Monitoring Nest Trees}

Our study methods were focused on locating and surveying as many nest cavities as possible within the greater study region, and executing repeated inspections of nests within the core study area to determine occupancy and turnover. The methods for locating and monitoring these nests was based on United States Forest Service protocols (Dudley and Saab 2003). We modified these field methods, which were initially created to study cavity-nesting birds in the mountainous forested areas of the western United States, to suit the flat, tropical, and highly-urbanized region surround Miami, Florida, USA. In traditional non-urban ecosystems, belt transects are used to completely search a relatively homogeneous study unit, usually hundreds of hectares per site. This type of survey is not possible in the urban environment, which are a patchwork of owned properties and disparate management practices. We instead performed a random walk survey, using multiple transportation methods. Rather than expressing densities of snags, cavities, and birds on an areal basis, we expressed density on a per-distance-searched basis, determined by carrying a GPS unit and recording search tracks. The primary method used for initial searches was a bicycle survey, as this transportation method allow for rapid access and close inspection of potential nest sites. As a search image was developed for rapidly locating nest cavities, we were able to efficiently survey large distances in the urban matrix, finding 30 or more nest trees per day when searching a new area. Driving surveys were conducted less often but allowed for long-distance searches into Palm Beach County and the Florida Keys. On bicycle surveys, nest inspection 
required a return visit with a motor vehicle to use an elevated video inspection system. Driving and walking surveys were both conducted with the nest inspection system, allowing for direct inspections on the first instance a nest cavity became evident. We assumed a difference in detectability in searches, assuming walking provides the highest detectability of nests because of the slow speed. Since walking was the main method used to search native upland forests, we compensated by adding additional vehicle-only surveys along forest roads slightly outside the core study area, in portions of Everglades National Park and the Florida Keys. Driving was assumed to be the least effective for surveys, because of higher speed. We attempted driving surveys only in areas where we could safely drive slowly enough to use our search image to locate nests without obstructing traffic. Even at slower speeds, usually 25-35 mph, this is considerably faster than our search speed by bicycle. We accounted for the difference in detectability by adding additional driving surveys to upland forest ecosystems types where the primary search method had been walking, and adding additional walking surveys to rural areas, wherever conditions where safe to do so. We surveyed the nest cavities in the core study area repeatedly over two breeding seasons, in 2017 and 2018.

\subsubsection{Field Methods for Recording and Inspecting Cavity Nests}

Nest inspections were conducted with an elevated video inspection using a custom-built camera for studying cavity-nesting birds (TreeTop Peeper Wireless Cavity Inspection Camera version 3.1) attached to a telescoping pole capable of inspecting nests $15 \mathrm{~m}$ above the ground surface (Luneau and Noel 2010). Inspecting the interior of cavities is important because ground-based surveys can be sufficient for accurately determining use by woodpeckers, but detects only about half of secondary cavity users 
(Ouellet-Lapointe et al. 2012). We determined the original excavator of each woodpecker cavity, recording whether we observed the woodpecker excavate the cavity or inferred woodpecker identity by the characteristics of the cavity. The low richness of woodpeckers $(n=4)$ in this environment allows for easy inference because of the differences in size and shape of the cavities they create. We determined whether each cavity was new (excavated during that season) or old (excavated $>12$ months prior). The wood color around the cavity entrances change considerably over seasons, and other clues like woodchips at the base of the tree indicated a recent excavation. As a newly initiated study, ours did not have data available on the age of existing older nests, but we inquired about nest ages with a variety of park rangers, homeowners, and local residents while examining nests. The oldest snags in the area's pine forests dated to Hurricane Andrew (1992), but most other snags were relatively recent. At each nest tree, we recorded species and diameter at breast height $(\mathrm{DBH})$ of the tree, and made note of the health and relative decay of the live or dead tree (snag). We recorded additional attributes for each nesting hole: the height of the entrance above the ground, the diameter of the entrance, the internal diameter of the nest, and the depth of the cavity. We determined the latter two measurements by examining the video footage, which we were able to compare to the size of known objects in the nest In addition to eggs, characteristic leaves and objects were found in nests; Swietenia mahogani (mahogany) leaves were common in European Starling nests, candy wrappers and other trash were indicative of Common Mynas.

Upon locating an active nest cavity, we monitored the nest for the duration of the field season, as frequently as time permitted but no more than once every three to four 
days, to minimize disturbance as specified by US Forest Service protocols (Dudley and Saab 2003). These protocols allow for daily inspections as a nest approaches fledgling stage, and we increased the frequency of our visits as possible. We always made behavioral observations before conducting direct nest inspections, allowing us to record a variety of interspecific interactions such as supplanting flights, aggressive vocal interactions, and usurpation attempts. It also helped avoid direct physical contact between birds and the nest inspection camera. Behavioral cues were helpful in determining the nesting stage. Nest fate was determined at the last observation using the knowledge of species life history and the individual nest history. Nests failed due to multiple causes, often usurpation by competing species, but also predation by Pantherophis snakes, raccoons, and other unknown causes. We focused our attention on nest usurpation as well as other interactions between bird species. Not all nest turnover was considered to be nest usurpation. For instance, we also observed sequential use by multiple species, which can be detrimental to species that raise multiple broods, but not nearly as consequential as hijacking an active nesting attempt.

\subsubsection{Data Analysis}

We mapped all data in ArcMap GIS (Version 10.2.2). Statistical analysis was conducted in IBM SPSS (Version 20). We performed one-way ANOVA on each nest tree characteristic (nest height, DBH, entrance hole diameter, cavity interior depth, and cavity interior diameter) to determine which differed significantly among species. When nest tree characteristics differed significantly among species, we used a Tukey post hoc test to identify subsets which were significantly different from each other. We performed a hierarchical cluster analysis, producing a dendrogram based on statistically significant 
nest cavity and tree characteristics, following Martin et al. (2004). We visually mapped the nest trees and birds to create a cavity nest web, highlighting the frequency of resource transfer between species. To compare the phenologies of different species, we calculated the proportion of weekly active nests, starting in the third week in February. We plotted this weekly proportion and fitted a third order polynomial trendline to the data in Excel, allowing for a visual comparison of reproductive phenologies. We separated records of all nest usurpations between species that were present in 4 nests or more, and created a chart to visualize hostile nest turnover in our core area during 2017 and 2018. Mean values reported in the results section are \pm 1 standard deviation.

This project was approved by the Institutional Animal Care and Use Committee (IACUC-16-066). At no point in this study did we touch or handle any vertebrate specimen, living or dead.

\subsection{Results}

\subsubsection{Cavity Suitability and Occupancy}

Over two field seasons, we located woodpecker nests in 967 trees, which included a total of 1,864 excavated cavities. We constructed a cavity nest web, highlighting the hierarchical flow of nests (Figure 5.2). We were able to monitor 330 trees containing 750 cavities at least four times during a season, and these were used to determine suitability and occupancy rates. We recorded 344 obviously incomplete cavities among these nest trees but did not include them in the analysis of cavities. $536(71.5 \%)$ of cavity entrances observed from the ground were suitable for occupation. Between two field seasons, 370 $(69.0 \%)$ of the suitable cavities were used for at least one nesting attempt. Of the 195 
unsuitable cavities 111 (56.9\%) were too shallow or otherwise incomplete excavations which appeared to be complete from ground level. The next largest portion of unsuitable cavities, 73 (37.4\%), had no floor, connecting down to one or more lower entrances. Eight unsuitable cavities (4.1\%) were so heavily decayed or broken inside that they did not appear suitable, even for species that bring considerable secondary nest material. Additionally, three unsuitable cavities (1.5\%) contained standing water during the breeding season. The camera couldn't be inserted in 19 cavities among the 750 we attempted to continuously monitor, usually because the angle of the nest entrance or the dense cover of woody vines that prevented the telescoping pole and camera from achieving the correct angle. We observed these cavities visually from the ground and did not observe animal activity. In addition to the 750 cavities we regularly monitored there were additional holes where we were unable to insert the camera but were able to determine occupancy by observing behavior, such as direct feeding of nestlings.

\subsubsection{Cavity Nest Characteristics}

We tested for species differences in nest characteristics, and one-way ANOVA indicated that nest height, entrance hole diameter, internal cavity depth, and internal diameter all differed significantly among species at $\mathrm{p}<0.001$, but tree DBH did not $(\mathrm{p}=$ 0.077). For each characteristic that differed significantly among species, we used the Tukey post hoc test to identify homogeneous subsets; in Figure 5.3, species means within a subset did not differ.

Post hoc tests for nest height showed two subsets. The Pileated Woodpecker used holes farther above the ground than the starling, myna, owl, and Red-bellied Woodpecker, while nest height in the other members of its group, i.e., the Orange-winged 
Parrot, Red-masked Parakeet, and Northern Flicker, did not significantly differ from that of other birds. Post hoc tests for entrance hole diameter suggests three subsets, with the Orange-winged Parrot using larger holes than other birds except the Pileated Woodpecker. The smallest four birds were not significantly different from the parakeet and owl in this regard. With respect to the internal dimensions of the cavities, both Psittacid species used hollows with considerably more internal space than all other birds. Their cavities were deeper than those of other birds, and their internal diameter was wider than others as well; the exception was the Pileated Woodpecker, which was indistinguishable from the Red-masked Parakeet in cavity depth. As these parrots are weak excavators, they are known to enlarge cavities, and we observed them enlarging Red-bellied Woodpecker entrance holes. They may also enlarge cavities internally. All of the Psittacid nests we were able to inspect were in palm snags, which have softer wood than other tropical trees (Chave et al. 2006). The soft palm wood may allow parrots to enlarge cavities that are otherwise too small. However, we were not able to determine anything visually distinct about the floor or walls of the larger cavities used by parrots to prove they enlarged the internal volume.

We classified species based on their nest cavity preferences, producing a dendrogram with several clusters of bird species (Figure 5.4). The primary division is between birds of small-medium body size and large birds. The first cluster consists of Orange-winged Parrot, Red-masked Parakeet, and Pileated Woodpecker, the three largest birds in our system, which require taller nests, larger entrance holes, or deeper cavities. The other primary cluster is composed of the five smaller birds. A secondary cluster of the smallest birds in the system (European Starling, Common Myna, and Red-bellied 
Woodpecker) shows great similarity in nest preference. Other things being equal, these species would therefore be expected to compete and usurp nests from one another. The Northern Flicker was classified just outside of this cluster, using slightly larger entrances cavities that it excavates and slightly taller trees. The Eastern Screech Owl is intermediate in size, and cluster analysis indicated it was closer to the small birds than the large birds in its nesting preferences.

\subsubsection{Overlap of phenology and nest usurpation}

Graphical analysis of breeding phenology overlap separated birds into three groups (Figure 5.5). The Pileated Woodpecker and Eastern Screech Owl were the earliest breeders in this system. They initiated nests as early as February and their interaction with other species is minimized by the early conclusion to their nesting cycle. Conversely, the two common exotic Psittacids hardly participated in hostile nest-web interactions due to breeding late in the season, at a time when all early breeding species have effectively terminated nesting. The parrots share preferences for cavity characteristics with the early breeders, particularly the Pileated Woodpecker (Figure 5.4). Despite the strong overlap in nest preferences, as well as a breeding habitat overlap in and around urban forest fragments, we found no direct interactions between parrots and Pileated Woodpeckers. Both Psittacids did enlarge the cavities of Red-bellied Woodpeckers but did not usurp any active cavities to do so.

The birds nesting in the peak season experienced the most numerous nest usurpations (Figure 5.6). The greatest number of these interactions were between European Starlings and Red-bellied Woodpeckers. These were the two most common breeders in our system, but they also shared similar nest preferences and overlapped 
substantially in breeding. The starlings began egg laying slightly before Red-bellied Woodpeckers, but their breeding activity declined before the woodpeckers finished. Half of all starling nests were active in late April and early May. The European Starling and Red-bellied Woodpecker were the two species that frequently raised multiple clutches, extending their breeding across the entire peak season. As a result, both species had a maximum of approximately $50 \%$ of total nests active during any single week. European Starling breeding activity peaked during the second two weeks of May, with $50.5 \%$ of all nests active. Red-bellied Woodpeckers peaked exactly one month later, with $52.7 \%$ active during the second week of June. From the second week in May to the second week in June, starling activity had declined dramatically from $50.5 \%$ of nests active to 24.7\% active. The Common Myna followed a similar breeding season as the starling, but with a slightly more concentrated season: $75 \%$ nests were active in late April. Most usurpation of Red-bellied Woodpecker nests by starlings occurred in mid-April to midMay, during the early-peak breeding season. Later in the season, Red-bellied Woodpecker nests rarely failed due to usurpation. Overall, 17 of the 93 Red-bellied Woodpecker nesting attempts we continuously monitored were usurped by European Starlings, while Red-bellied Woodpeckers usurped five cavities from European Starlings. In at least four of these five instances, we are sure the woodpecker was recapturing a hole recently usurped by starlings. Many new Red-bellied Woodpecker holes were taken, though not usurped directly from actively-nesting woodpeckers. Out of 260 freshlyexcavated Red-bellied Woodpecker nests, 129 (49.6\%) were used by starlings at some point during the season. The Red-bellied Woodpecker lost the most total active nests to 
starling usurpation, but the Northern Flicker lost a greater proportion of their active nests. Four of ten Northern Flicker nests we monitored were usurped by starlings.

Common myna nests were roughly as common as parrot nests, but they usurped more cavities because they bred during the peak season, using the same cavities as Redbellied Woodpeckers, Northern Flickers, and European Starlings. Although mynas did not usurp any active Northern Flicker nests, we did record the taking of a freshlyexcavated cavity, and aggressive supplanting flights by mynas against a solitary flicker. We observed six instances of mynas taking freshly-excavated Red-bellied Woodpecker holes, as well as additional aggressive interactions between mynas and Red-bellied Woodpeckers. The mynas appear to pose a disruptive threat to the local cavity nest web.

\subsection{Discussion}

\subsubsection{Cavity Occupancy and Nest Characteristics}

Continuous monitoring of 330 nest trees with 536 distinct and suitable cavities has revealed a cavity nest web with limited slack: $69 \%$ of suitable cavities were occupied at some point. With over two thirds of apparently suitable cavities used, the Miami area is fairly typical of urban regions where ideal nesting sites are limited (Blewett and Marzluff 2005, Morrison and Chapman 2005, LaMontagne et al. 2015, Tomasevic and Marzluff 2017, Evans et al. 2018). Beyond Miami’s low vacancy rate, other evidence for cavity limitation included conspecific brood parasitism by European Starlings (Romagnano et al. 1990, Eadie et al. 1998, Pilz et al. 2005). We found up to nine eggs/nestlings at once in European Starling nests, and other suspected conspecific parasitic breeding when egg counts increased $>1$ per day. Conspecific brood parasitism 
is possible without nest limitation, but it is additional anecdotal evidence supporting the low vacancy rate we observed. We were able to exclude over two hundred cavities regularly surveyed as unsuitable, but it is possible that birds have preferences that we were unable to detect, such as affinities for a particular microclimate (Lõhmus and Remm 2005, Camprodon et al. 2008, Clement and Castleberry 2013). We discounted cavities due to shallow interiors and standing water, but 166 cavities appeared indistinguishable on nest camera video from some cavities attracting competition from multiple species. Currently we can only speculate about microclimate in the cavities, and how it may differ depending on the nest location in sun or shade, but the landscape position of snags didn't indicate any obvious relationship with productivity. A thermometer attached to camera probes could provide some data on future inspections of nest cavities, and long-term emplacement of climate recorders could explain daily cycles of temperature and humidity, which are certain to vary over the course a breeding season.

The physical attributes of cavity size appear to correspond with overall body size of these birds. Cluster analysis of cavity usage divided groups of birds by their size, but in isolation this classification did not predict competition between birds. Pileated Woodpeckers were not in competition with the Orange-winged Parrots or Red-masked Parakeets with whom they share similar cavity nest characteristics. Instead, the species which usurped active Pileated Woodpecker nests shared more in phenology than nest characteristics. Inactive Pileated Woodpecker cavities, especially older ones, were used by the parrots. The use of large, older cavities by the largest secondary users mirrors the relationships between cavity nesting birds in British Columbia, where large-bodied nonexcavators used cavities that were 3-16 years old, at the period of lowest overall 
occupancy rates by the excavating species and therefore lowest competition (Edworthy et al. 2018). Internal cavity dimensions tend to increase (especially in live trees) due to secondary enlargement and weathering of natural elements, and become more suitable to large-bodied birds over time (Edworthy and Martin 2014). Pileated Woodpeckers very rarely reuse nests for breeding in subsequent years, so any further occupation by Psittacids is unlikely to impact this woodpecker species (Bull and Jackson 2011). The lack of nest reuse by Pileated Woodpeckers may help avoid nest web interactions if potential competitors have discovered their nest locations during the previous year.

5.5.2 Phenology, nest usurpation, and management of exotic birds

Several birds were involved in usurping nests, particularly the Sturnids. These birds shared nest characteristics and phenology with the two medium-sized woodpeckers, and were recorded in other aggressive interactions with the woodpeckers. The relationship between Sturnids and native woodpeckers sharing similar cavity characteristics is common in other parts of North America, where starlings are a deeplyentrenched competitor. In British Columbia, competition between starlings and Northern Flickers was found to be high at the beginning of the breeding season, and declined rapidly thereafter (Wiebe 2003). Delaying reproduction resulted in lower fecundity except when $3 / 4$ or more nests are usurped. Our sample size for Northern Flicker nests (n = 10) was comparatively low, but $40 \%$ of nests were usurped by starlings, suggesting a serious conservation threat to a woodpecker that is relatively uncommon in this region. The Red-bellied Woodpecker fared better, with only $18.3 \%$ of active nests usurped by starlings. Flickers in British Columbia had lower rates of active nest usurpations by starlings, ranging from 4.1-9.1\% (Wiebe 2003). Many excavated cavities were taken by 
starlings, but we do not believe these displaced active nesting attempts ongoing by woodpeckers or other species. In Mississippi, $52 \%$ of nest cavities newly excavated by Red-bellied Woodpecker were taken by starlings (Ingold 1989). We found almost the same results in Miami, where 49.6\% of freshly excavated Red-bellied Woodpecker cavities were occupied by starlings at some point. Similar results of this competition were observed in Ohio, where 39\% of new Red-bellied Woodpecker holes were taken by starlings (Ingold 1994).

In tropical Florida, long breeding seasons allow for delayed reproduction by Redbellied Woodpeckers without any obvious decline in clutch size or fecundity. The breeding season for cavity-nesting birds is approximately twice as long in Miami, Florida as in British Colombia (Wiebe 2003). In temperate climates, the delay of reproduction incurs serious fitness costs and reduction of fecundity (Ingold 1996). The European Starling and Red-bellied Woodpecker were the two species that frequently raised multiple clutches, extending their breeding across the entire peak season. The breeding season for these two birds effectively spanned the transition between tropical Florida's dry and rainy seasons. As the two most common species, with the greatest number of competitive interspecific interactions, the difference of one month in their peak breeding may reduce usurpations. Nest usurpations occurred primarily in April and May, with no starlings recorded usurping Red-bellied Woodpecker nest after 16 May. We monitored Red-bellied Woodpecker nesting attempts that continued five weeks past the last starling nest. In northern latitudes, early egg-laying should be favored because of shorter breeding seasons (Wiebe 2003). In tropical Florida, temperature alone is unlikely to 
restrict breeding, but phenology may be related to shifting food resource availability across the rainy and dry seasons.

This analysis of the cavity nest webs indicates that Common Mynas could represent a significant threat to native birds if their populations increase. The myna shows behavioral dominance in its relationship with interspecific competitors. Mynas usurped nests from Red-bellied Woodpeckers and starlings, and we recorded aggressive interactions with flickers. None of these birds successfully usurped a cavity held by mynas. In a list of the world's most destructive invasive species, only three birds were listed, including the starling and myna (Lowe et al. 2000). The European Starling is so firmly established in North America that complete eradication is impossible. The Myna was first established in South Florida in the early 1980s, and the growing population has expanded in range for several decades (Pranty 2007). Common mynas have the potential to invade large portions of North America, and this could have devastating effects on cavity-nesting birds. Since a large proportion of Northern Flicker nests are failing due to starling usurpation, there is concern that if mynas became as common as starlings, Sturnid competition for nest cavities could eradicate breeding populations of flickers entirely. The effects on Red-bellied Woodpeckers could be less severe because of their longer breeding season. Starlings are too numerous and widespread to eradicate but continuous control efforts could be beneficial to native birds in an environment where woodpecker holes are plentiful, but about half of the dominant woodpecker's new holes are taken by starlings each year. Both Sturnid species are vulnerable to trapping using live lures (Campbell et al. 2012). 
The breeding season of the exotic Psittacids in Miami was largely a surprise, and provides new information for managers of urban natural areas in Miami. The ideal comparison would have been phenology data on the native, extinct Carolina Parakeet. There is no data on their breeding phenology, and relatively minimal information on their reproduction overall (McKinley 1978, Saikku 1990, Snyder 2004). In South America, Psittacids have varying reproductive phenologies, with some smaller species breeding earlier than the larger ones (Brightsmith 2005a). In Miami, the larger Orange-winged Parrot breeding season peaked four weeks before the smaller Red-masked Parakeet. Data from exotic Rose-ringed Parakeets in Europe and the Middle East indicated these parrots are early breeders (Strubbe and Matthysen 2009, Czajka et al. 2011, Orchan et al. 2012, Luna et al. 2017). In our study area, Orange-winged Parrots and Red-masked Parakeets bred too late to interact with the birds sharing similar cavity preferences. The ability of these parrots to enlarge cavities also increases the pool of potential nest cavities available to them. Older nest cavities may have softer, more decayed wood, which they can more easily tear and enlarge, reducing opportunities to compete with other cavity excavators. The exotic Psittacids in Miami do not pose a direct threat to Pileated Woodpeckers or Eastern Screech Owls through non-trophic nest interactions. We did not record any direct evidence that a growing population of these Psittacids would cause nest competition with any native species.

If managers seek to protect native cavity-nesting birds from invasive competitors, control efforts should instead be directed towards Sturnids. These birds have an established track record of destructive invasions in North America, Australia, Africa, and Pacific islands (Harper et al. 2005, Peacock et al. 2007, Blackburn et al. 2009, Sodhi et 
al. 2011). There is some evidence from Australia that myna impacts may be more limited to urban areas and structures, and therefore not threatening conservation of native fauna in relict natural areas (Lowe et al. 2011). In Miami, starlings have already penetrated the wilderness of Everglades National Park, ejecting Northern Flicker and Red-bellied Woodpecker eggs, and we found mynas nesting just kilometers east of the park boundary. The incipient invasion of Common Myna is still in a phase where complete eradication is possible. With a locally small myna population, eradication of birds and closing of the introduction pathway is still possible, before a species is widespread and abundant, and population control and impact mitigation are the only options (Grarock et al. 2013). Locally, if myna populations grow like the starling population did, Northern Flickers could be extirpated from the study region. Further north in Peninsular Florida, there are additional native woodpeckers and secondary cavity nesting birds which can be impacted (McComb et al. 1986, Land et al. 1989, Gault et al. 2004, Blanc and Walters 2008b). The myna represents an additional conservation threat to the threatened Red-cockaded Woodpecker, and the declining Red-headed Woodpecker as its invasion expands beyond South Florida. 


\subsection{References}

Blackburn, T. M., and P. Cassey. 2007. Patterns of non-randomness in the exotic avifauna of Florida. Diversity and Distributions 13:519-526.

Blackburn, T. M., J. L. Lockwood, and P. Cassey. 2009. Avian Invasions: The Ecology \& Evolution of Exotic Birds. Oxford University Press, New York.

Blanc, L. A., and J. R. Walters. 2008a. Cavity Excavation and Enlargement as Mechanisms for Indirect Interactions in an Avian Community. Ecology 89:506-514.

Blanc, L. A., and J. R. Walters. 2008b. Cavity-Nest Webs in a Longleaf Pine Ecosystem. The Condor 110:80-92.

Blewett, C. M., and J. M. Marzluff. 2005. Effects of urban sprawl on snags and the abundance and productivity of cavity-nesting birds. Condor 107:678-693.

Brightsmith, D. J. 2005a. Parrot Nesting in Southeastern Peru: Seasonal Patterns and Keystone Trees. The Wilson Bulletin 117:296-305.

Brightsmith, D. J. 2005b. Competition, Predation and Nest Niche Shifts among Tropical Cavity Nesters: Phylogeny and Natural History Evolution of Parrots (Psittaciformes) and Trogons (Trogoniformes). Journal of Avian Biology 36:64-73.

Bull, E. L., and J. A. Jackson. 2011. Pileated Woodpecker (Dryocopus pileatus). Page in A. F. Poole, editor. The Birds of North America, online. Version 2. Cornell Lab of Ornithology, Ithica, New York.

Campbell, S., S. Cook, L. Mortimer, G. Palmer, R. Sinclair, and A. P. Woolnough. 2012. To catch a starling: testing the effectiveness of different trap and lure types. Wildlife Research 39:183-191.

Camprodon, J., J. Salvanyà, and J. Soler-Zurita. 2008. The Abundance and Suitability of Tree Cavities and Their Impact on Hole- Nesting Bird Populations in Beech Forests of NE Iberian Peninsula. Acta Ornithologica 43:17-31.

Chave, J., H. C. Muller-Landau, T. R. Baker, T. A. Easdale, T. E. R. Hans Steege, and C. O. Webb. 2006. Regional and phylogenetic variation of wood density across 2456 neotropical tree species. Ecological Applications 16:2356-2367.

Clement, M. J., and S. B. Castleberry. 2013. Tree structure and cavity microclimate: Implications for bats and birds. International Journal of Biometeorology 57:437450 .

Cockle, K. L., K. Martin, and G. Robledo. 2012. Linking fungi, trees, and hole-using birds in a Neotropical tree-cavity network: Pathways of cavity production and implications for conservation. Forest Ecology and Management 264:210-219.

Cockle, K. L., K. Martin, and T. Wesołowski. 2011. Woodpeckers, decay, and the future of cavity-nesting vertebrate communities worldwide. Frontiers in Ecology and the Environment 9:377-382. 
Cornelius, C., K. Cockle, N. Politi, I. Berkunsky, L. Sandoval, V. Ojeda, L. Rivera, M. J. Hunter, and K. Martin. 2008. Cavity-nesting birds in neotropical forests: cavities as a potentially limiting resource. Ornitologia Neotropical 19:253-268.

Czajka, C., M. P. Braun, and M. Wink. 2011. Resource Use by Non-Native Ring-Necked Parakeets (Psittacula krameri) and Native Starlings (Sturnus vulgaris) in Central Europe. The Open Ornithology Journal 4:17-22.

Davis, A., R. E. Major, and C. E. Taylor. 2013. Housing Shortages in Urban Regions: Aggressive Interactions at Tree Hollows in Forest Remnants. PLoS ONE 8.

Dudley, J., and V. Saab. 2003. A Field Protocol to Monitor Cavity-Nesting Birds. Page Res. Pap. RMRS-RP-44. US Department of Agriculture, Forest Service, Rocky Mountain Research Station. Fort Collins, Colorado.

Duever, M. J., J. F. Meeder, L. C. Meeder, and J. M. McCollom. 1994. The climate of south Florida and its role in shaping the Everglades ecosystem. Pages 225-248 in S. Davis and J. C. Ogden, editors. Everglades: The Ecosystem and Its Restoration. CRC Press, Boca Raton, Florida.

Eadie, J., P. Sherman, and B. Semel. 1998. Conspecific brood parasitism, population dynamics, and the conservation of cavity-nesting birds. Pages 306-340 in T. Caro, editor. Behavioral ecology and conservation biology. Oxford University Press, New York.

Edworthy, A. B., and K. Martin. 2014. Long-term dynamics of the characteristics of tree cavities used for nesting by vertebrates. Forest Ecology and Management 334:122128.

Edworthy, A. B., M. K. Trzcinski, K. L. Cockle, K. L. Wiebe, and K. Martin. 2018. Tree cavity occupancy by nesting vertebrates across cavity age. Journal of Wildlife Management 82:639-648.

Epps, S. A. 2007. Parrots of South Florida. Pineapple Press, Inc.

Evans, B. S., R. Reitsma, A. H. Hurlbert, and P. P. Marra. 2018. Environmental filtering of avian communities along a rural-to- urban gradient in Greater Washington, D.C., USA. Ecosphere 9:1-19.

Forys, E. A., and C. R. Allen. 1999. Biological invasions and deletions: community change in south Florida. Biological Conservation 87:341-347.

Gault, K. E., J. R. Walters, J. Tomcho, L. F. Phillips, and A. Butler. 2004. Nest Success of Southeastern American Kestrels Associated with Red-Cockaded Woodpeckers in Old-Growth Longleaf Pine Habitat in Northwest Florida. Southeastern Naturalist 3:191-204.

Gibbons, P., and D. Lindenmayer. 2000. Tree Hollows and Wildlife Conservation in Australia. Wildlife Conservation 051:3-19. 
Grarock, K., D. B. Lindenmayer, J. T. Wood, and C. R. Tidemann. 2013. Using invasion process theory to enhance the understanding and management of introduced species: A case study reconstructing the invasion sequence of the common myna ( Acridotheres tristis ). Journal of Environmental Management 129:398-409.

Harper, M. J., M. A. McCarthy, and R. Van Der Ree. 2005. The use of nest boxes in urban natural vegetation remnants by vertebrate fauna. Wildlife Research 32:509516.

Ingold, D. J. 1989. Nesting Phenology and Competition for Nest Sites among RedHeaded and Red-Bellied Woodpeckers and European Starlings. The Auk 106:209217.

Ingold, D. J. 1994. Influence of nest-site competition between European Starlings and woodpeckers. Wilson's Bulletin 106:227-241.

Ingold, D. J. 1996. Delayed Nesting Decreases Reproductive Success in Northern Flickers : Implications for Competition with European Starlings. Journal of Field Ornithology 67:321-326.

LaMontagne, J. M., R. J. Kilgour, E. C. Anderson, and S. Magle. 2015. Tree cavity availability across forest, park, and residential habitats in a highly urban area. Urban Ecosystems 18:151-167.

Land, D., W. R. Marion, and T. E. O'Meara. 1989. Snag availability and cavity nesting birds in slash pine plantations. Journal of Wildlife Management 53:1165-1171.

Lõhmus, A., and J. Remm. 2005. Nest quality limits the number of hole-nesting passerines in their natural cavity-rich habitat. Acta Oecologica 27:125-128.

Lowe, K. A., C. E. Taylor, and R. E. Major. 2011. Do Common Mynas significantly compete with native birds in urban environments? Journal of Ornithology 152:909921.

Lowe, S., M. Browne, S. Boudjelas, and M. De Poorter. 2000. 100 of the world's worst invasive alien species: a selection from the global invasive species database. Volume 12. Inasive Species Specialst Group, Auckland.

Luna, A., D. Franz, D. Strubbe, A. Shwartz, M. P. Braun, D. Hernández-Brito, Y. Malihi, A. Kaplan, E. Mori, M. Menchetti, C. A. M. van Turnhout, D. Parrott, F. M. Chmielewski, and P. Edelaar. 2017. Reproductive timing as a constraint on invasion success in the Ring-necked parakeet (Psittacula krameri). Biological Invasions 19:2247-2259.

Luneau, M. D., and B. L. Noel. 2010. A wireless video camera for viewing tree cavities. Journal of Field Ornithology 81:176-185.

Martin, K., K. E. H. Aitken, and K. L. Wiebe. 2004. Nest sites and nest webs for cavitynesting communities in interior British Colombia, Canada: Nest characteristics and niche partitioning. The Condor 106:5-19. 
Martin, K., and J. M. Eadie. 1999. Nest webs: A community-wide approach to the management and conservation of cavity-nesting forest birds. Forest Ecology and Management 115:243-257.

McComb, W. C., S. A. Bonney, R. M. Sheffield, and N. D. Cost. 1986. Snag Resources in Florida: Are They Sufficient for Average Populations of Primary Cavity-Nesters? Wildlife Society Bulletin 14:40-48.

McKinley, D. 1978. Clutch Size, Laying Date, and Incubation Period in the Carolina Parakeet. Bird-Banding 49:223-233.

Morrison, J. L., and W. C. Chapman. 2005. Can Urban Parks Provide Habitat for Woodpeckers? Northeastern Naturalist 12:253-262.

Orchan, Y., F. Chiron, A. Shwartz, and S. Kark. 2012. The complex interaction network among multiple invasive bird species in a cavity-nesting community. Biological Invasions 15:429-445.

Ouellet-Lapointe, U., P. Drapeau, P. Cadieux, and L. Imbeau. 2012. Woodpecker Excavations Suitability for and Occupancy by Cavity Users in the Boreal Mixedwood Forest of Eastern Canada. Ecoscience 19:391-397.

Owre, O. T. 1973. A Consideration of the Exotic Avifauna of Southeastern Florida. The Wilson Bulletin 85:491-500.

Peacock, D. S., B. J. Van Rensburg, and M. P. Robertson. 2007. The distribution and spread of the invasive alien common myna, Acridotheres tristis L. (Aves: Sturnidae), in southern Africa. South African Journal of Science 103:465-473.

Pell, A. S., and C. R. Tidemann. 1997. The impact of two exotic hollow-nesting birds on two native parrots in Savannah and Woodland in eastern Australia. Biological Conservation 79:145-153.

Pilz, K. M., H. G. Smith, and M. Andersson. 2005. Brood parasitic European starlings do not lay high-quality eggs. Behavioral Ecology 16:507-513.

Pranty, B. 2007. Status and distribution of Common Myna (Acridotheres tristis) in Florida. North American Birds 61:658-665.

Pranty, B., and S. A. Epps. 2002. Distribution, Population Status, and Documentation of Exotic Parrots in Broward County, Florida. Florida Field Naturalist 30:111-150.

Romagnano, L., A. S. Hoffenberg, and H. W. Power. 1990. Intraspecific brood parasitism in the European starling. The Wilson Bulletin 102:279-291.

Saikku, M. 1990. The Extinction of the Carolina Parakeet. Environmental History Review 14:1-18.

Snyder, N. F. R. 2004. The Carolina parakeet: glimpses of a vanished bird. 1st ed. Princeton University Press, Princeton, New Jersey. 
Sodhi, N. S., C. H. Sekercioglu, J. Barlow, and S. K. Robinson. 2011. Biotic Invasions and Tropical Birds. Pages 126-151 Conservation of Tropical Birds. First Edit. Wiley-Blackwell, Hoboken, New Jersey.

Strubbe, D., and E. Matthysen. 2009. Establishment success of invasive ring-necked and monk parakeets in Europe. Journal of Biogeography 36:2264-2278.

Tomasevic, J. A., and J. M. Marzluff. 2017. Cavity nesting birds along an urban-wildland gradient: is human facilitation structuring the bird community? Urban Ecosystems 20:435-448.

Wiebe, K. L. 2003. Delayed timing as a strategy to avoid nest-site competition: testing a model using data from starlings and flickers. Oikos 100:291-298.

Wiebe, K. L., W. D. Koenig, and K. Martin. 2007. Costs and benefits of nest reuse versus excavation in cavity-nesting birds. Annales Zoologici Fennici 44:209-217. 


\subsection{Figures}

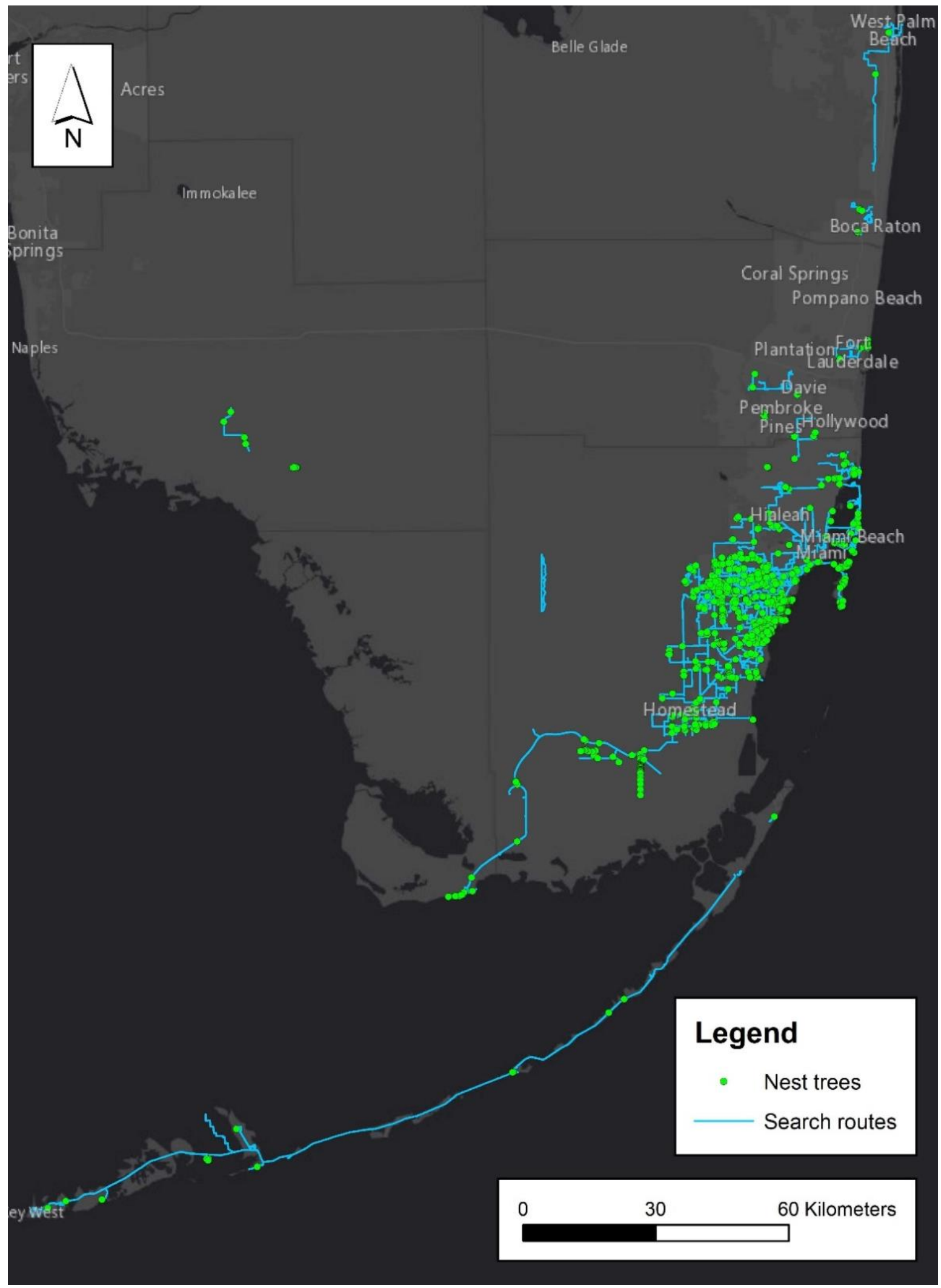


Figure 5.1 Study region, showing search routes and nest trees found. The core study area encompassed Miami-Dade, County, Florida, but individual nest surveys were made south to the Florida Keys, north to West Palm Beach, and west

to Fakahatchee Strand State Preserve. Survey routes followed a random walk where driving, bicycling, and walking was safely allowed. 


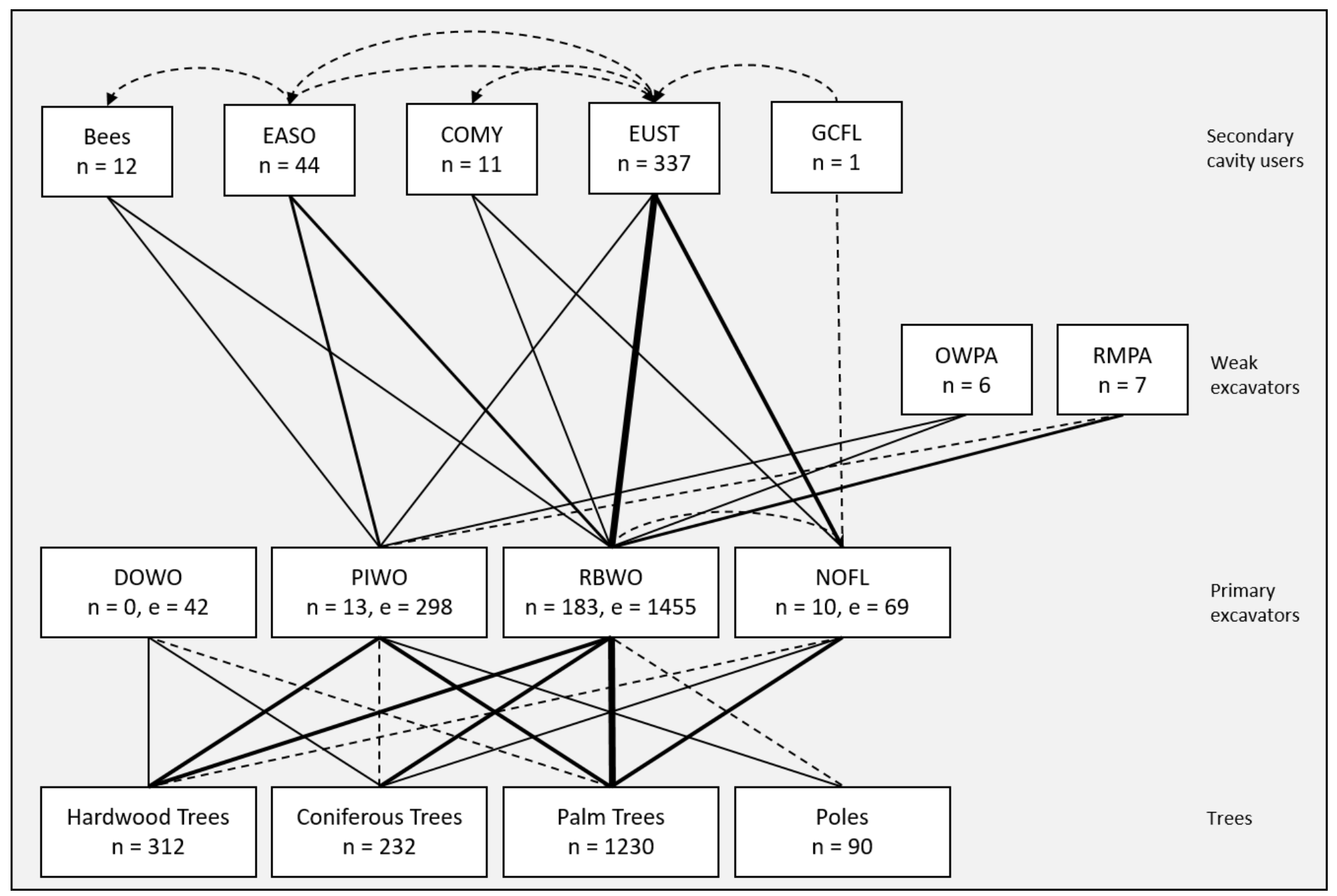


Figure 5.2 Cavity nest web diagram highlighting the hierarchical flow of nests from creation through subsequent use. For each tree category, $n$ indicates the total number of cavities excavated within the substrate. For primary

excavators, weak excavators, and secondary cavity users, $\mathrm{n}$ indicates the number of active nests. For primary excavators, e indicates the number of cavities attributed to each woodpecker. Line weight in the nest web indicates the relative frequency of cavity creation or transfer. Within primary excavators and secondary cavity users,arrow direction indicates nest movement between species, for example from the Red-bellied Woodpecker to NorthernFlicker. The alpha codes for the birds used are as follows: EASO = Eastern Screech Owl. COMY = CommonMyna. DOWO = DownyWoodpecker. EUST European Starling. GCFL = Great-crested Flycatcher. OWPA

$=$ Orange-winged Parrot.RMPA $=$ Red-masked Parakeet.PIWO = Pileated Woodpecker.RBWO = Redbellied Woodpecker. NOFL $=$ Northern Flicker. 


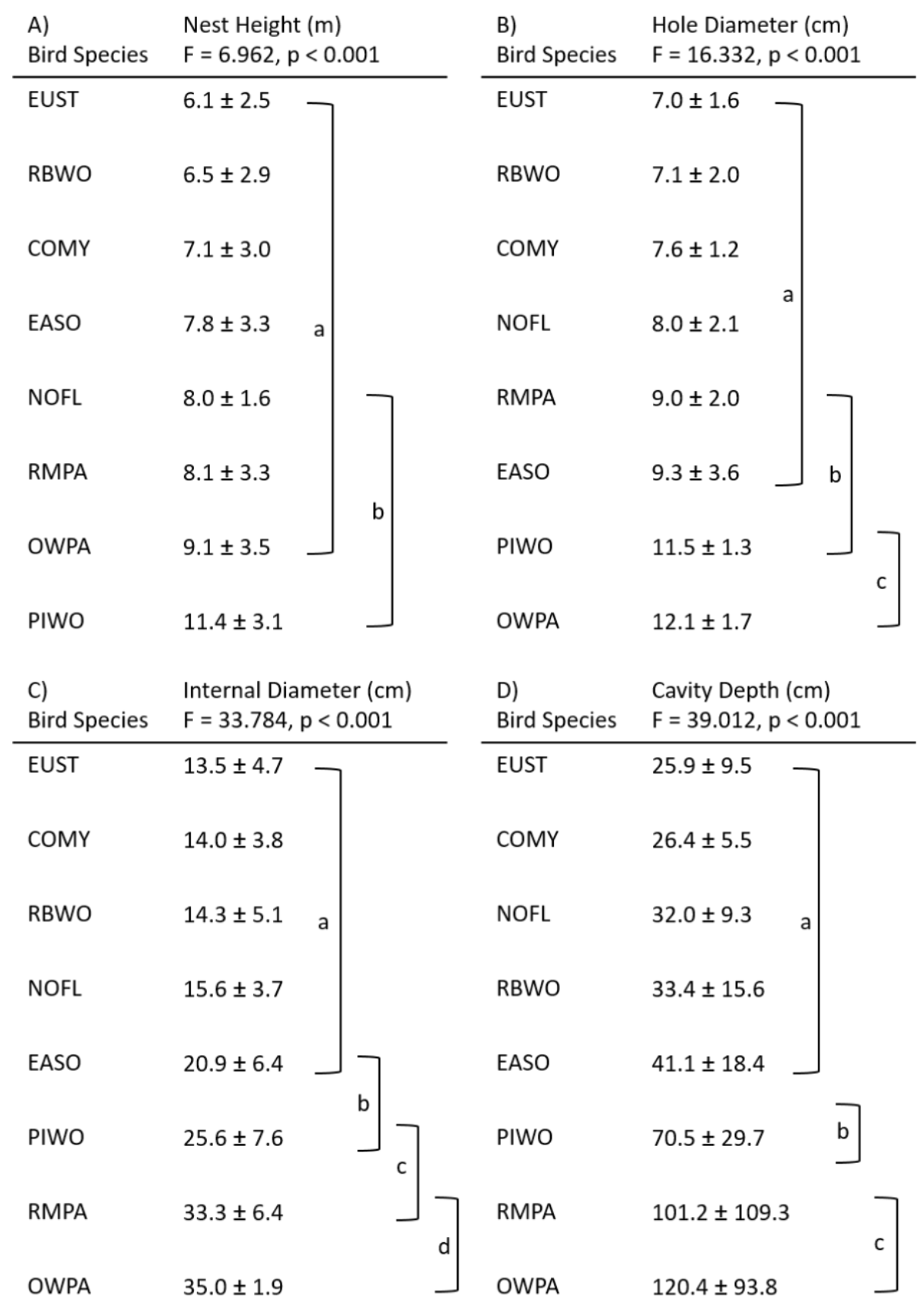

Figure 5.3 Nest tree and hole characteristics of birds breeding in Miami woodpecker cavities, A) nest height, B) entrance hole diameter, C) internal nest diameter, and D) cavity depth. For each characteristic tested, birds are listed in increasing mean, \pm 1 
standard deviation. Lettered brackets indicate subsets identified by the post-hoc Tukey HSD test. All characteristics differed significantly except for DBH ( $F=1.845, \mathrm{p}$ $=0.077$ ), which was excluded from the subsequent hierarchical cluster analysis. The alpha codes for the birds used are as follows: EASO $=$ Eastern Screech Owl. COMY $=$ Common Myna. EUST $=$ European Starling. OWPA $=$ Orange-winged Parrot. RMPA $=$ Red-masked Parakeet. PIWO $=$ Pileated Woodpecker. RBWO $=$ Red-bellied Woodpecker. NOFL $=$ Northern Flicker 


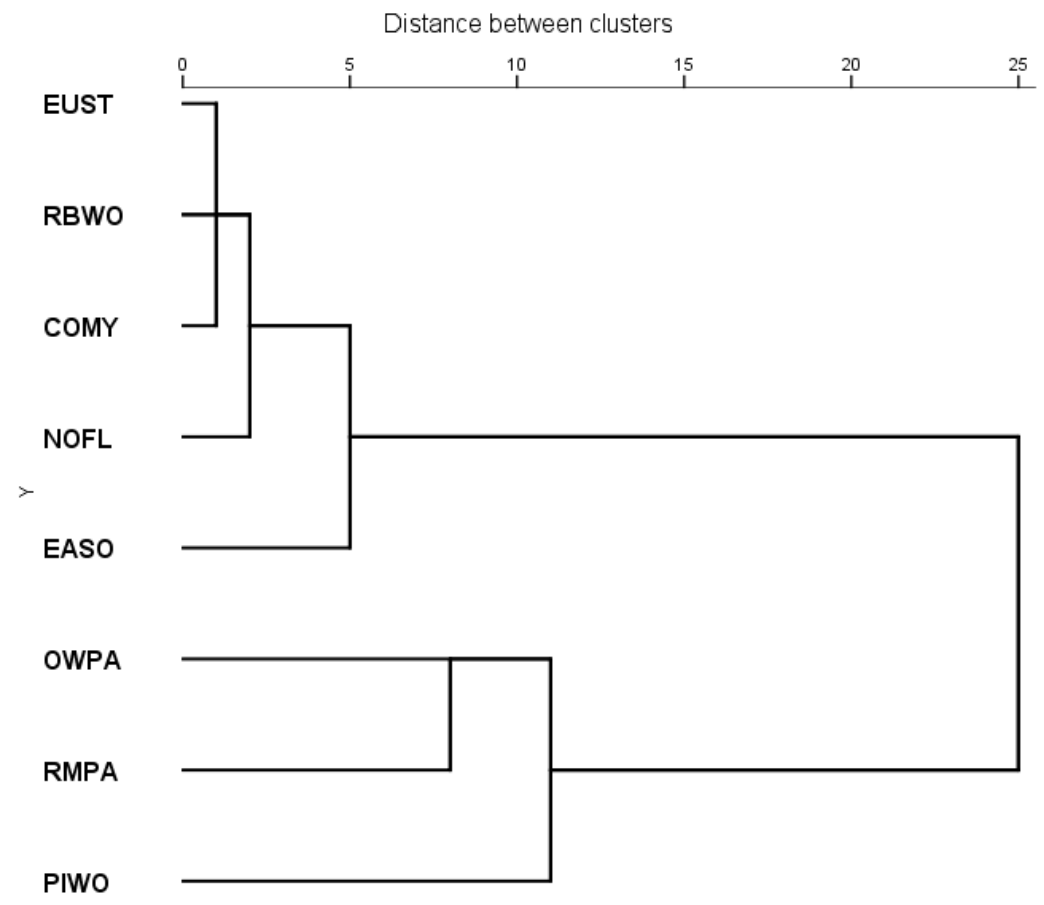

Figure 5.4 The analysis of nest cavity preferences showed several clusters of bird species. The primary division is between birds of small-medium body size and large birds. The first cluster consists of Orange-winged Parrot, Red-masked Parakeet, and Pileated Woodpecker, the three largest birds in our system, which will require larger entrance sizes or deeper cavities. The other cluster is composed of the five smaller birds. The European Starling, Common Myna, and Red-bellied Woodpecker are the smallest birds in the system and the most similar innestpreferences. This cluster also includes the Northern Flicker and Eastern Screech Owl, intermediate sized birds. The alpha codes for the birds used are as follows: EASO = Eastern Screech Owl. COMY = Common Myna. EUST = European Starling. OWPA = Orange-winged Parrot. RMPA = Redmasked Parakeet. PIWO = Pileated Woodpecker. RBWO $=$ Red-bellied Woodpecker. NOFL $=$ Northern Flicker. 


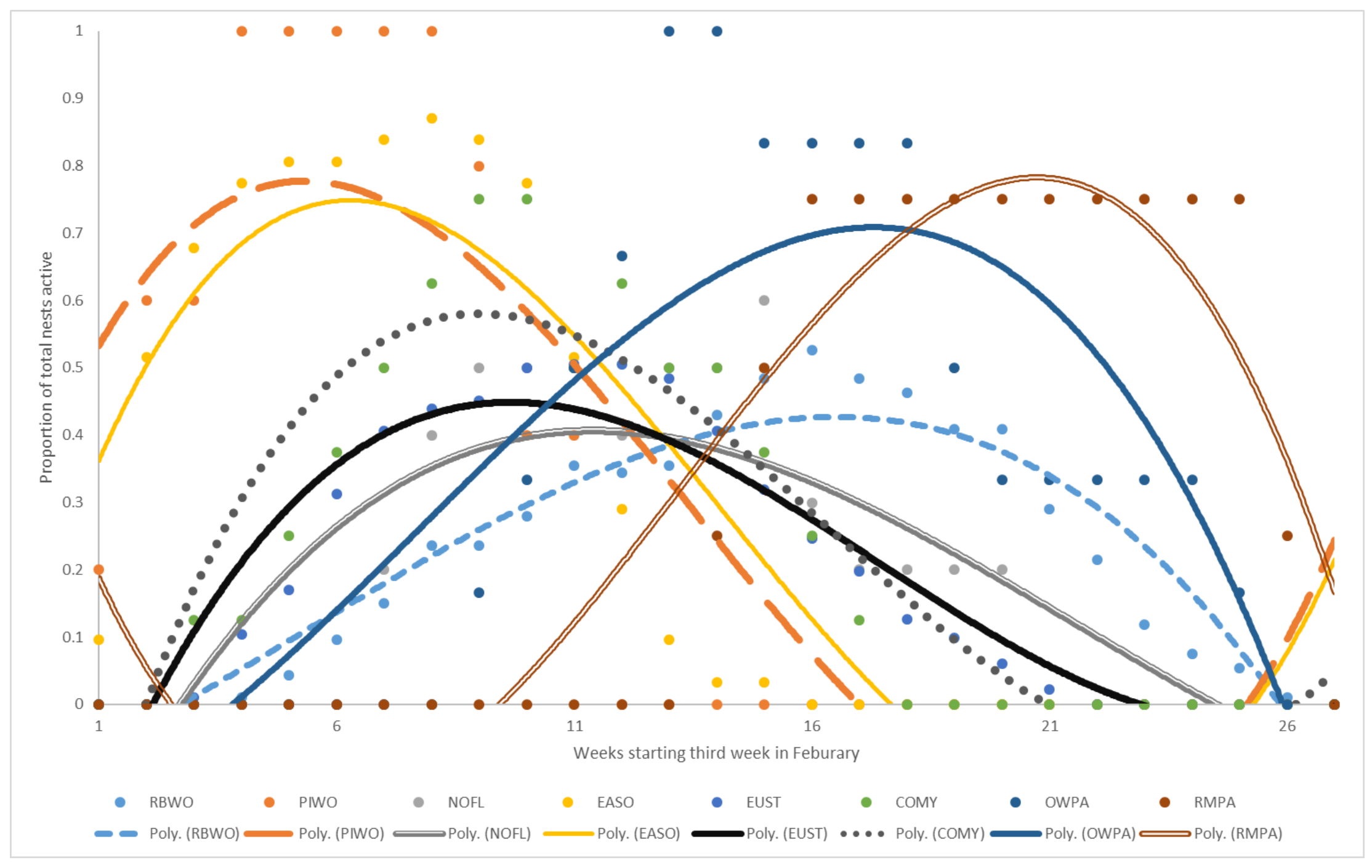


Figure 5.5 Breeding phenologies of eight cavity nesting bird species in Miami-Dade County, Florida, during 2017-2018 breeding season, following analysis in Orchan et al. (2012). Points represent the weekly proportion of active nesting attempts per species, and trendlines follow a third order polynomial curve. Time indicated on the $\mathrm{X}$ axis is weeks starting the 3rd week in February. Visual analysis separates birds into early, peak, and late season breeders. Pileated Woodpecker and Eastern Screech Owl breed first. The peak season includes Northern Flicker, Common Myna, European Starling, and Red-bellied Woodpecker, although this last species has the longest season, extending into the late period. The two Psittacid species breed last. The alpha codes for the birds used are as follows: EASO = Eastern Screech Owl. COMY = Common Myna. EUST = European Starling. OWPA = Orange-winged Parrot. RMPA = Red-masked Parakeet. Woodpecker PIWO $=$ Pileated Woodpecker. RBWO $=$ Red-bellied NOFL $=$ Northern Flicker. 


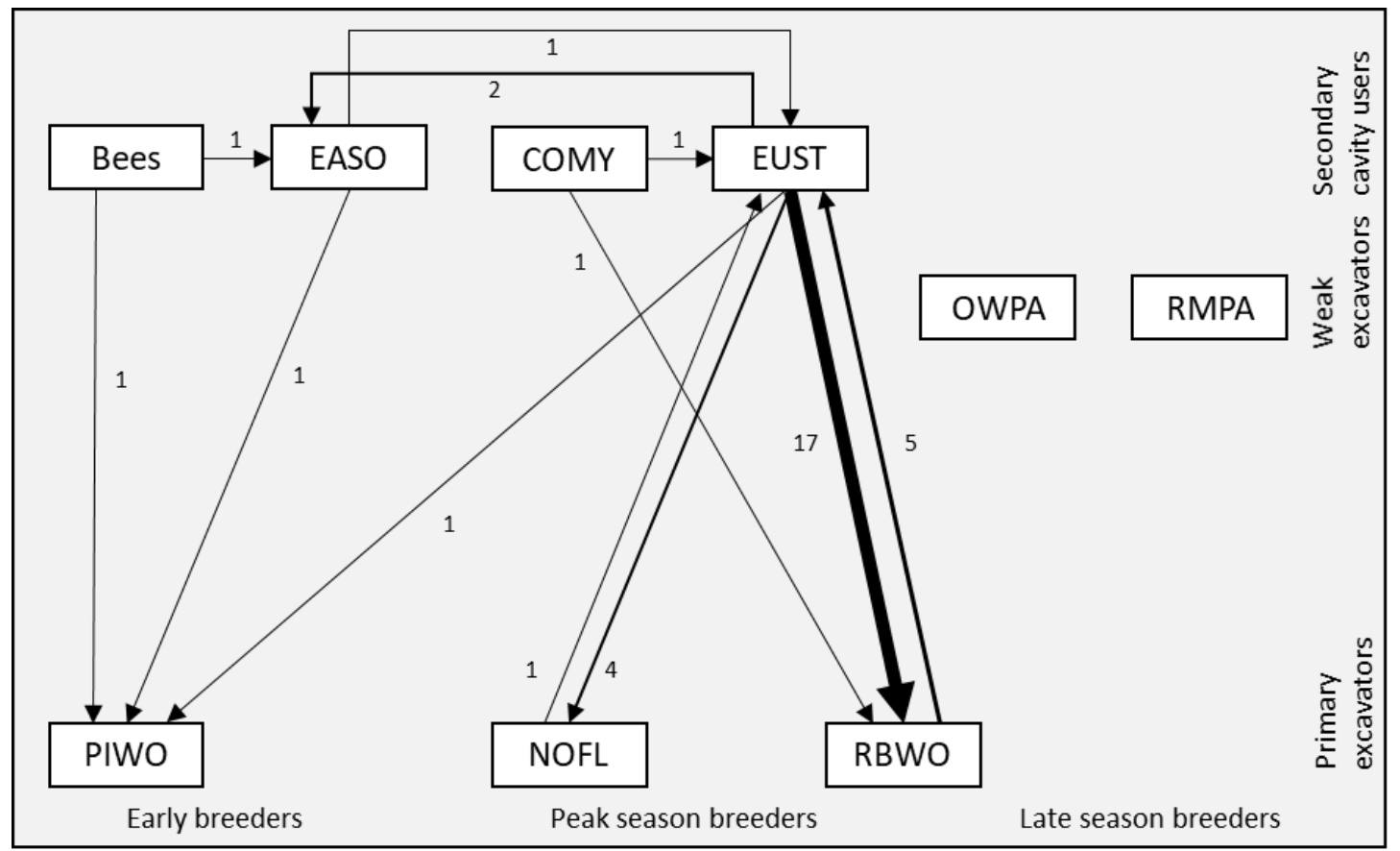

Figure 5.6 Usurpations of active nests in a cavity nest web, $n=370$ cavities used for $1+$ nesting attempt, out of $n=536$ suitable cavities monitored continuously over two breeding seasons. Arrows indicate the direction of usurpation, towards the losing species. Arrow thickness reflects the number of usurpations. Species are arranged by season, according to breeding phenology. In the absence of phenology data, bees were placed in the early season. Both usurpations of active bird nests by bees occurred in the first six weeks of monitoring; other new hives were found in cavities in the early season. Psittacids were not involved in active nest usurpations. The alpha codes for the birds used are as follows: EASO = Eastern Screech Owl. COMY $=$ Common Myna. EUST $=$ European Starling. OWPA $=$ Orange-winged Parrot. RMPA = Red-masked Parakeet. PIWO = Pileated Woodpecker. RBWO = Redbellied Woodpecker. NOFL $=$ Northern Flicker . 


\section{CHAPTER 6. SUMMARY AND CONCLUSIONS}

The study of cavity nest web disruption in Miami begins with a survey of woodpeckers, and their nest substrate. The human development activities and planted communities of tropical Miami have created an urban forest where half of trees are arborescent palms. Within the surveyed urban environments, woodpeckers used $83 \%$ palms as substrate compared to the $53.6 \%$ palms in the landscape. In the broader matrix of suburbs, relict forests, and disturbed areas, woodpeckers have a wider mix ture of hardwood trees, coniferous trees, palm trees, and utility poles to choose from. In the entire region, $63.1 \%$ of nests were excavated in palms, more than the other three categories combined. We located 967 nest trees with 1,864 cavities and determined that woodpeckers preferentially used palm snags in any habitat cover type where they were available. The relict upland forests preserved in the urban matrix had the highest concentration of woodpecker cavities found, but not significantly more than parks and botanical gardens.

My research revealed a particular nesting relationship between the most common woodpecker and the most common nest tree species. The most common woodpecker was the Red-bellied Woodpecker, which was widespread in all terrestrial landscapes, creating $78.1 \%$ of all cavities. The royal palm was the most common nest tree, representing over $1 / 4$ of all woodpecker nest trees found in our study. The royal palm grows larger than most common palms; it is present in natural areas and is one of the most widely planted landscaping plants. Pileated Woodpeckers also excavated many royal palms, allowing the large woodpecker historically categorized as a mature-forest specialist to breed in 
habitat islands of urban forest fragments surrounded by intensive urbanization. Natural decay cavities suitable for secondary cavity users are virtually nonexistent in this environment, so providing substrate for woodpeckers is critical for bird conservation locally. Collectively, palms were disproportionately important to woodpecker in Miami, and could be equally important for woodpeckers in other Caribbean urban regions.

The value of standing dead palms (snags) in urban areas was highlighted by a hurricane that occurred between my field seasons. Hurricane Irma made landfall southwest of my core study area, bringing the most substantial winds and rain of our study period. The hurricane felled snags and broke limbs off of trees that supported woodpecker nests. I checked on trees immediately afterwards, and used these data to understand which nest sites were most likely to persist after the hurricane, and compare nest site characteristics before and after the storm. The storm affected some nest substrate types more than others. Utility poles, which are pine trees shaped and chemically treated to inhibit decay and buried for stability, lost few cavities to the hurricane. Nests in pine snags fared particularly poorly, with the highest rate of snag loss, and fewest new snags excavated in the first year following the storm. This resulted in a reduction in nest availability in the plots surveyed. Nests in palms and hardwoods persisted at intermediate rates, but following the storm even more of the new cavities were excavated in palms. The soft wood of the palms that already attracts woodpeckers under background conditions becomes a more valuable resource when a major disturbance reduces the existing resource supply. Trees excavated the year following the hurricane were $23 \%$ shorter than trees with nests found before the hurricane, but other attributes of the trees and nests were unchanged. In urban areas, palm snags can be a 
valuable resource for cavity nesting birds, especially immediately after a major disturbance, when the substrate provides ample opportunities for excavation.

Active monitoring of nest cavities was conducted to determine nest occupancy and turnover. I monitored 750 cavities to determine species occupancy and turnover. Of special interest were Miami's many parrot species, which have been suspected of breeding in woodpecker nests. While not all parrots are tree-cavity nesting species, based on published accounts in the native ranges of parrots, I expected quite a few of the dozens of parrots observed in Miami to have an active breeding population in woodpecker holes. For some species, like the Mitred Parakeet, I determined that they avoid the tree cavities they use in their native range by nesting in anthropogenic structures, avoiding the cavity nest web altogether. I found significant breeding populations of two parrots, the Orangewinged Parrot and the Red-masked Parakeet, using woodpecker cavities. Geographic analysis of nests combined with citizen-science data indicate that these parrots are completely restricted to developed areas and the relict natural areas within the urban matrix, not spreading into the Florida Everglades or other protected wilderness in South Florida. Exotic parrots breeding elsewhere in the world have harmed native cavitynesting birds through interference competition, but competitive interference in southeast Florida is minimized by the urban affinities of parrots in this region. The most common parrots observed are the Mitred Parakeet and Monk Parakeet, neither of which have entered the woodpecker cavity nest web.

Multiple exotic birds can be present within the cavity nest web and not evenly impact the native birds. Native woodpeckers must compete with both native secondary cavity users, as well as exotic competitors. Eastern Screech Owls were the only native 
secondary user to have a significant breeding presence in this region. Several species have been extirpated by habitat loss, such as the Brown-headed Nuthatch and Eastern Bluebird. The Great-crested Flycatcher is almost extirpated, with only one failed nest found by cavity inspection. The exotic secondary cavity nesters included four species: two Sturnids and two parrots. The parrots are actually weak cavity excavators, meaning they can enlarge a cavity entrance or make other modifications. The well-established European Starling is joined in Miami by the Common Myna, a more recent invader which has been globally vilified for its cavity nest web interactions. I asked if the timing of reproduction determines which exotic species will usurp cavities from native birds with similar nest preferences. The starling is well known for usurping woodpecker cavities. Starlings were the most common bird in the study and usurped $18.3 \%$ of active Red-bellied Woodpecker nests. A small population of Common Mynas also usurped woodpecker nests, including the locally declining Northern Flicker. I expected parrots to usurp active cavities based on the breeding phenology of Rose-ringed Parakeets studied as an invasive species in Europe. However, parrots in Miami bred months later than expected, thus avoiding competition with birds that share similar cavity preferences. Hole preferences alone were not enough to predict cavity usurpation, as parrots would have been expected to usurp cavities from Pileated Woodpeckers and owls, which finished breeding before parrots began. Sturnids bred during the peak of the season, setting up usurpations from Red-bellied Woodpeckers and Northern Flickers. The results of our investigation suggest possible benefits from trapping and removal of Common Myna, which are still in the establishment phase of invasion in our study region. A growing population of mynas could exert considerable pressure on cavity nest webs. The 
mynas have a fierce reputation as global invaders and cavity usurpers, and are breeding at the edge of a protected wilderness. Control efforts would be most effective against this small, geographically-restricted population in Miami. 
VITA

JOSHUA M. DIAMOND

1988

2010

2012-2019

2014

2016
Born, Washington, District of Columbia

B.A., Environmental Science and Biology

Hampshire College

Amherst, Massachusetts

Graduate Teaching and Research Assistant

Florida International University

Miami, Florida

M.S., Environmental Studies, Environmental Policy and Management

Florida International University

Miami, Florida

Graduate Certificate in Geographic Information Systems Florida International University

Miami, Florida

\section{PUBLICATIONS}

Diamond, J. M. 2017. First North American report of an American Kestrel (Falco sparverius) roosting in a Monk Parakeet (Myiopsitta monachus) nest. Florida Field Naturalist 45:18-20.

Diamond, J. M. 2018. Record of an Exceptionally Low Nest of a Red-bellied Woodpecker in Florida. Southeastern Naturalist 17:N68-N71.

Diamond, J. M., J. Blanco, and J. Freixa. 2016. White-crowned Pigeons (Patagioenas leucocephala) in suburban Miami-Dade County : A review of literature and citizen science data. Florida Field Naturalist 44:147-193.

Diamond, J. M., and J. T. Heinen. 2016. Conserving rare plants in locally-protected urban forest fragments: A case study from Miami-Dade County, Florida. Urban Forestry \& Urban Greening 20:1-11.

Diamond, J. M., and M. S. Ross. 2016. Canopy gaps do not help establish pioneer species in a South Florida dry forest. Journal of Tropical Ecology 32:107-115.

Diamond, J. M., and M. S. Ross. 2018. Tree selection and foraging height of wintering Yellow-bellied Sapsuckers (Sphyrapicus varius) in an urban environment. The Wilson Journal of Ornithology 130:932-939. 